Portland State University

PDXScholar

Dissertations and Theses

Dissertations and Theses

Spring 6-7-2013

\title{
Air-quality and Climatic Consequences of Bioenergy Crop Cultivation
}

William Christian Porter

Portland State University

Follow this and additional works at: https://pdxscholar.library.pdx.edu/open_access_etds

Part of the Climate Commons, Environmental Sciences Commons, and the Other Physical Sciences and Mathematics Commons

Let us know how access to this document benefits you.

\section{Recommended Citation}

Porter, William Christian, "Air-quality and Climatic Consequences of Bioenergy Crop Cultivation" (2013). Dissertations and Theses. Paper 1042.

https://doi.org/10.15760/etd.1042

This Dissertation is brought to you for free and open access. It has been accepted for inclusion in Dissertations and Theses by an authorized administrator of PDXScholar. Please contact us if we can make this document more accessible: pdxscholar@pdx.edu. 


\title{
Air-quality and Climatic Consequences of Bioenergy Crop Cultivation
}

\author{
by
}

\author{
William Christian Porter
}

A dissertation submitted in partial fulfillment of the requirements for the degree of

\author{
Doctor of Philosophy \\ in \\ Applied Physics
}

\author{
Dissertation Committee: \\ Aslam Khalil, Chair \\ Kelley Barsanti \\ Andrew Rice \\ Chris Butenhoff \\ Dean Atkinson
}

Portland State University 2013 


\begin{abstract}
Bioenergy is expected to play an increasingly significant role in the global energy budget. In addition to the use of liquid energy forms such as ethanol and biodiesel, electricity generation using processed energy crops as a partial or full coal alternative is expected to increase, requiring large-scale conversions of land for the cultivation of bioenergy feedstocks such as cane, grasses, or short rotation coppice. With land-use change identified as a major contributor to changes in the emission of biogenic volatile organic compounds (BVOCs), many of which are known contributors to the pollutants ozone $\left(\mathrm{O}_{3}\right)$ and fine particulate matter $\left(\mathrm{PM}_{2.5}\right)$, careful review of crop emission profiles and local atmospheric chemistry will be necessary to mitigate any unintended air-quality consequences. In this work, the atmospheric consequences of bioenergy crop replacement are examined using both the high-resolution regional chemical transport model WRF/Chem (Weather Research and Forecasting with Chemistry) and the global climate model CESM (Community Earth System Model). Regional sensitivities to several representative crop types are analyzed, and the impacts of each crop on air quality and climate are compared. Overall, the high emitting crops (eucalyptus and giant reed) were found to produce climate and human health costs totaling up to $40 \%$ of the value of $\mathrm{CO}_{2}$ emissions prevented, while the related costs of the lowest-emitting crop (switchgrass) were negligible.
\end{abstract}




\section{Acknowledgements}

I would like to thank my advisors, Dr. Aslam Khalil and Dr. Kelley Barsanti, whose guidance, insight, and support have been instrumental throughout these past five years. Special thanks and appreciation also go to Dr. Erik Bodegom and Dr. Erik Sanchez, whose willingness to train and include me in their labs as an undergraduate student provided the foundation for my future work at Portland State University. My gratitude also goes to Dr. Andrew Rice, Dr. Chris Butenhoff, and Dr. Jeremy Parra whose advice on matters both technical and philosophical has always been especially valuable. To my parents, whose love has always been the most steady source of encouragement and strength I have ever known, thank you.

Finally, this document is dedicated to Rachel and Liam, who add such depth and meaning to my life. I hope to somehow offer you both a measure of the joy you bring to me. 
Table of Contents

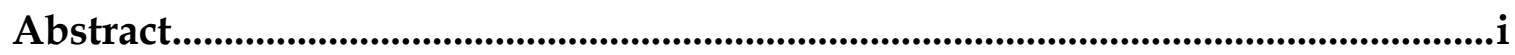

Acknowledgements .................................................................................................. ii

List of Tables ............................................................................................................... vi

List of Figures................................................................................................................ vii

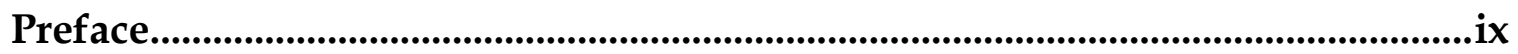

Chapter 1. Bioenergy and Bioenergy Crops: A Brief Review .................................1

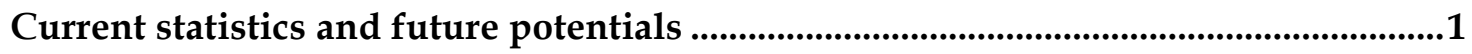

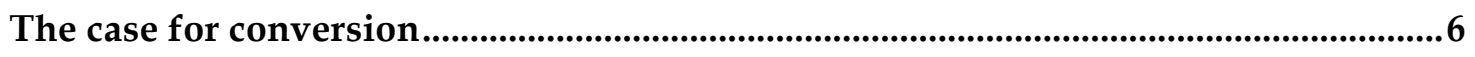

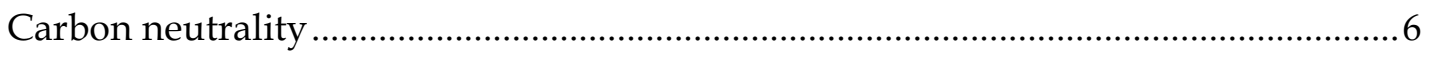

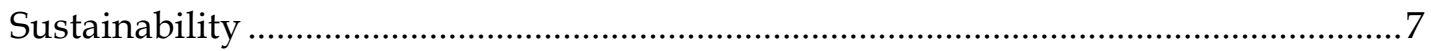

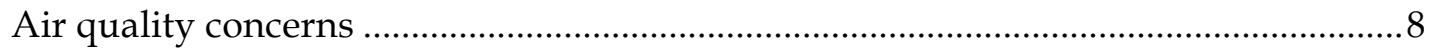

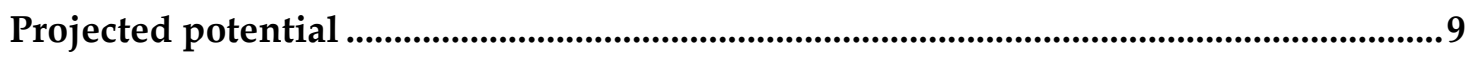

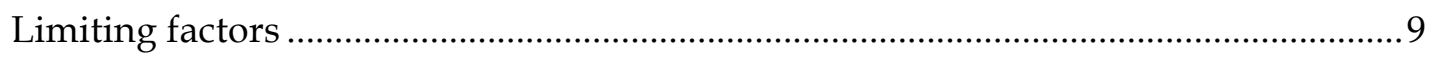

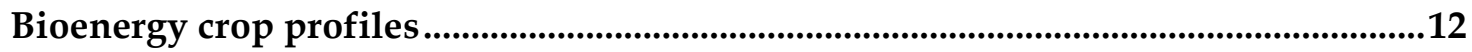

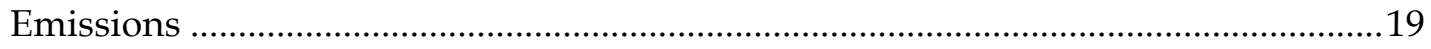

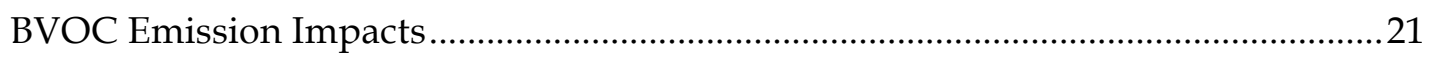

Chapter 2. Considering the air quality impacts of bioenergy crop production: a case study involving Arundo donax ........................................................................... 31 


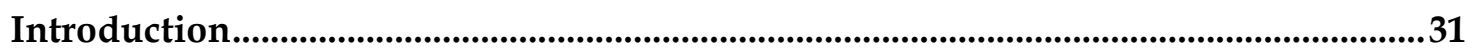

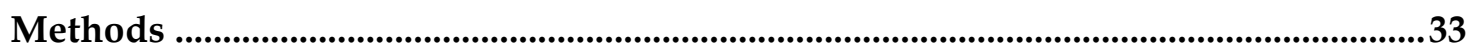

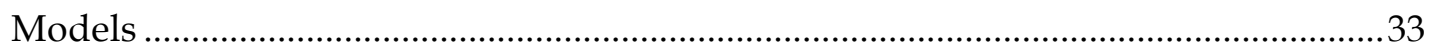

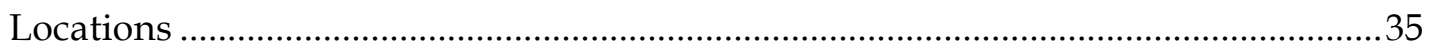

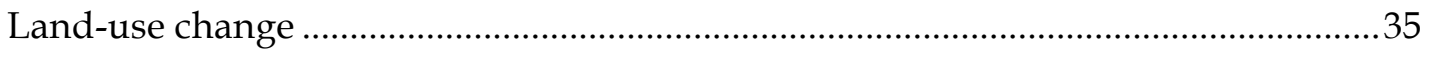

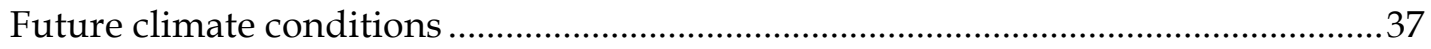

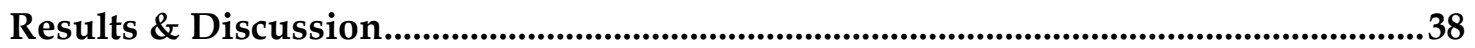

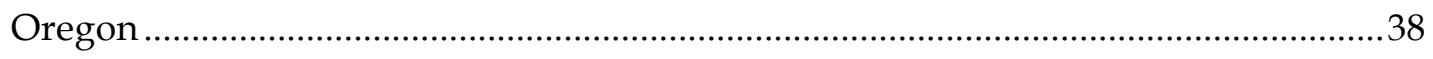

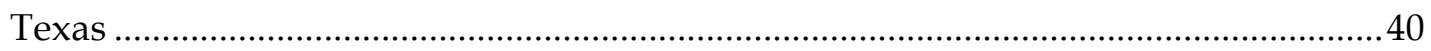

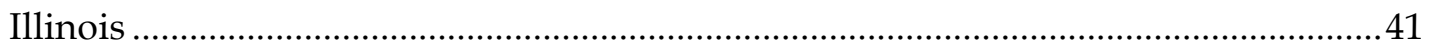

Chapter 3. Greening the globe: A worldwide analysis of the atmospheric consequences of bioenergy crop cultivation..................................................50

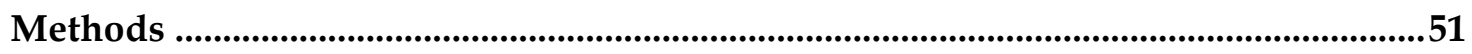

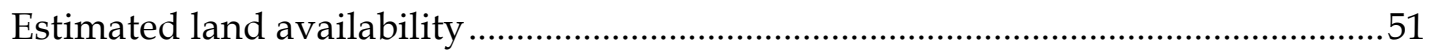

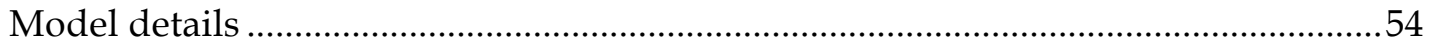

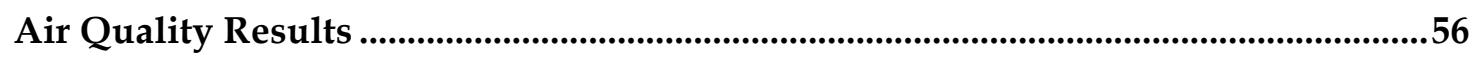

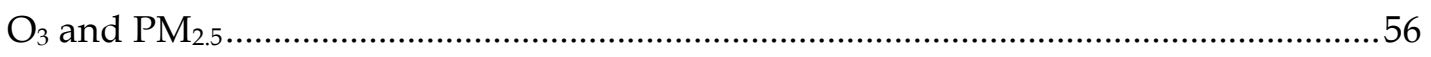

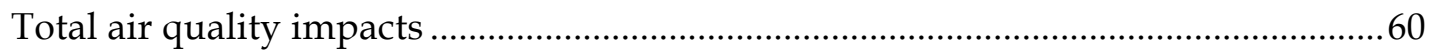

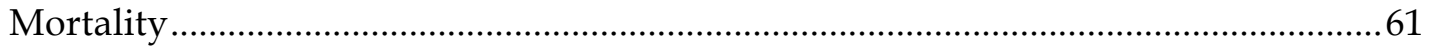

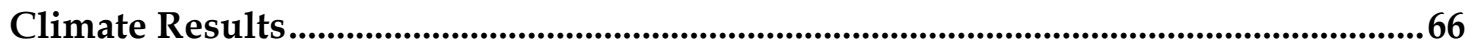

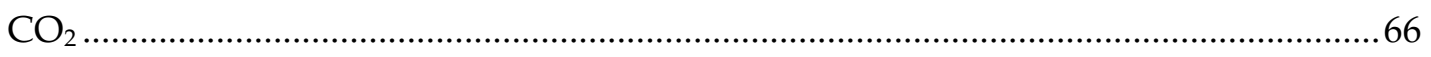

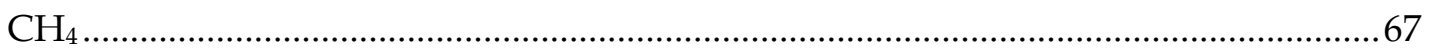

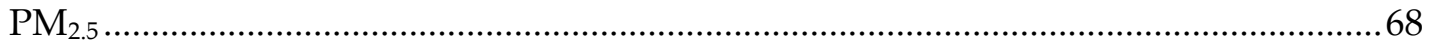

iv 
Total estimated costs.

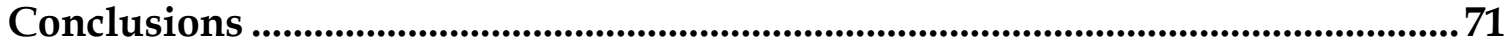

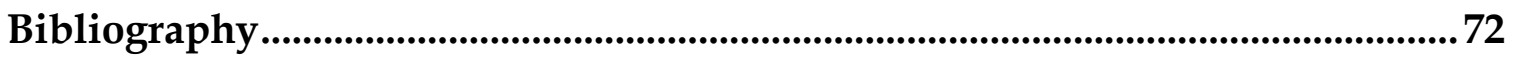

Appendix A: Supplementary Information for Chapter 2 .........................................83

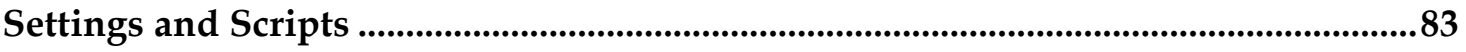

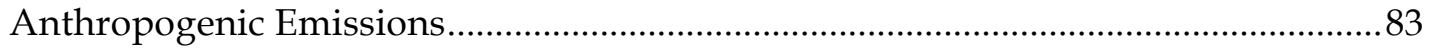

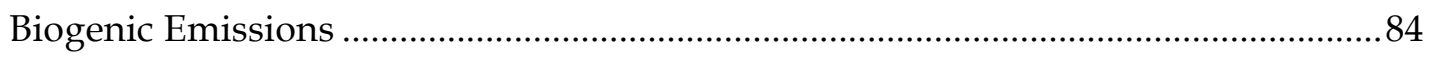

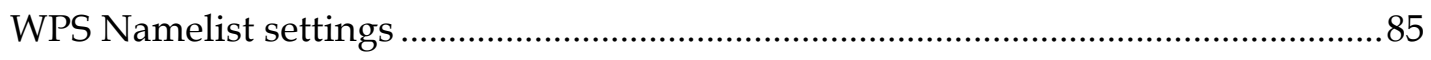

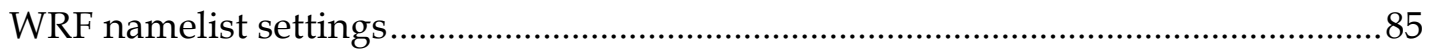

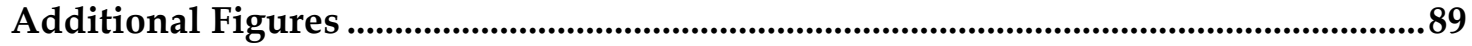

Appendix B: Supplementary Information for Chapter 3.........................................92

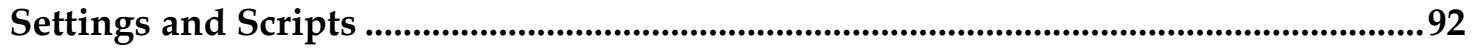

Land replacement …………………………………………………………….....

Additional figures....................................................................................................................93 


\section{List of Tables}

Table 1. Literature emission rates for selected species...............................................19

Table 2. Total replacement area by region and case (Mha) ………..........................52

Table 3. Settings used for all 46 simulated cases …………………….....................55

Table 4. Average Energy Crop Air Quality Scores by region and pollutant .........65 


\section{List of Figures}

Figure 1. Renewable energy generation by source for 2011 ...................................... 2

Figure 2. Net summer US electricity generation from non-hydroelectic renewable

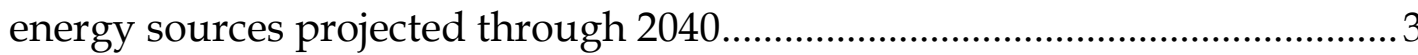

Figure 3. Modeling framework for regional simulations using WRF/Chem .......33

Figure 4. Peak 8-hour average $\mathrm{O}_{3}$ levels and peak change histograms for modeled replacement areas

Figure 5. SOA mass concentrations for the Illinois replacement area

Figure 6. Maximum increase in peak 8-hour average $\mathrm{O}_{3}$ levels for Illinois case .. 45

Figure 7. Modeling framework used for global land-use change simulations .....51

Figure 8. Changes in $\mathrm{NO}_{\mathrm{x}}+$ oxidation product $\left(\mathrm{NO}_{\mathrm{y}}\right)$ concentrations under $\mathrm{RCP}$ scenarios

Figure 9. Annual cycles for population-weighted base $\mathrm{O}_{3}$ and changes with $25 \%$ replacement for each region. Shading indicates maxima and minima for all three anthropogenic emission scenarios, \pm annual standard deviations.

Figure 10. Annual cycles for population-weighted base fine SOA and changes with $25 \%$ replacement for each region. Shading indicates maxima and minima for all three anthropogenic emission scenarios, \pm annual standard deviations. 
Figure 11. Normalized and summed air quality impacts..........................................61

Figure 12. Total deaths predicted in each region, by crop type and replacement scale. Error bars represent uncertainty in mortality rate changes. Note increased y-axis bounds for China and India.

Figure 13. Averaged climate and health costs over all replacement scales ...........70 


\section{Preface $^{1}$}

Meeting expected bioenergy demands in the $21^{\text {st }}$ century is likely to involve significant changes in both regional land use and in the composition of regional cropping systems. A great deal of effort has thus been directed at assessing the impacts of large-scale cultivation of biomass crops on food production, ${ }^{1}$ water supply, ${ }^{2}$ and ecological diversity. ${ }^{3}$ However, thus far, much less attention has been paid to the potential impacts of biomass crop production on regional air quality. This topic is of emerging importance as many fast-growing, highyielding biomass crops are known to release large quantities of biogenic volatile organic compounds (BVOCs), particularly the volatile hemiterpene isoprene. ${ }^{4-8}$ Given that isoprene is a major precursor of both tropospheric ozone $\left(\mathrm{O}_{3}\right)^{9-11}$ and secondary organic aerosol (SOA) $)^{12-14}$ (and thus fine particulate matter, $\mathrm{PM}_{2.5}$ ), large-scale production of isoprene-emitting biomass crops has the potential to significantly impact regional air quality.

\footnotetext{
${ }^{1}$ This section is reproduced by permission from "Considering the air quality impacts of bioenergy crop production: a case study involving Arundo donax" by WC Porter, KC Barsanti, EC Baughman, and TN Rosenstiel, Environmental Science and Technology, 46, 9777-9784, 2012. Copyright 2012. American Chemical Society.
} 
Emission of BVOCs from plant vegetation (mostly from leaves) is the largest

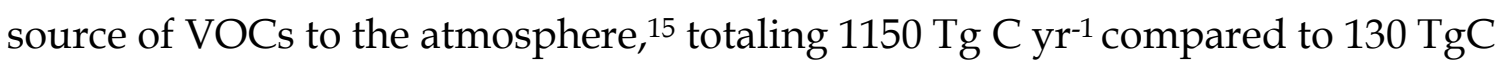
$\mathrm{yr}^{-1}$ from anthropogenic sources. ${ }^{16}$ As the magnitude and chemical diversity of BVOC emissions are very plant-species specific, ${ }^{17-19}$ shifting vegetation patterns and species composition - as well as overall changes in land use and land cover can have significant consequences for atmospheric composition. Given the important role of BVOCs in modulating atmospheric chemistry, ${ }^{20-23}$ substantial previous modeling work has examined how anthropogenic-driven land-use and land-cover change, e.g. deforestation, afforestation, urbanization, ${ }^{24-31}$ as well as climate-driven land-use and land-cover change ${ }^{32-35}$ may influence atmospheric composition through BVOC emissions.

The projected global increase in the demand for biomass crops for heat and power production will be an important driver of land-use change in the near term. ${ }^{36,37}$ As many current and proposed bioenergy crops such as poplar (Populus), willow (Salix), oil palm (Elaeis guineensis) and Eucalyptus are significant emitters of isoprene, ${ }^{38-40}$ large-scale land-use change associated with cultivation of these bioenergy crops has the potential to significantly impact regional atmospheric chemistry. ${ }^{27}$ Recently, Ashworth et al. ${ }^{30}$ considered the air quality impacts of a global transition to biofuel crop cultivation, examining oil palm establishment in SE Asia and short rotation coppice species in North America; results from their modeling scenarios highlighted the potential negative impacts 
that widespread establishment of isoprene-emitting bioenergy crops may have on regional air pollution-regulation efforts.

Because the atmospheric impacts of increased isoprene emission are highly dependent on background atmospheric conditions, particularly regional concentrations of nitrogen oxides $\left(\mathrm{NO}_{\mathrm{x}}\right)$, the potential for isoprene-emitting crop production to reduce air quality is highly region specific. ${ }^{25,41-44}$ Recent studies of the kudzu invasion in the southeastern United States ${ }^{45}$ (which has high background $\mathrm{NO}_{\mathrm{x}}$ ) and the increase of oil palm plantations in Malaysia ${ }^{5}$ (which has low background $\mathrm{NO}_{\mathrm{x}}$ ) have underscored the important role of local $\mathrm{NO}_{\mathrm{x}}$ concentrations in modulating local $\mathrm{O}_{3}$ formation in response to an increase in regional isoprene emissions.

Despite the demonstrated potential for isoprene-emitting bioenergy crops to impact regional air quality, consideration of these impacts has received relatively little attention in the debate over bioenergy crop development. However, consideration of candidate crop species' BVOC emission profiles could be used to inform the selection of regionally appropriate biomass cropping systems, particularly in the context of regional chemical and meteorological conditions, thereby avoiding negative unintended consequences of bioenergy development on regional air quality in some areas. 


\section{Chapter 1. Bioenergy and Bioenergy Crops: A Brief Review Current statistics and future potentials}

Bioenergy, the conversion of biomass into usable energy forms such as heat or electricity, has been a staple of the global energy budget for hundreds of thousands of years. The use of harvested wood for cooking or heating water has historically been one of the most common forms of bioenergy, and it remains in wide use through much of the developing world today. However, newer forms of bioenergy involving fast-growing, low-input crops and higher efficiency processing methods have come to the forefront of renewable energy generation technologies, and a resurgence in the use of biomass among industrialized countries appears to be underway.

Biodiesel and cellulosic ethanol, both products of liquifaction technologies designed to distill combustible elements of biomass into a dense, easily handled form, have become major components of the transportation fuel budget in the US and Brazil. The addition of prepared biomass to traditional coal-burning power plants has reduced the cost, emissions, and carbon footprint of electricity generation in many areas, and the possibility of complete conversion to biomass fuels is currently being explored.

As of the year 2011 biomass accounted for over 4 EJ of US energy production, or just over $5 \%$ of total domestic production (Figure 1). ${ }^{46}$ This number is expected to more than double over the next 30 years, as pressure to reduce carbon emissions 
increases the development and adoption of renewable sources such as wind, solar, and bioenergy (Figure 2). While expectations for biofuels to capture a large fraction of the liquid fuels market have dampened in recent years due in part to a boom in production from shale and other so-called "tight oil" reservoirs, the growth rate of all renewables is still expected to outpace that of fossil fuels over the coming decades. ${ }^{46}$ Growth of biomass as a source of renewable energy is expected to be particularly strong through 2020 due to the current popularity of cofiring projects (in which biomass is added to existing coal burning plants as a supplementary fuel) as a result of state-level support and decreasing overhead costs.
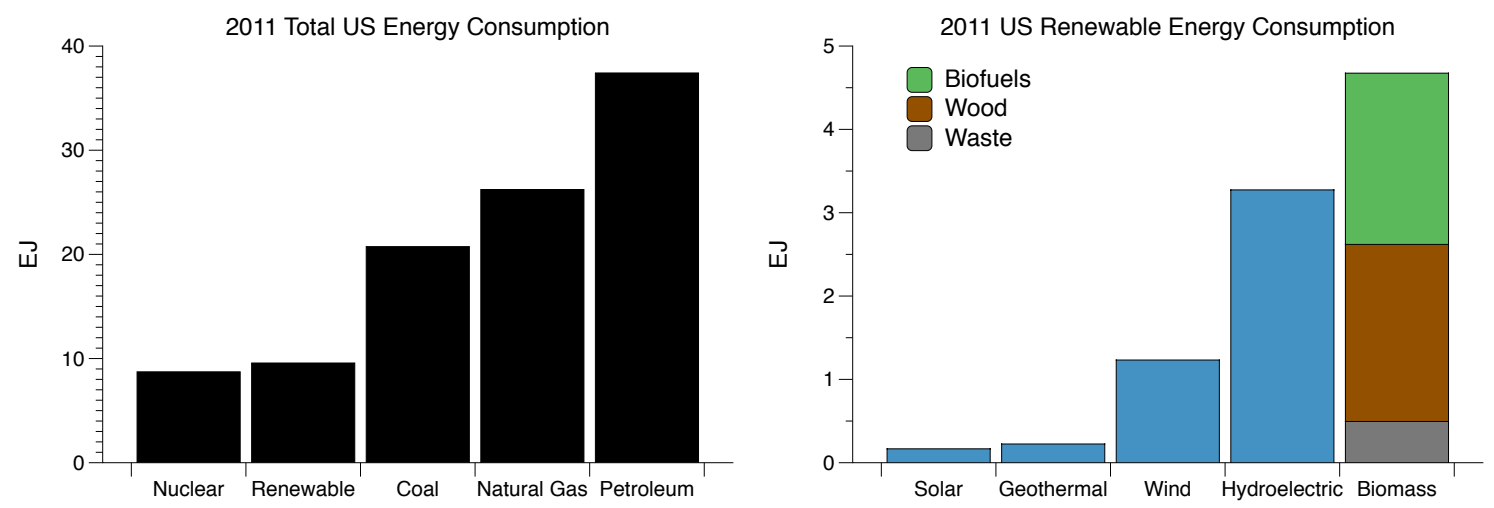

Figure 1. Renewable energy generation by source for $2011 .{ }^{47}$ Biofuels includes diesel and ethanol, plus coproducts from their production. Waste category includes landfill gas, sludge waste, and agricultural byproducts. 


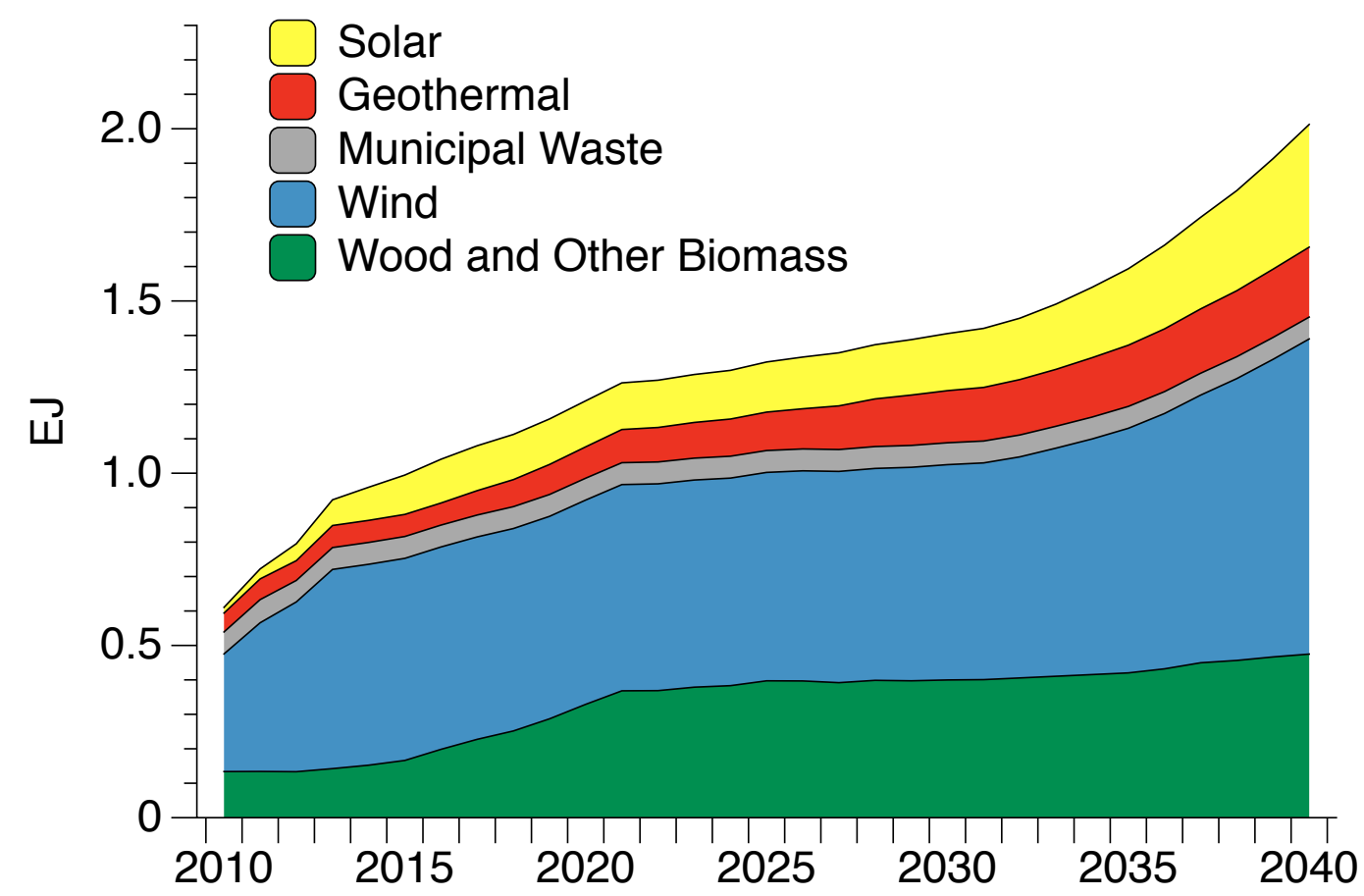

Figure 2. Net summer US electricity generation from non-hydroelectic renewable energy sources projected through $2040 .{ }^{47}$ While wind is currently experiencing the fastest growth among the sources listed, bioenergy is expected to rapidly accelerate in total production through the coming decade.

Furthermore, even with reduced production from cellulosic ethanol compared to earlier expectations, biofuel consumption in the transportation sector is expected to increase in percent share of total liquid fuels from $3.5 \%$ to $5.8 \%$, further boosting demand for grown feedstocks.

Estimates of peak potential for bioenergy production worldwide vary greatly, partly due to widely varying criteria used to assess costs and limitations on the placement and productivity of bioenergy crops. A recent review of 19 literature estimates for future bioenergy production found values ranging everywhere from 0 to 1,550 EJ/year (a span that exceeds current global energy consumption 
by a factor of three), with an average of approximately 400 EJ/year (Offermann et al., 2011 and references therein). ${ }^{48}$ While the range of future potential estimates speaks to the complexity of limiting factors that may or may not prove significant under future conditions, at the very least these studies show a high potential for bioenergy to contribute to the global energy budget.

The conversion of next-generation bioenergy crops to more energy efficient forms may involve liquid, solid, or gas phase fuels. While there has been substantial support for the development of biofuel infrastructure in the transportation sector in some regions, the cost of liquid fuel production in most countries remains prohibitive without subsidies or other incentives. While there are some examples of biofuels successfully competing against gasoline, for example the ethanol industry in Brazil, they remain the exception rather than the rule due to the complexities and costs involved in the efficient conversion from crop to fuel. ${ }^{49}$

Global production of liquid ethanol occurs primarily in Brazil and, more recently, the United States. While the Brazilian ethanol industry is based on sugarcane, the US has thus far primarily focused on corn as a feedstock. Although ethanol produced from corn kernels has been shown to result in a positive Net Energy Balance (NEB), generating more net energy than that of the fossil fuels used to produce it, the gains are modest - only $25 \%$ more energy is returned than consumed..$^{50}$ Furthermore, this positive NEB is possible only when 
the energy equivalent values of coproducts (such as distillers' dry grain, commonly used as a feedstock) are included; without these secondary products, ethanol production from corn grain would likely involve a net energy loss. Alternate feedstocks and techniques have been proposed, including cellulosic fermentation procedures that would allow for the conversion of much greater percentages of the plant, but full-scale commercial applications of these technologies have not yet been realized.

The use of treated biomass to produce solid fuel has gained increasing popularity as a substitute for coal, either to be co-fired alongside it or to replace it entirely. The ongoing conversion to torrefied biomass combustion of a coal plant in Oregon, USA represents the largest such endeavor to date; if successful, it is likely that additional conversions would soon follow. More details on this conversion and its potential regional impacts are provided in chapter 2 .

Gasification, the conversion of bio or fossil fuels into combustible gas form, is another possible means of converting grown crops into useable fuels. Typically using air, oxygen, or steam at elevated temperatures $\left(800^{\circ} \mathrm{C}\right.$ or greater) to initiate the formation of carbon monoxide $(\mathrm{CO})$, carbon dioxide $\left(\mathrm{CO}_{2}\right)$, hydrogen gas $\left(\mathrm{H}_{2}\right)$, and methane $\left(\mathrm{CH}_{4}\right)$, gasification boasts energy conversion efficiencies of up to $80 \%$, requires relatively simple equipment, and could be a cost-effective means of generating electricity from biomass in developing countries. ${ }^{51}$ 


\section{The case for conversion}

\section{Carbon neutrality}

One of the main arguments for a switch from fossil fuels to bioenergy sources hinges on the reduction or elimination of $\mathrm{CO}_{2}$ emissions. While the combustion of fossil fuels transfers ancient carbon from the earth into the atmosphere, carbon released from biocrop combustion is (in principle) cyclical, as it will be reabsorbed by the next generation of new crops grown for future burning. In theory this closed-loop allows bioenergy sources to be "carbon neutral," with zero net emissions of $\mathrm{CO}_{2}$. However, whether or not bioenergy can be considered truly carbon neutral depends somewhat on the definition of carbon neutrality being used, as well as the cultivation and processing methodologies involved.

On a fundamental level, a single tree grown for fuel must absorb as much or more carbon than is released when it is burned. The carbon released into the atmosphere upon combustion was the same carbon fixed into sugars and solid plant structures through photosynthetic processes during the plant's growth, for example by the reaction

$$
6 \mathrm{CO}_{2}+6 \mathrm{H}_{2} \mathrm{O} \stackrel{h v}{\rightarrow} \mathrm{C}_{6} \mathrm{H}_{12} \mathrm{O}_{6}+6 \mathrm{O}_{2} .
$$

Furthermore, since typical harvesting procedures leave some parts of the plant behind (typically underground roots and stems), there is generally some sequestration of fixed carbon into the soil. The limits of this soil sequestration are not fully understood ${ }^{52}$, but unless and until they are reached the cultivation of 
bioenergy crops would theoretically result in an overall increase of sequestered carbon over one complete cycle of growth, harvest, and combustion.

However, examining the net carbon emissions of bioenergy crop combustion from a practical perspective should also include any anthropogenic sources involved in the cultivation, harvesting, and transport of the crop itself, since these are emissions that presumably would not have occurred had the energy not been produced. When these sources are included, the net increase in fixed carbon sequestration can become reduced or even become a net decrease, depending on the magnitudes of emissions vs. sequestration. ${ }^{33,54}$ Furthermore, correct calculations of the change in greenhouse gas concentrations should take into account the lag that exists between the pulse of $\mathrm{CO}_{2}$ emitted on combustion and the slow sequestration that takes place on replanting. 55

\section{Sustainability}

Another advantage of bioenergy sources is the theoretical sustainability of growing replenishable energy crops rather than extracting finite resources. Although total estimates of global coal reserves are highly speculative, peak production is projected to occur at some point before the year 2050.56 Establishing alternative means of electricity generation before this time is likely to be crucial to energy security, especially with global energy consumption continuing to rise each year. ${ }^{57}$ The question of whether or not biomass-based fuels can be considered "sustainable" is a complex one, dependent on factors 
such as land use, water availability, and fertilization requirements. ${ }^{58,59}$ However, the potential for cultivated crops to provide energy beyond the inevitable decline of finite fossil resources remains attractive, assuming sufficient efficiency.

\section{Air quality concerns}

In some cases the development of bioenergy production may occur due to air quality concerns. For example, in the case of the Boardman, OR coal plant conversion described later in this work, failure to comply with $\mathrm{SO}_{2}$ air quality standards was a direct influence on the decision to repurpose the plant for bioenergy torrefaction and combustion. However, the actual emissions of any given biomass combustion system depend heavily on the fuel and combustion methods used, along with the preventive measures (if any) implemented. The chemical composition of feedstock, temperature of combustion, and nature of fuel preparation can all affect total emissions, though in general emissions of biomass combustion tend to be lower than those of coal.

$\mathrm{NO}_{\mathrm{x}}$ is an emission type of particular concern due to its ability to affect the formation of surface-level $\mathrm{O}_{3} ; \mathrm{NO}_{\times}$production in otherwise pristine areas can lead to much higher buildups of average daily $\mathrm{O}_{3}$ levels, especially in the presence of natural or anthropogenic VOC sources. $\mathrm{NO}_{\mathrm{x}}$ is formed during combustion through three general pathways: the thermal mechanism, the fuel mechanism, and the prompt mechanism. The thermal mechanism is independent of fuel source, forming $\mathrm{NO}$ and $\mathrm{NO}_{2}$ from ambient nitrogen and oxygen in the 
air. However, it is very temperature dependent, and is not a significant factor below $750^{\circ} \mathrm{C}$. The fuel mechanism of $\mathrm{NO}_{x}$ formation utilizes nitrogen bound in the fuel source itself, using $\mathrm{HCN}$ or $\mathrm{NH}_{3}$ as an intermediate species between bound nitrogen and the final released oxide. The prompt mechanism involves reactions between nitrogen in the air and fuel-bound hydrocarbon radicals, and is in general of less importance than the other two reactions pathways. Due to thermal and prompt mechanisms, biomass combustion will never be free of $\mathrm{NO}_{\mathrm{x}}$ emissions, but results suggest that emissions can be reduced relative to coal by choosing low-nitrogen feedstocks and burning at reduced temperatures.

\section{Projected potential}

\section{Limiting factors}

Land

Competition for land-use is already a strong limit on bioenergy crop expansion in some areas, and this competition is only expected to increase as populations continue to rise in most regions worldwide. With ethanol production already impacting US corn prices ${ }^{1}$, the further expansion of bioenergy crops into traditional agricultural lands must be weighed carefully against the loss of food productivity. Increases in corn-based ethanol in the United States have not been without economic costs; there is evidence of significant connections between agricultural costs and energy costs, primarily driven by the accelerated expansion of the US corn market into ethanol production during recent 
decades. ${ }^{60}$ These economic feedbacks represent increased coupling between the food and energy markets, through which food prices may be affected by changes in the cost of gasoline, and vice versa. With corn prices expected to increase along with the domestic ethanol market, at least in the short-term, alternative fuelstocks capable of more efficient energy conversion ratios using less soil treatment may be necessary to see continued growth.

Water

Compared to other forms of energy production, bioenergy cultivation and production is extremely water-intensive. Not only would a push towards biofuels likely result in a large expansion of total irrigated areas, the water needs of some of the most likely bioenergy crop candidates tend to be higher than typical agricultural crops $^{2}$, potentially leading to further constraints on an already limited resource. While the water required to generate $1 \mathrm{MWh}$ using fossil fuel sources such as oil and coal is generally less than 1,000 liters, irrigation for enough corn to produce the same amount of energy is estimated to be between 2.2 and 8.7 million liters. ${ }^{2}$ Based on current population growth rates and nutritional needs, water demands for irrigation are expected to nearly double by the year 2050. Even assuming increased efficiencies in water collection and irrigation technologies, a gap of $3300 \mathrm{~km}^{-3}$ of water is projected - about $1 / 4$ of the total expected irrigation demand. ${ }^{61}$ Adding to this gap through increased energy 
crops may prove extremely problematic, especially in regions without plentiful and renewable fresh water resources.

\section{Energy infrastructure}

Generating efficient forms of energy from bioenergy crops is not as simple as simply growing the plants themselves. Conversion of the energy to electricity or liquid fuels requires a great deal of processing; either torrefaction (or a similar form of densification) in the case of solid-fuel electricity generation, or chemical processing in the case of ethanol and liquid fuels. While progress has been made towards the establishment of this infrastructure in many regions, the upfront investment of time and capital is not always feasible in many of the areas that might otherwise be ideal for bioenergy. ${ }^{62}$

\section{Crop productivity}

Growing bioenergy crops will only make sense in the long-term if the value of energy produced per acre justifies the cost of cultivation. For this reason, the productivity possible for any given area of land (largely a function of soil quality, local topography, and typical growing season meteorology) will be a determining factor in the cost/benefit analysis of bioenergy crop suitability. This is especially important if (as assumed in the global study described in Chapter 3) bioenergy feedstocks are to be grown primarily on land deemed less than ideal for productive agricultural crop cultivation. 
Biogenic emissions

Another concern more recently recognized regarding the large-scale adoption of bioenergy has been the impacts that the expected land-use change would have on the emission of BVOCs such as isoprene and the many other related terpenes. Important contributors to certain criteria pollutants such as ozone $\left(\mathrm{O}_{3}\right)$ and fine particulate matter $\left(\mathrm{PM}_{2.5}\right)$, BVOCs are emitted at different rates from different species under identical conditions, making large-scale conversion of land a potentially significant influence on regional air quality, depending on the crop and replacement location. Furthermore, increased BVOC emissions globally would result in an increased sink for the hydroxyl radical $(\mathrm{OH})$, which could impact the lifetimes of other species such as the greenhouse gas $\mathrm{CH}_{4}$, resulting in climate impacts as well. It turns out that many of the most popular bioenergy crops in consideration worldwide are also among the heaviest BVOC emitters, making the choice of crop a particularly important decision.

\section{Bioenergy crop profiles}

The most popular bioenergy crop candidates all tend to share certain properties, including a fast growth rate, reasonable resilience to typical stresses, and manageable soil treatment requirements. ${ }^{63}$ However, there remains high diversity in specific crop traits, including emission profiles: 
Eucalyptus (Eucalyptus spp.)

A broad genus encompassing hundreds of species, some eucalypts have become popular biofuel candidates due to their resilience and rapid growth rates. ${ }^{64}$ Native to Australia and its surrounding islands, eucalypt plantations can now be found worldwide, with a total area recently estimated to be approximately 12-14 million hectares, primarily in Asia and South America. ${ }^{55,66}$ Plantation production tends to be dominated by E. grandis, E. globulus, E. urophylla, and E. camaldulensis, with these four species making up about $80 \%$ of global eucalypt plantations. ${ }^{64}$ BVOC emissions from eucalypts are among the highest of any species, and include both isoprene and monoterpenes.

Giant Reed (Arundo donax)

Previously known primarily as a decorative plant and an invasive species throughout the state of California, the giant reed A. donax has come to the forefront of bioenergy discussions due to its selection in the ongoing conversion of a $500 \mathrm{MW}$ power plant in Oregon, USA. Fast growing and hardy, A. donax does have limited drought resistance, making plentiful irrigation a necessity. A. Donax is a high emitter of isoprene, but releases only trace amounts of other BVOCs. While specific isoprene emission values have varied somewhat, even the most conservative of laboratory measurements place it among the highestranking emitters. 
Switchgrass (Panicum virgatum)

A perennial drought-resistant North American grass, P. virgatum is a popular low-input bioenergy crop candidate. Emissions of BVOCs from P. virgatum are minimal, with only small amounts of monoterpenes measured. ${ }^{8}$ Switchgrass is not the only low-emitting grass-type crop under consideration as a bioenergy feedstock - high-diversity grassland has been identified as a possible candidate, potentially yielding greater mass per hectare than monoculture crops on degraded or low-quality land. ${ }^{67}$

Giant Miscanthus (Miscanthus x giganteus) This fast-growing, low-input crop has received much attention as a bioenergy feedstock candidate. A perennial hybrid, $M x g$ is fairly drought and temperature tolerant, has few known pest problems, and generates high annual yields, even with little to no soil treatment. Although the plant's sterile flowers make the establishment of new plots less convenient than seeded options, once established Mxg requires very little maintenance. Emissions of BVOCs from Miscanthus x giganteus are much lower than the physiologically similar A. donax, with only trace amounts of isoprene and monoterpenes reported. ${ }^{68}$

Sugarcane (Saccharum spp.)

Characterized by elevated concentrations of sucrose in the stem, the perennial grasses known as sugarcane boast some of the highest energy in/energy out 
ratios in the world. Ratios of 1:8 are estimated for tropical sugarcane processed for ethanol, with ratios of 1:3 estimated for cane grown under more temperate conditions. ${ }^{69,70}$ Although additional work is necessary to develop sugarcane varieties with increased cold and pest tolerance, the high energy density of the cane has maintained interest in developing it as an energy crop. Sugarcane is known to be a non-emitter of isoprene, ${ }^{71}$ but its emissions profile for other BVOC species is unknown.

Oil Palm (Elaeis guineensis)

Already an important tropical plantation crop, especially in Malaysia and Indonesia, oil palm cultivation has increased as demand for its wood and oil products has increased. Total global plantations were estimated to cover over 16 million hectares in 2011, up from 13 million hectares just 5 years earlier. ${ }^{72}$ Oil palm is among the highest emitters of isoprene, ${ }^{73}$ and may also contribute to SOA formation due to high emission rates of estragole, an oxygenated VOC whose SOA yield is believed to be comparable to that of typical monoterpenes. ${ }^{74}$

Poplar (Populus spp.)

Fast-growing woody trees originally from North America, many poplar species (along with their hybrids) are already well-established commercial crops for the paper and wood product industries. Plantations are currently being examined as possible sources of feedstock for cellulosic ethanol distillation in the Pacific 
Northwest United States. Poplar emissions are relatively well-documented, and show it to be a high-emitter of isoprene. ${ }^{75}$ Experiments on transgenic, nonisoprene emitting poplar show that these techniques may prove valuable in reducing or even eliminating atmospheric impacts of large-scale energy crop plantations, though some increased sensitivity of the transgenic plants to temperature stress has been reported.76,77

Willow (Salix spp.)

Like eucalyptus and poplar, shrub willow is a woody crop that has been targeted for research due to potential biofuel applications. Capable of producing high yields within a few years, willow also boasts a broad genetic diversity, with pest and disease resistance varying greatly among species. This diversity is expected to prove invaluable to matching the crop to local conditions at any given plantation site. Once established, willow plantations are capable of producing 7-8 total harvests, each requiring a 3 to 4 year maturation phase. ${ }^{63}$ Irrigation may not be necessary in many typical growing environments, though yield would be expected to be lower without it. Nitrogen treatment may be necessary to some degree, depending on soil quality. ${ }^{78,79}$ Willow is a high isoprene-emitter, though monoterpene emissions appear to be minimal. ${ }^{68}$ 
Pine (Pinus spp.)

One of the most important sources of lumber worldwide, pine has lately also been suggested as a possible bioenergy feedstock in some areas. ${ }^{80}$ Recent studies have identified several species of pine as high emitters of sesquiterpenes. Measurements of monoterpene emissions have been lower in magnitude, while isoprene has not shown up at all. ${ }^{81-83}$

Corn (Zea mays)

The top agricultural crop in the United States by both acres harvested and total sales, corn has seen a dramatic increase in use as a fuelstock for the production of ethanol over the past 10 years. ${ }^{47}$ This increase has tapered off more recently, as other technologies and fuelstocks with greater potential efficiencies have begun to compete with corn. Emissions of most BVOCs from corn are negligible, though trace amounts of methanol, toluene, and green leaf volatiles have been measured. ${ }^{84}$ None of these emission rates appear to exceed $1.20 \mathrm{nmol} \mathrm{m}^{-2} \mathrm{~s}^{-1}$, and are well below typical emissions for other popular crops.

Sorghum (Sorghum bicolor)

Long considered a traditional agricultural/forage crop, sorghum has more recently gained attention for its energy production potential. Sorghum is available in a wide variety of cultivars and hybrids which produce varying amounts of sugars and other carbohydrates, making them potentially adaptable 
to either direct combustion or liquid fuel production. Although a perennial in its native tropical environments, sorghum is planted from seed and harvested as an annual crop. As an annual, sorghum produces greater yield in its first year of planting than other perennial crops, which could give it a role as a transition or insurance crop in the event of perennial crop failure. However, unlike perennial options, sorghum would require regular crop rotation to maintain high yields and soil quality. BVOC emissions from sorghum, like most other traditional agricultural crops, are quite low. ${ }^{85,86}$ Isoprene and monoterpene emissions could be expected to be negligible, making the transition to energy sorghum a nonissue from an air-quality perspective. 
Table 1. Literature emission rates for selected species. All rates normalized to $30^{\circ} \mathrm{C}$ and 1000 $\mu \mathrm{mol} \mathrm{m} \mathrm{m}^{-2} \mathrm{~s}^{-1}$ PPFD.

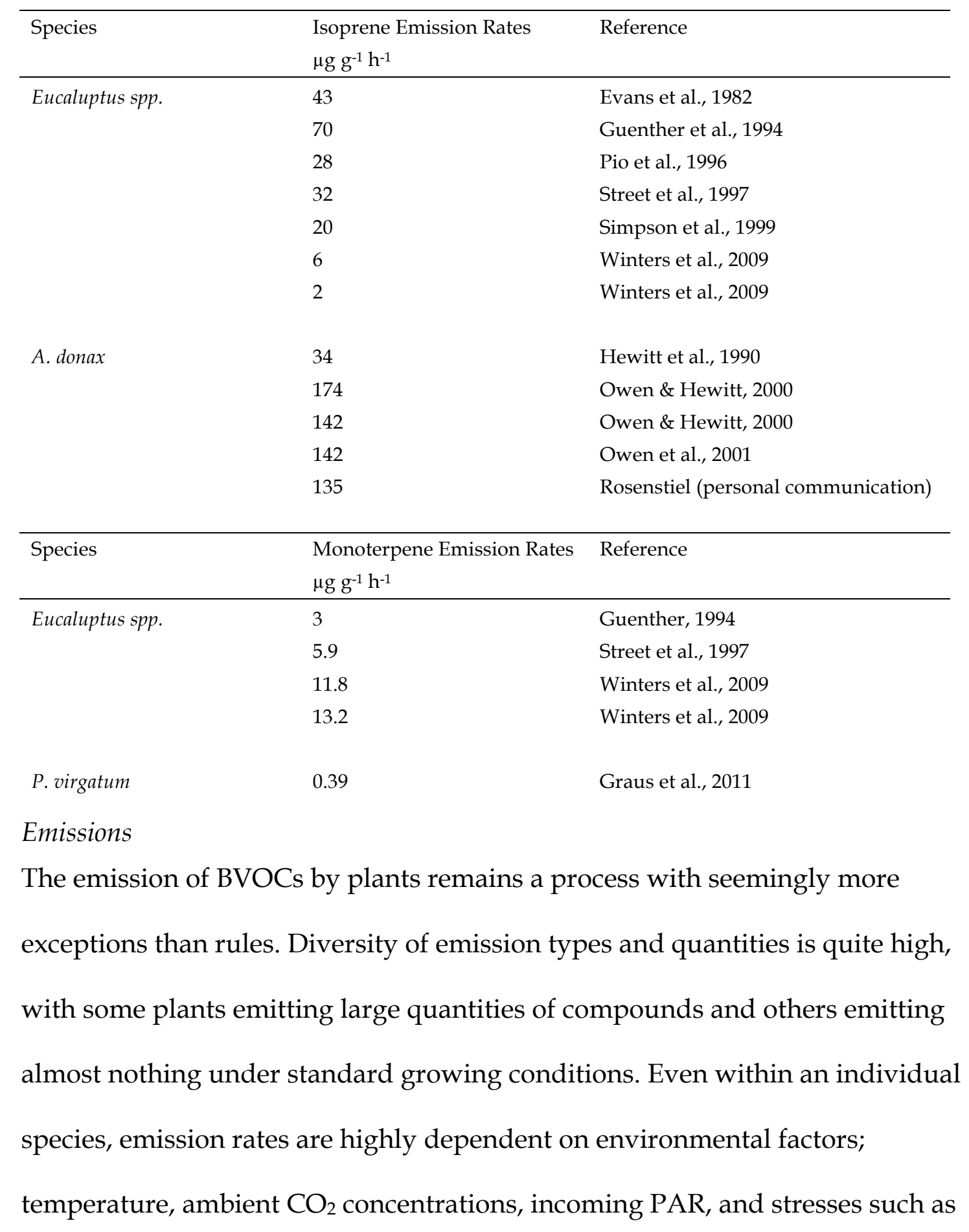


drought and herbivory are all important factors in determining emission rates and types.

Theories regarding the physiological benefit of emitting BVOCs at all are almost as diverse as the emissions themselves. The production of large quantities of apparently non-essential hydrocarbons (considering the number of successful plant species lacking emissions almost entirely) comes at a very real biological cost, which must presumably bring some kind of corresponding benefits to the emitting plant. Ultimately formed from the biological building blocks dimethylallyl pyrophosphate (DMAPP) and isopentenyl pyrophosphate (IPP), BVOCs require significant amounts of not only the carbon atoms themselves, but also adenosine triphosphate (ATP) and glutamate synthase (NADPH), crucial contributors to the most fundamental biological processes in plants. ${ }^{87}$ Under standard temperatures and other conditions, the production of isoprene within high emitting species typically requires energy representing $2 \%$ of photosynthetic activity, with much higher percentages possible under stress conditions. ${ }^{87}$ So what are these plants gaining in exchange for this substantial energy cost?

Perhaps the best documented of emission benefits are those related to temperature and oxidative stresses. In experiments analyzing the ability of kudzu leaves to recover from short, high-temperature episodes, isoprene production proved extremely beneficial. While standard leaves were able to 
recover $90 \%$ of their full photosynthetic strength within 20 minutes of the heat episode, leaves which had been treated with the isoprene inhibitor fosmidomycin recovered by only $60 \%$ in the same amount of time. ${ }^{88}$ Several studies have also found an increased resistance to $\mathrm{O}_{3}$ stresses among highemitting plants, with isoprene and related compounds serving as antioxidants within and around the plant. 89,90

\section{BVOC Emission Impacts}

Ozone

While stratospheric $\mathrm{O}_{3}$ is most commonly generated through the reactions commonly known as the Chapman cycle,

$$
\begin{aligned}
& \mathrm{O}_{2} \stackrel{h v}{\rightarrow} \mathrm{O}+\mathrm{O} \\
& \mathrm{O}+\mathrm{O}_{2} \rightarrow \mathrm{O}_{3},
\end{aligned}
$$

surface $\mathrm{O}_{3}$ is primarily produced through the photo-oxidation of $\mathrm{NO}_{2}$, which is then replenished through reactions with peroxy radicals, including those of VOCs such as isoprenoids ${ }^{91}$ :

$$
\begin{aligned}
& \mathrm{RH}+\mathrm{OH}+\mathrm{O}_{2} \rightarrow \mathrm{RO}_{2}+\mathrm{H}_{2} \mathrm{O} \\
& \mathrm{RO}_{2}+\mathrm{NO} \rightarrow \mathrm{RO}+\mathrm{NO}_{2} \\
& \mathrm{RO}+\mathrm{O}_{2} \rightarrow \mathrm{R}^{\prime} \mathrm{CHO}+\mathrm{HO}_{2} \\
& \mathrm{HO}_{2}+\mathrm{NO} \rightarrow \mathrm{OH}+\mathrm{NO}_{2} \\
& 2\left(\mathrm{NO}_{2}+\mathrm{O}_{2}\right) \rightarrow \mathrm{NO}+\mathrm{O}_{3} \\
& \text { Net }: \mathrm{RH}+4 \mathrm{O}_{2} \rightarrow \mathrm{R}^{\prime} \mathrm{HCO}+2 \mathrm{O}_{3}+\mathrm{H}_{2} \mathrm{O} .
\end{aligned}
$$


The catalytic nature of this cycle means that each individual hydrocarbon $(\mathrm{RH})$ is capable of producing multiple $\mathrm{O}_{3}$ molecules as long as the new hydrocarbon $\left(\mathrm{R}^{\prime}\right)$ contains additional $\mathrm{C}-\mathrm{H}$ bonds.

Elevated levels of VOCs and $\mathrm{NO}_{x}$, therefore, are strongly correlated to $\mathrm{O}_{3}$ increases. If the $\mathrm{NO}_{x} / \mathrm{VOC}$ ratio in an area becomes too high or too low, the increase in $\mathrm{O}_{3}$ will begin to taper off as the efficiency of the cycle described above begins to decrease. At very low $\mathrm{NO}_{x} / \mathrm{VOC}$ ratios additional VOCs will actually begin to react directly with $\mathrm{O}_{3}$, acting as a sink and reducing concentrations of the pollutant. However, it should be noted that these areas would then be extremely sensitive to increases in local $\mathrm{NO}_{x}$ emissions, a risk highlighted in a recent examination of the increased $\mathrm{NO}_{x}$ sensitivity of Malaysian oil palm plantations. ${ }^{5}$ In this study, elevated isoprene levels were detected over oil palm plantations compared to the background rainforest concentrations. While $\mathrm{O}_{3}$ levels were not shown to exhibit increases due to low ambient $\mathrm{NO}_{x}$ emissions, projections of the effects of increased emissions were drastically different, with the high-isoprene plantation cases expected to show significant degradation in air quality at $\mathrm{NO}_{\mathrm{x}}$ levels of 1-10 ppb.

Tropospheric $\mathrm{O}_{3}$ increases are of concern for a variety of reasons, including human health, crop yield, and climatic impacts. A criteria pollutant, increases in $\mathrm{O}_{3}$ have been linked to increased hospitalization and mortality rates. This correlation appears to be unrelated to initial $\mathrm{O}_{3}$ levels, meaning that the 
relationship between $\mathrm{O}_{3}$ and human health is nearly linear, regardless of background $\mathrm{O}_{3}$ levels. WHO has recommended an peak 8-hour average Air Quality Guideline of $100 \mu \mathrm{g} \mathrm{m}^{-3}$, or approximately $52 \mathrm{ppb}$, with $160 \mu \mathrm{g} \mathrm{m}^{-3}$ (83 $\mathrm{ppb}$ ) identified as an interim target and $240 \mu \mathrm{g} \mathrm{m}^{-3}(124 \mathrm{ppb})$ considered dangerously high. ${ }^{92}$

Another known impact of $\mathrm{O}_{3}$ increases is on crop yield, with high $\mathrm{O}_{3}$ levels linked to increased plant stress and stunted growth for many typical agricultural crops. A recent study of large-scale isoprene-emitting crop cultivation in Europe found the cost of crop losses due to elevated $\mathrm{O}_{3}$ less than, but comparable to, the cost of health effects. ${ }^{93}$

As a greenhouse gas, tropospheric $\mathrm{O}_{3}$ is also a contributor to planetary warming. The IPCC estimates that increases in tropospheric $\mathrm{O}_{3}$ account for approximately $0.5 \mathrm{~W} \mathrm{~m}^{-2}$ of radiative forcing since 1750 , slightly less than a quarter of the radiative forcing ascribed to $\mathrm{CO}_{2} \cdot{ }^{94}$ Large changes in tropospheric $\mathrm{O}_{3}$ could therefore have an impact on global planetary temperatures, should the changes be of sufficient magnitude.

$\mathrm{PM}_{2.5}$

Elevated levels of $\mathrm{PM}_{2.5}$, another EPA criteria pollutant, have also been linked to respiratory and cardiovascular problems both in terms of long-term averages and short-term episodes. WHO guidelines recommend annual mean 
concentrations of $\mathrm{PM}_{2.5}$ below $10 \mu \mathrm{g} \mathrm{m}^{-3}$, with an initial interim target of $35 \mu \mathrm{g}$ $\mathrm{m}^{-3} .{ }^{92}$ Regions at this interim target are projected to experience increases in longterm mortality risk of approximately $15 \%$ relative to regions at the recommended level. In addition to this long-term average recommendation, WHO guidelines recommend daily 24-hour average $\mathrm{PM}_{2.5}$ concentrations below $25 \mu \mathrm{g} \mathrm{m} \mathrm{m}^{-3}$, with an initial interim target of $75 \mu \mathrm{g} \mathrm{m}^{-3}$.

$\mathrm{PM}_{2.5}$ also affects climatology through direct and indirect aerosol effects. By absorbing and scattering incoming and outgoing radiation, aerosols can directly influence the atmosphere's radiation budget (the so-called direct effect). This effect is believed to have a net cooling impact on surface temperatures. Aerosols can also affect radiation by altering cloud albedos and lifetimes through the indirect and semi direct effects, processes estimated to have small, but important radiative forcing impacts.

$\mathrm{PM}_{2.5}$ is affected by changes in biogenic emissions primarily through the formation of SOA, which is itself a product of BVOC oxidation processes. As the hydrocarbons typically emitted within the biosphere become progressively more oxidized by species such as $\mathrm{OH}, \mathrm{NO}_{3}$, and $\mathrm{O}_{3}$, they tend also to become less and less volatile, eventually forming condensable species which can contribute to aerosol formation and growth. Accurately modeling SOA formation has proven complicated due in part to the high diversity of precursors, products, and phase transition properties involved, and a variety of methods have been developed to 
address these complexities. Early work began with the assumption that VOC oxidation products contributing to SOA formation were all of negligible volatility and could not subsequently revert to the gas phase. Later efforts added to models the ability of condensed oxidation products to revert to the gas phase, should vapor pressure changes warrant it, as well as aerosol growth through both adsorption and absorption of compounds that would not otherwise form particles. ${ }^{95-97}$ Efforts to characterize the most common SOA precursors by condensability resulted in a generalized model in which the aerosol mass yield of any given product $\left(Y_{i}\right)$ could be predicted given initial aerosol mass concentration $\left(\mathrm{M}_{0}\right)$ a proportionality constant relating concentration of reacted gas to concentration of product formed $\left(\alpha_{i}\right)$, and a phase partitioning coefficient $\left(K_{o m, i}\right)^{98:}$

$$
Y_{i}=M_{0}\left(\frac{\alpha_{i} K_{\mathrm{om}, \mathrm{i}}}{1+K_{\mathrm{om}, \mathrm{i}} M_{0}}\right) .
$$

The result of the above equation is a factor $(Y)$ which can be multiplied by the total mass of reactive organic gas (in $\mu \mathrm{g} \mathrm{m}^{-3}$ ) to predict the total mass of aerosolphase products. To fit experimental results as efficiently as possible, the dozens of actual oxidation products of any given species type are binned into two products, one higher-volatility and one lower, resulting in four parameters for each precursor - two $\alpha$ values and two $K$ values. 
While computationally tractable and reasonably accurate under certain conditions, the two-product model described above can fail to give accurate results when the actual oxidation products of VOCs cannot be cleanly lumped into the two assumed bins. The possibility of additional reactions and further changes to the volatility of the new products is likewise not captured. More recently, a number of new methods have been proposed, including the partitioning of compounds into a basis set of volatility bins, ${ }^{99}$ a 2-dimensional carbon number-polarity grid for the binning and modeling of ongoing reactions, ${ }^{100}$ and parameterizations based on the carbon number and oxidation state of the organic hydrocarbons. ${ }^{101}$

Binning based on the so-called volatility basis set seeks to parameterize VOC evolution based on a uniform range of saturation concentrations ranging from nonvolatile $\left(0.01 \mathrm{\mu g} \mathrm{m}^{-3}\right)$ to completely vapor phase $\left(100 \mathrm{mg} \mathrm{m}^{-3}\right)$. Using this basis set approach, the ongoing evolution of compounds spanning a wide range of initial volatilities can be described through the effects of oxidation, dilution, and other processes on total mass in each volatility bin. ${ }^{99}$

In the carbon number-polarity grid approach, the binning of compounds is extended to two dimensions - the first a simple count of carbon atoms present, and the second a measure of total molecular polarity (tmp). Although accurately assessing any given molecule's polarity is difficult, it may be possible to use known proxy parameters such as enthalpy of vaporization. ${ }^{100}$ 
More recently, the use of carbon oxidation state $\left(\mathrm{OS}_{\mathrm{c}}\right)$ as a second dimension to accompany carbon number $\left(\mathrm{n}_{\mathrm{c}}\right)$ has been proposed as a means of characterization the evolution of organic aerosols and precursors. Under this scheme, the primary chemical processes of fragmentation, oligomerization, and functionalization can all be represented by well-defined movements within $\mathrm{OS}_{\mathrm{c}} / \mathrm{n}_{\mathrm{c}}$ space, with the eventual fate of organic carbon tending to push towards $\mathrm{CO}_{2}$.

Evaluating health impacts

To normalize and combine levels of criteria pollutants into a single metric, the EPA generated the Pollutant Standards Index (PSI) - a series of "segmented linear functions" that categorized regional air quality as a function of measured levels of criteria pollutants. First referenced in 1976,102 the PSI was later renamed the Air Quality Index (AQI), and makes use of air quality level breakpoints for each individual pollutant to divide local concentrations into qualitative categories ("good", "moderate", "unhealthful", and "very unhealthful") each of which span a set range on the PSI scale from 0 to 500 (in which 0 to 50 represents "good" air quality, for example). Linear interpolation is used to generate a score for each pollutant, with an increase in score representing a decrease in air quality, by the stepwise function

$$
\begin{aligned}
& y=\frac{b_{i+1}-b_{i}}{a_{i+1}-a_{i}}\left(x-a_{i}\right)+b_{i} \\
& \text { for } a_{i}<x \leq a_{i+1} \\
& \text { where } i=1,2, \ldots, 6 .
\end{aligned}
$$


Here, pollutant concentrations $(x)$ within individual air-quality categories are assigned scores $(y)$ based on upper and lower thresholds for concentrations (a) and scores $(b)$ within that category. While the EPA's AQI was shown to be useful in evaluating air quality, it received some criticism for its handling of multiple pollutants; the final AQI score comes from only the species with the highest calculated value, meaning that cumulative effects of multiple pollutants at unhealthful levels are not recognized.

To address this, attempts at alternative metrics in which elevated concentrations of multiple pollutants are taken into account have been created.103-105 Swamee and Tyagi (1999) created a modified aggregate index which combined multiple standards using a formula meeting the following conditions: a) perfect zero scores for one criteria pollutant should not affect poor scores in another; and b) as any individual pollutant's score approaches infinity, so too should the aggregate index itself; c) as the number of pollutants with non-zero subindices goes to infinity, so too should the aggregate index; and d) the final metric should be free from ambiguity (unnecessary alarm), meaning that high aggregate scores should only be generated when at least one pollutant is actually at unhealthful levels. Note that simple aggregation schemes such as sums, averages, and the EPA's AQI all fail at least one of these conditions: summed scores suffer from ambiguity, as the metric can be made arbitrarily high simply by taking more species into account; averages are inappropriately lowered when one pollutant is 
high while the others are low; and the EPA's AQI fails to account for multiple pollutants all at comparable unhealthful levels. To this end, the general formula

$$
I=\left(\sum_{i=1}^{N} s_{i}^{1 / p}\right)^{p}
$$

was used, with $p$ serving as an aggregation parameter modifying the sensitivity of the formula to multiple elevated values, and $s_{\mathrm{i}}$ the individual sub-indices generated from

$$
s=s_{s}\left(\frac{q}{q_{s}}\right)^{m},
$$

in which $s_{\mathrm{s}}$ and $q_{\mathrm{s}}$ are a scaling coefficient and species-specific standard benchmark values, respectively. Combined metrics such as this will prove invaluable in cases where multiple pollutants at unhealthy levels generate human-health impacts greater than those predicted by either concentration taken individually.

Donovan et al., 2005 generated an urban tree air quality score (UTAQS) similar to those described above to represent the impacts of trees upon urban air quality. ${ }^{106}$ Opting for a simple sum of air quality changes, the following equation was used

$$
\operatorname{UTAQS}\left(\mathrm{O}_{3}\right)=-100\left(\frac{\Delta \mathrm{O}_{3}}{\mathrm{AQS}_{\mathrm{O3}}}\right)
$$


where $\Delta \mathrm{O}_{3}$ is the change in $\mathrm{O}_{3}$ with respect to some base state, and AQSO3 is the air-quality standard for ozone. Similar scores were generated for other species $\left(\mathrm{HNO}_{3}, \mathrm{NO}, \mathrm{NO}_{2}\right.$, and PAN), and used to compare the impacts of different tree species upon urban air quality. In this work, a variation of the simple summing method of Donovan et al., 2005 is used to analyze the population-weighted global changes in chapter 3 . While a more complex scoring methodology such as that described in Eq. 7 may prove more accurate overall, lack of information on proper coefficients for $\mathrm{PM}_{2.5}$ make their proper implementation difficult at this time. In the absence of these coefficients, examining scores for $\mathrm{O}_{3}$ and $\mathrm{PM}_{2.5}$ both individually and summed can provide a simple estimate for how air quality could be expected to change under various landuse scenarios, as well as which species would be most responsible for those changes. 


\section{Chapter 2. Considering the air quality impacts of bioenergy crop production: a case study involving Arundo donax ${ }^{\dagger}$}

\section{Introduction}

To investigate how biomass crop production could differentially influence local atmospheric composition, here we examine how large-scale cultivation of the biomass crop Arundo donax, an isoprene emitting species, ${ }^{4,107}$ may influence regional air quality at three study locations across the United States (US):

Oregon, Texas and Illinois. A. donax, the giant cane, was selected as the representative biomass crop for this investigation because it has been selected for use in the progressing coal to biocharcoal conversion project in northeastern Oregon. ${ }^{108}$

As the extent of predicted impacts will depend on other meteorological, climatological, and chemical conditions such as $\mathrm{NO}_{\mathrm{x}}$ concentrations, two other US locations, one in eastern Texas and one in northern Illinois, also were selected. While $\mathrm{NO}_{\mathrm{x}}$ levels also can affect the extents of SOA formation, ${ }^{109,110}$ the effects of $\mathrm{NO}_{x}$ levels, and more specifically the relative amounts of peroxy radical $\left(\mathrm{HO}_{2}\right)$, nitrogen oxide $(\mathrm{NO})$ and nitrogen dioxide $\left(\mathrm{NO}_{2}\right)$ on SOA formation from

\footnotetext{
†This chapter is reproduced by permission from "Considering the air quality impacts of bioenergy crop production: a case study involving Arundo donax" by WC Porter, KC Barsanti, EC Baughman, and TN Rosenstiel, Environmental Science and Technology, 46, 9777-9784, 2012. Copyright 2012. American Chemical Society.
} 
isoprene are not sufficiently understood to be included in highly parameterized chemical transport models. Most regional and global models utilize the isoprene SOA parameters of Henze and Seinfeld, ${ }^{14}$ which represent the upper range of observed laboratory SOA yields from photoxidation of isoprene under high and low NOx conditions. ${ }^{111,112}$ Results from this work will be discussed in the context of developing a greater understanding of the potential impacts of isopreneemitting bioenergy crops on regional air quality, including the influence of sitespecific factors on the extent of any such impacts. Outstanding research needs for further modeling studies and future work also are discussed. 


\section{Methods}

Models

WRF/Chem ${ }^{113}$ was chosen to simulate the air quality impacts of land-use change associated with biomass production (Figure 3). WRF/Chem allows online mesoscale modeling of emissions, transport and chemistry. Model runs were set up on a $100 \times 75$ grid, with $12 \mathrm{~km} \times 12 \mathrm{~km}$ grid cells. Meteorology input for all runs was generated from $1^{\circ}$ Climate Forecast System Reanalysis (CFSR) data; topographical input was generated from 30 second US Geological Survey data provided by the University Corporation for Atmospheric Research (UCAR),

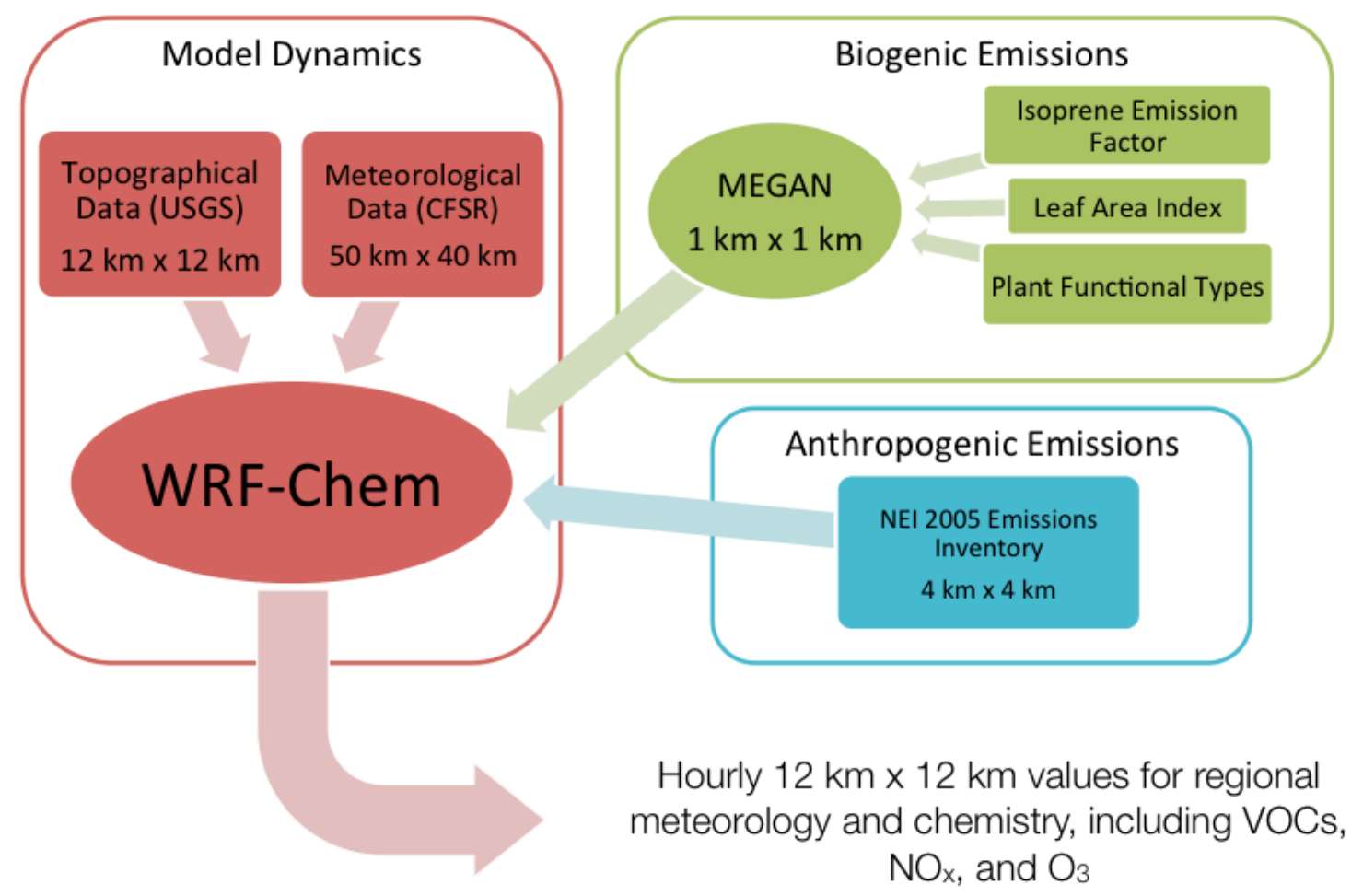

Figure 3. Modeling framework for regional simulations using WRF/Chem 
regridded to $12 \mathrm{~km} \times 12 \mathrm{~km}$ using the WRF Preprocessor System (WPS).

Microphysics dynamics, cumulus convection, shortwave radiation, and longwave radiation were performed following the Lin et al. scheme, ${ }^{114}$ Grell 3D ensemble scheme, Goddard shortwave scheme, ${ }^{115}$ and the rapid radiative transfer model (RRTM), ${ }^{116}$ respectively. Surface processes were handled using the Noah Land-Surface Model, ${ }^{117}$ which includes dry deposition processes following the Wesely scheme. ${ }^{118}$ Anthropogenic emissions were generated based on the 2005 National Emissions Inventory dataset (NEI05) and biogenic emissions were generated by the Model of Emissions of Gases and Aerosols from Nature (MEGAN) version 2.0. ${ }^{17} \mathrm{WRF} /$ Chem has been shown capable of successfully representing observed levels of $\mathrm{O}_{3}$ and $\mathrm{NO}_{\mathrm{x}}$ in previous studies using inputs and methodology similar to those used in this study. ${ }^{119-123}$

RACM-ESRL was chosen as the gas-phase chemical mechanism (Regional Atmospheric Chemistry Mechanism, updated ${ }^{122}$ to include the Mainz Isoprene Mechanism ${ }^{124,125}$ and reactions/rate constants from the Earth System Research Laboratory ${ }^{126,127}$ ) with photolysis simulated following the Madronich scheme. ${ }^{128}$ The gas-phase chemical mechanism SAPRC-99129 with the Model for Simulating Aerosol Interactions and Chemistry (MOSAIC) ${ }^{130}$ was used to simulate $\mathrm{PM}_{2.5}$. MOSAIC now includes a reduced version of the volatility basis set (VBS) ${ }^{99,131}$ which was selected here for treatment of SOA formation. The simplified 2- 
species VBS has been shown to produce SOA results comparable to the full 9species VBS. ${ }^{131}$

\section{Locations}

Conversion of existing agricultural cropland to biomass was examined for coal power plants in three US locations: the Boardman plant in northeastern Oregon, the Martin Lake plant in eastern Texas, and Will County Station in northern Illinois. The Boardman plant has been targeted for conversion from traditional coal to regionally-sourced biocharcoal combustion (torrefied A. donax) by 2020 and thus was modeled the most extensively, including three two-month runs covering July and August for the years 2001, 2003, and 2005. These years were chosen from the past decade to cover a range of precipitation and temperature values, as precipitation and temperature may significantly impact BVOC emissions. ${ }^{87}$ From these runs, a 4-week period exhibiting consistently high isoprene emissions was chosen for illustration of the potential impact on SOA levels. Since the Boardman region exhibits both low $\mathrm{NO}_{x}$ and low overall VOC levels (average $\mathrm{NO}_{x}$ and formaldehyde, $\mathrm{HCHO}$, both less than $2 \mathrm{ppb}$ ), the hypothetical locations in Texas and Illinois were chosen to represent a high $\mathrm{NO}_{x} /$ high VOC regime and a high $\mathrm{NO}_{x} /$ low VOC regime, respectively.

\section{Land-use change}

For each location, the size of the replacement area was determined based on each coal plant's power capacity and area projections for the Boardman plant. ${ }^{108}$ The 
exact location of each replacement area was selected by examining existing plant functional type (PFT) maps and filtering for those already exhibiting a high level of herbaceous cover (i.e., existing cropland). Starting at the location of the power plant itself and moving outward in concentric squares, grid cells with cropland PFT values of $80 \%$ or greater $(70 \%$ or greater in the Texas location) were deemed suitable for conversion. Due to differences in existing PFT distributions, the density of converted area varied between the sites. Total replaced area and density for the three locations were as follows: $460 \mathrm{~km}^{2}(114,000$ acres) over an approximately $1600 \mathrm{~km}^{2}$ area in Oregon, $960 \mathrm{~km}^{2}$ (463,000 acres) in an area of approximately 10,000 $\mathrm{km}^{2}$ in Texas, and $935 \mathrm{~km}^{2}$ (213,000 acres) in an area of approximately $1700 \mathrm{~km}^{2}$ in Illinois. For the selected cells, the MEGAN input maps for isoprene emission factor (EF) and leaf area index (LAI) were then modified. In the absence of observed canopy-level emission data for A. donax, leaf-level emission rates for the crop were compared to those of the four PFTs used by MEGANv2.0. ${ }^{17}$ Even conservative leaf-level isoprene emission rates reported for $A$. donax $\left(34 \pm 9.8 \mu \mathrm{g} \mathrm{C} \mathrm{g}^{-1} \mathrm{hr}^{-1}\right)^{4}$ were comparable to those represented in the highest isoprene emitting PFT type (broadleaf trees), ${ }^{132}$ thus the selected areas were assigned an isoprene EF of $12.6\left(\mathrm{mg}\right.$ isoprene $\left.\mathrm{m}^{-2} \mathrm{hr}^{-1}\right)$, the value used for the broadleaf tree PFT. Though the assigned value is the highest canopy-level isoprene EF in MEGANv2.0, this value may underestimate true emissions from A. donax, given leaf-level emissions of $142 \pm 78 \mu \mathrm{g} \mathrm{C} \mathrm{g}^{-1} \mathrm{hr}^{-1}$ have 
been reported in the field. ${ }^{18}$ Measured LAI values for A. donax under field conditions currently are not available, thus the default LAI of $5\left(\mathrm{~m}^{2} \mathrm{~m}^{-2}\right)$ was assumed. ${ }^{17}$ Based on reported LAI data for similar crops such as Miscanthus giganteus, the assumed value likely substantially underestimates the LAI of highdensity A. donax canopies. Additional simulations therefore were performed using LAI values up to $10 \mathrm{~m}^{2} \mathrm{~m}^{-2}$.

The increase in LAI values associated with the replacement of agricultural lands with high-density A. donax (assumed peak LAI of 5-10 $\mathrm{m}^{2} \mathrm{~m}^{-2}$ ), may have further impacts on atmospheric composition due to an increase in dry deposition associated with land surface changes..$^{24,30,35}$ To assess the relative importance of this process on predicted $\mathrm{O}_{3}$ levels, sensitivity runs were performed in which the input surface area datasets were modified to reflect the increase in LAI and surface roughness resulting from the conversion to A. donax.

\section{Future climate conditions}

While the current conversion timeline for the Boardman coal plant will result in the described land-use change under current climatic conditions, long-term planning requires an examination of how future changes to local climatology and atmospheric composition might affect analyses such as presented here. In particular, increased temperatures and $\mathrm{CO}_{2}$ levels have both been identified as important and competing climatic drivers of changing biogenic emissions. ${ }^{6,15,133-}$

135 Using temperature and $\mathrm{CO}_{2}$ increases chosen from IPCC estimates for the year 
$2060\left(+1.5^{\circ} \mathrm{C}\right.$ and $\left.600 \mathrm{ppm} \mathrm{CO} 2\right),{ }^{94}$ emission factors were modified using the $\mathrm{CO}_{2}$ feedback parameterization described by Heald et al., ${ }^{134}$ while the temperature feedback was included through modified input meteorology files.

\section{Results \& Discussion}

All three locations exhibited increased levels of both $\mathrm{O}_{3}$ and SOA with the conversion of land to bioenergy production as represented by changes to MEGAN input data assumed for A. donax. The magnitude of these increases varied greatly between locations, with background $\mathrm{NO}_{x}$ and VOC levels, conversion area scale and density, and local meteorology and climatology, all likely factors in the predicted sensitivity to the increased isoprene emissions.

\section{Oregon}

Relative to the two hypothetical locations, Boardman had a smaller total replacement area and cleaner air (background $\mathrm{NO}_{x}$ of $3 \mathrm{ppb}$ ). Though peak isoprene levels increased by almost an order of magnitude above the replacement area, increases in peak 8-hour $\mathrm{O}_{3}$ were 2 ppb or less (Figure $4 \mathrm{~A}$ ). Comparing midday $\mathrm{NO}_{x}$ plus oxidation products $\left(\mathrm{NO}_{y}\right)$ to $\mathrm{O}_{3}$ levels at the Oregon site reveals a positive and linear dependence, described by Sillman and $\mathrm{He}^{136}$ as representative of a $\mathrm{NO}_{\mathrm{x}}$-sensitive regime. ${ }^{136}$ To investigate this sensitivity, default $\mathrm{NO}_{x}$ emissions in the simulated area were adjusted upward and downward by 50\% following Donovan et al. (2005) 106 and the pre- and postA. donax cropland conversion simulations were repeated. Despite the low overall 
response of $\mathrm{O}_{3}$ levels to increased isoprene emissions, sensitivity to $\mathrm{NO}_{x}$ clearly was observed; decreasing $\mathrm{NO}_{\mathrm{x}}$ emissions by $50 \%$ resulted in the vast majority of peak $\mathrm{O}_{3}$ changes remaining at less than $0.5 \mathrm{ppb}$, while increasing $\mathrm{NO}_{x}$ emissions by $50 \%$ resulted in more days with peak $\mathrm{O}_{3}$ changes in the $1.5 \mathrm{ppb}$ to $3.0 \mathrm{ppb}$ range (Figure 4B). These results are consistent with previous studies suggesting that the impact of isoprene emissions from bioenergy crop development may be highly dependent on local $\mathrm{NO}_{\mathrm{x}}$ concentrations. ${ }^{5}$ Furthermore, these results indicate that $\mathrm{NO}_{x}$ emissions higher than those represented in the NEI05 (e.g., due to current inventory uncertainties or future anthropogenic development) could lead to greater air quality impacts from isoprene emission associated with the cultivation of A. donax. Changes to predicted daytime average SOA levels were $<+0.01 \mu \mathrm{g} \mathrm{m}^{-3}$ and subsequently resulted in no observable changes to $\mathrm{PM}_{2.5}$ levels. 

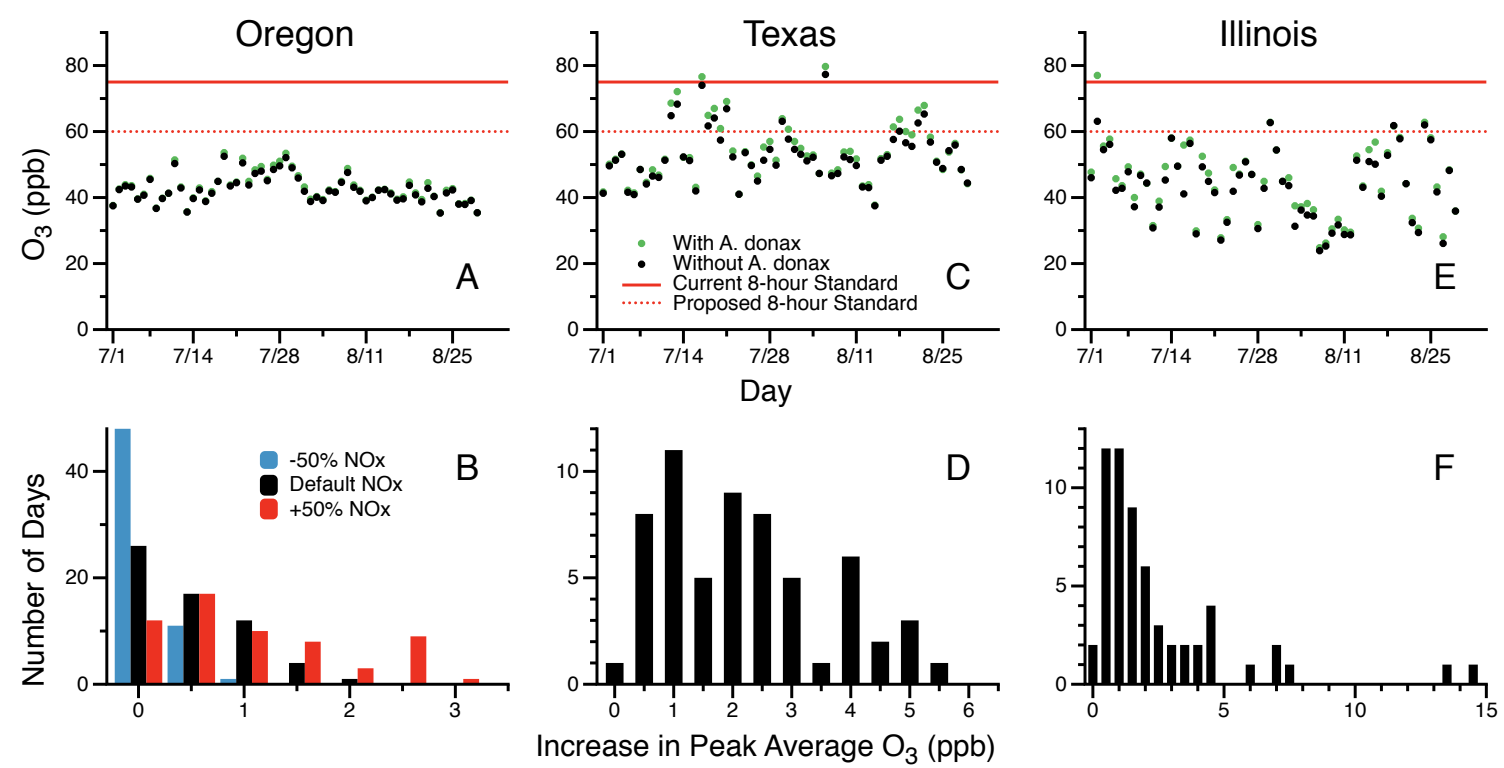

Figure 4. Peak 8-hour average $\mathrm{O}_{3}$ levels and peak change histograms for modeled replacement areas in Oregon (A, B), Texas (C, D), and Illinois (E, F). In panels A, C, and E, filled black circles indicate predicted $\mathrm{O}_{3}$ levels without Arundo donax and filled green circles with $A$. donax. The current National Ambient Air Quality Standard for ozone (8-hour) is $75 \mathrm{ppb}^{137}$ (solid red line in panels A, C, E); a reduction to $60 \mathrm{ppb}$ (dashed red line) has been proposed. ${ }^{138}$ The sensitivity of predicted $\mathrm{O}_{3}$ to modeled $\mathrm{NO}_{x}$ levels is demonstrated for the Boardman, OR site in panel $\mathrm{B}$, where original $\mathrm{NO}_{x}$ levels (black bars) were reduced by $50 \%$ (blue bars) and increased by $50 \%$ (red bars).

\section{Texas}

The Martin Lake replacement area, greater and more disperse than Boardman, also exhibited much higher initial $\mathrm{O}_{3}$ levels (Figure 4C). The predicted response to additional isoprene in this replacement location was significantly greater, with many days exhibiting an increase in peak 8-hour $\mathrm{O}_{3}$ of $3 \mathrm{ppb}$ to $6 \mathrm{ppb}$ (Figure 4D). The larger replacement area coupled with higher ambient $\mathrm{NO}_{x}$ levels (12 $\mathrm{ppb}$ ) are likely two key reasons for the predicted differences between Texas and Oregon; a comparison of midday $\mathrm{NO}_{\mathrm{y}}$ to $\mathrm{O}_{3}$ for the Texas site reveals mixedregime characteristics, with less $\mathrm{NO}_{\mathrm{x}}$ sensitivity than the Boardman location.

When combined with initial $\mathrm{O}_{3}$ levels already at or around the current EPA 
standard of $75 \mathrm{ppb}$, these results suggest that a conversion of the Martin Lake plant based on biomass cultivation of $A$. donax (following the example of the Boardman case) could result in the degradation of regional air quality, i.e., an additional number of days nearing and/or exceeding the $\mathrm{O}_{3}$ standard. With the $\mathrm{O}_{3}$ standard based on each year's $4^{\text {th }}$ highest 8 -hour average levels, ${ }^{139}$ even a small number of additional days exceeding the standard could result in nonattainment and potential adverse consequences for human health. Similarly to Oregon, the predicted changes in the average daytime SOA levels $(+0.01 \mu \mathrm{g}$ $\left.\mathrm{m}^{-3}\right)$ resulted in no observable changes to $\mathrm{PM}_{2.5}$ levels. These predicted changes in SOA are comparable to those reported in Ashworth et al., 2012 for short rotation coppice in North America.

\section{Illinois}

With high daytime $\mathrm{NO}_{\mathrm{x}}$ levels (34 ppb) and low background VOC levels (3.1 ppb $\mathrm{HCHO}$ ) the additional isoprene emissions in this crop replacement location had dramatically different results (Figure 4E). The average increase in peak 8-hour $\mathrm{O}_{3}$ for this region was $2.7 \mathrm{ppb}$, with some days exhibiting an increase of over $14 \mathrm{ppb}$, as a consequence of $A$. donax establishment. Episodes of this magnitude, while sporadic and probably highly dependent on day-to-day variation in meteorology, illustrate the potential risks of cultivating (on a large scale) high isoprene-emitting crops in VOC-sensitive regions. With almost no observed correlation between midday $\mathrm{NO}_{y}$ and $\mathrm{O}_{3}$, the Illinois replacement location fits the 
Sillman and $\mathrm{He}^{136}$ description of a $\mathrm{NO}_{x}$-saturated regime, helping to explain the sensitivity to VOC emissions and magnitude of $\mathrm{O}_{3}$ increases in Illinois compared to the Oregon and Texas locations.

In contrast to Oregon and Texas, an examination of SOA production for the Illinois replacement area reveals that the establishment of an isoprene-emitting biomass crop, such as A. donax, in this region may lead to elevated SOA levels as well. Though the predicted changes in SOA levels over the course of the 60-day runs varied greatly, the additional isoprene resulted in average increases of $2 \%$ in peak $\mathrm{PM}_{2.5}$ levels. With $A$. donax, the highest SOA levels averaged $0.42 \mu \mathrm{g} / \mathrm{m}^{3}$ (one-hour, 12:00 pm, average of 10 highest days) and $0.32 \mu \mathrm{g} / \mathrm{m}^{3}$ (eight-hour, 8:00 am to 4:00 pm, average). For the same 10 days without $A$. donax, SOA levels averaged $0.21 \mu \mathrm{g} / \mathrm{m}^{3}$ (one-hour) and $0.17 \mu \mathrm{g} / \mathrm{m}^{3}$ (eight-hour). Greater sensitivity to isoprene emissions was observed on days not necessarily included in the days with absolute highest SOA levels. The 10 days displaying the greatest sensitivity to isoprene emissions (Figure 55) exhibited average increases of $0.22 \mu \mathrm{g} / \mathrm{m}^{3}$ (onehour) and $0.16 \mu \mathrm{g} / \mathrm{m}^{3}$ (eight-hour); a maximum hourly increase of $0.67 \mu \mathrm{g} / \mathrm{m}^{3}$ of SOA was predicted. 


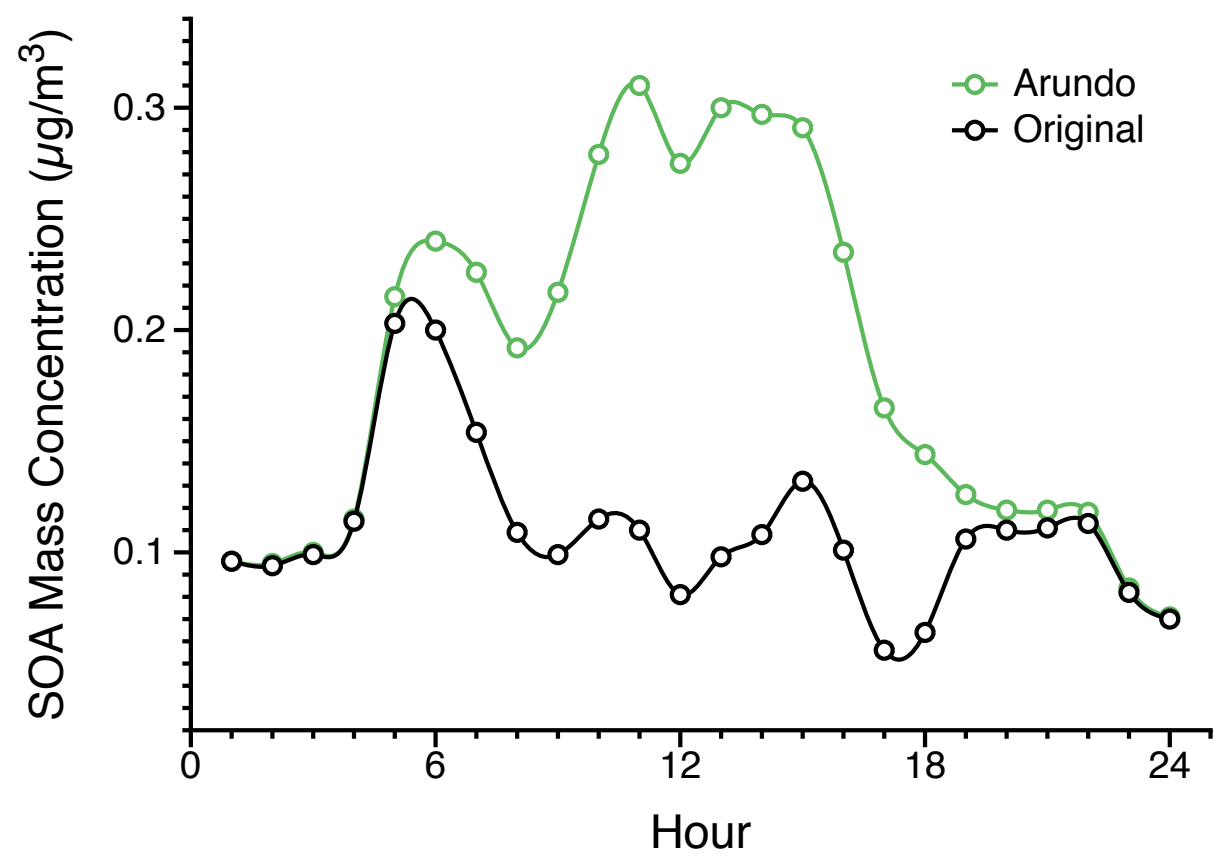

Figure 5. SOA mass concentrations for the Illinois replacement area, averaged over the 10 days exhibiting the greatest change in peak one-hour SOA level (12:00 pm), without (black trace) and with (green trace) Arundo donax.

The above reported increases in predicted $\mathrm{O}_{3}$ levels showed negligible sensitivity to increasing LAI (from 5 to $10 \mathrm{~m}^{2} \mathrm{~m}^{-2}$ ) within MEGAN due to the rapid reduction in LAI sensitivity for values above $5 .{ }^{17}$ Within the dry deposition scheme, increasing LAI from $\sim 2-3 \mathrm{~m}^{2} \mathrm{~m}^{-2}$ (existing croplands) to $5 \mathrm{~m}^{2} \mathrm{~m}^{-2}$ (A. donax) resulted in negligible changes to the predicted $\mathrm{O}_{3}$ increases at all three replacement sites; however, increasing LAI to $10 \mathrm{~m}^{2} \mathrm{~m}^{-2}$ resulted in a reduction in predicted $\mathrm{O}_{3}$ increases at all sites, as increased deposition effects overpowered the small increase in emissions at these higher LAI values. The greatest impact was observed for the Illinois replacement location, with increases in average 8hour $\mathrm{O}_{3}$ reduced by up to $23 \%$; the relatively high density of this replacement 
area may have contributed to this observed sensitivity. These results suggest increased $\mathrm{O}_{3}$ deposition may partially mitigate predicted $\mathrm{O}_{3}$ increases as a consequence of the production of high isoprene-emitting/high-LAI biomass crops, such as A. donax. As LAI values for $A$. donax are likely to fall within this broad range of 5-10 $\mathrm{m}^{2} \mathrm{~m}^{-2}$, accurate measurement of these values under field conditions and their inclusion in future modeling scenarios are important considerations. As demonstrated here, factors such as ambient $\mathrm{NO}_{x}$ levels, local meteorology and climatology, and density of the replacement area will influence the overall air-quality impacts of large-scale conversions such as the one currently planned in Boardman, Oregon. While an isoprene-emitting crop such as A. donax may prove ideal in Boardman or similar locations with relatively low ambient $\mathrm{NO}_{\mathrm{x}}$, such a replacement scheme may have negative consequences on regional $\mathrm{O}_{3}$ levels if replicated in areas with a greater sensitivity to the increased BVOC emissions. Although the greatest increases in $\mathrm{O}_{3}$ and SOA formation will occur above and around the actual crop replacement areas, the effects on air quality can be expected to extend well beyond the immediate vicinity, depending on local meteorology (Figure 66). Thus, consideration of potential changes in $\mathrm{O}_{3}$ and SOA levels throughout the surrounding region should be considered when evaluating the possible air quality consequences of large-scale establishment of isoprene-emitting crops. 


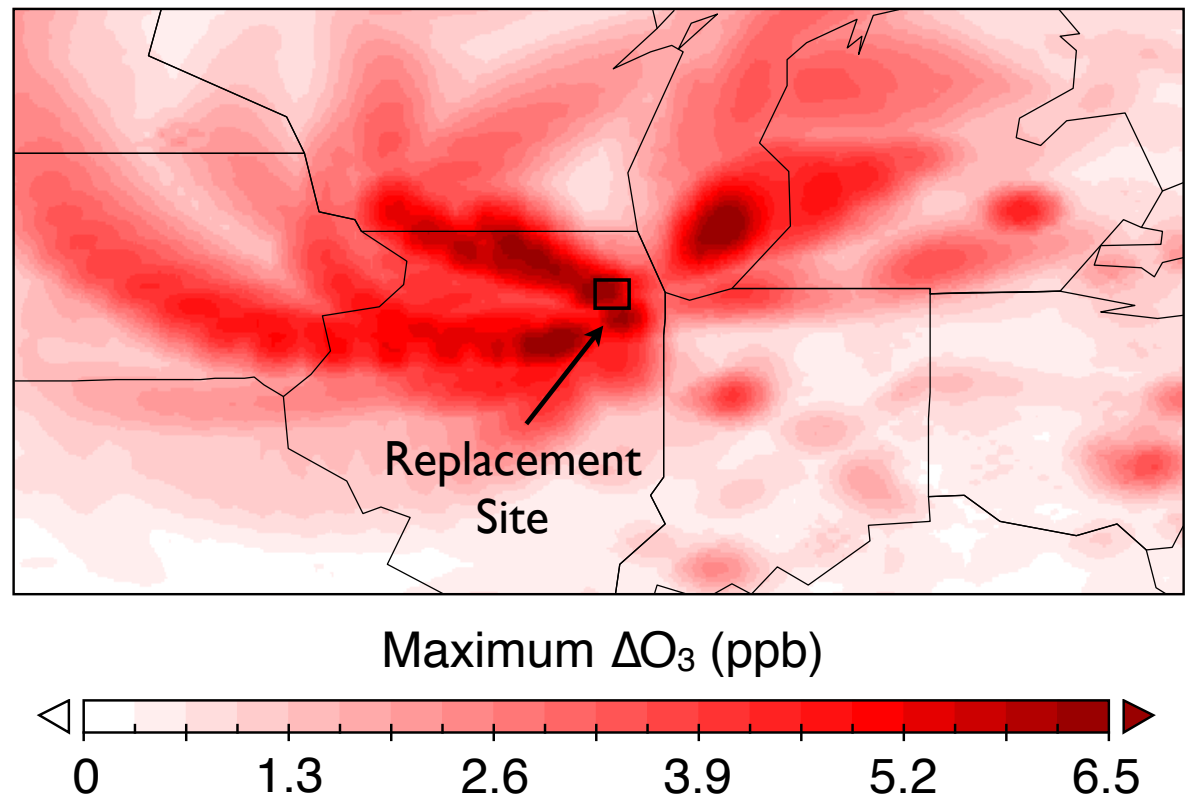

Figure 6. Maximum increase in peak 8-hour average $\mathrm{O}_{3}$ levels for Illinois case over 60-day simulation. The color bar is saturated at $6.5 \mathrm{ppb}$, but values as high as $14.5 \mathrm{ppb}$ were predicted.

While the specific conditions of the three replacement scenarios considered here differ substantially, our general findings are consistent with those of other recent studies. Ashworth et al..$^{30}$ examined the results of expanded biofuel production (primarily short-rotation coppice plants such as poplar) in the northwest, midwest, and southeast US, concluding that there would likely be very little impact on $\mathrm{O}_{3}$ and SOA in and around Oregon, but greater increases in the midwest, specifically around Illinois. Similarly, Wiedinmyer et al. ${ }^{27}$ examined the air quality consequences of expanding isoprene-emitting poplar plantations in the Pacific Northwest, and found that $\mathrm{O}_{3}$ levels could actually be expected to decrease slightly in this scenario, should $\mathrm{NO}_{\mathrm{x}}$ levels remain low. The findings of 
Wiedinmyer et al. further support the demonstrated $\mathrm{NO}_{x}$-sensitivity of the Boardman region and relatively small predicted increases in $\mathrm{O}_{3}$ levels.

As leaf isoprene emissions increase with leaf temperature, ${ }^{140,141}$ but decrease with increasing atmospheric $\mathrm{CO}_{2}, 6,142,143$ ongoing global change may further impact overall BVOC emissions from long-lived bioenergy cropping systems. Heald et al. ${ }^{134}$ found that the competing influences of increasing temperature and increasing atmospheric $\mathrm{CO}_{2}$ concentrations largely compensate one another, resulting in little change to emissions based on future climate alone; the dominant driver of future changes in BVOC emissions, and subsequently air quality, was land-use change. Consistent with these results, we also found that the competing effects of temperature and $\mathrm{CO}_{2}$ on base isoprene emissions in all three regions effectively canceled each other out. Furthermore, the consequences on $\mathrm{O}_{3}$ as a result of crop conversion under future temperature and $\mathrm{CO}_{2}$ projections were largely unchanged in Oregon and Illinois (within $1 \%$ of $\mathrm{O}_{3}$ increases from land-use change under current climate conditions). However, in the Texas location the increase in predicted $\mathrm{O}_{3}$ from $A$. donax establishment was reduced by $33 \%$ under future climate conditions, suggesting that the impacts of global change on the relationship between isoprene emission from bioenergy crops and air quality may differ among replacement regions.

The results of this and previous studies clearly point to an important connection between isoprene emissions from bioenergy crop cultivation and regional air 
quality, but there are a number of important uncertainties that must be quantified and minimized for practical risk-assessment applications. From an emissions perspective, comprehensive emission profiles and LAI values under actual field conditions for $A$. donax (or for any candidate bioenergy species) must be appropriately evaluated and verified for accurate assessments to be made. While this study examined only the air quality impacts of increased isoprene emissions, other BVOCs play an important role in the formation of air pollutants, necessitating characterization of the comprehensive emissions profiles for crops of interest. ${ }^{144}$ It should be noted that many emerging bioenergy crops have been relatively poorly characterized with respect to BVOC emissions (particularly under field conditions), and variety or cultivar specific patterns of BVOC emissions from candidate bioenergy crops are rarely considered. ${ }^{8}$ Responses of emissions to on-going components of global change, including temperature and atmospheric $\mathrm{CO}_{2}$ levels also contribute to overall uncertainty in predicted emissions and should be further developed. ${ }^{134}$ Regarding $\mathrm{O}_{3}$ and SOA formation, gas-phase chemical mechanism and SOA models are still undergoing significant developments, ${ }^{99,145-147}$ which will further improve prognostic capabilities with respect to the spatial and temporal variations in pollutant levels (particularly SOA and thus $\mathrm{PM}_{2.5}$ ) resulting from various replacement scenarios.

The overarching goals of this and future work are to initiate the development of a framework for crop and site selection that will enable the expected growth in 
bioenergy-based electricity generation to proceed with minimal impacts on regional air quality. Although there is significant potential in 'greening' our national energy portfolio through the widespread development of bioenergy, selection of regionally-appropriate crop species should involve characterization and assessment of BVOC emissions in order to minimize the unintended consequences on air quality associated with bioenergy conversion, and the largescale shifts in vegetation composition associated with bioenergy crop development. In evaluating crops with significant isoprene and other BVOC emissions, characteristics such as energy density, growth rate, fertilizer and water requirements, and other ecological impacts must be included alongside BVOC emissions profiles to generate a complete evaluation of economic viability and environmental impacts, allowing for the development of an overall ranking of potential crops' impacts on air quality, in a manner similar to the work done by Donovan et al. ${ }^{106}$ to evaluate the photochemical smog-forming potential of urban trees. In regions where establishment of isoprene emitting bioenergy crops may negatively influence regional air quality, selection of bioenergy crop species with lower BVOC emissions (e.g. switchgrass, sugarcane, rapeseed) $)^{8}$ may be more appropriate. Further identification, characterization, and development of low-BVOC emitting bioenergy crops and crop varieties, as well as genetic approaches for reducing isoprene emissions in crops with high economic value, ${ }^{76}$ 
are two key strategies for ensuring selection of plant genotypes suitable for largescale biomass production with minimal impacts on regional air quality. 


\section{Chapter 3. Greening the globe: A worldwide analysis of the atmospheric consequences of bioenergy crop cultivation}

While high-resolution regional models will be important tools for assessing the atmospheric impacts of specific replacement proposals such as the ongoing project in Boardman described in chapter 2, a global analysis can provide information on not only general regional sensitivities and risks, but also potential global climate effects. To this end, the Community Earth System Model (CESM) was used to simulate the air quality and climate impacts of large-scale bioenergy crop cultivation based on estimates of abandoned and low-quality land potentially suitable for conversion (Figure 7). 


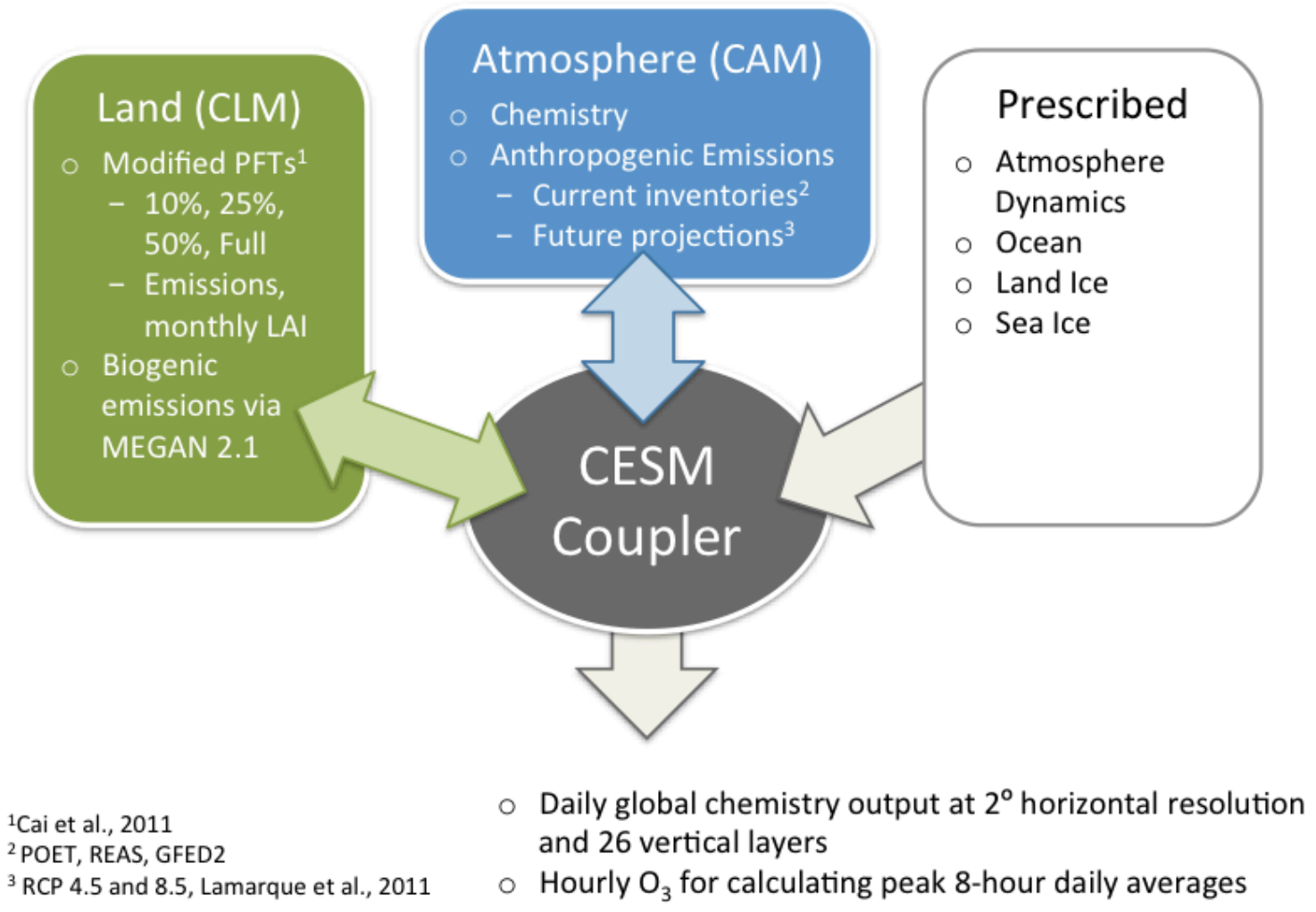

Figure 7. Modeling framework used for global land-use change simulations

\section{Methods}

\section{Estimated land availability}

Estimates of marginal and underutilized land that could potentially be converted to bioenergy crop cultivation were taken using the results of Cai et al. 2011. ${ }^{148}$ With a total of over 1100 Mha in Africa, China, Europe, India, South America, and the United States, this scenario includes areas identified as marginal (abandoned, degraded, and/or low quality) cropland, grassland, savanna, and shrubland, excluding those lands currently used as pasture for livestock. As the area designated under this scenario is aggressive, exceeding some current bioenergy adoption estimates, reduced cases $(50 \%, 25 \%$, and $10 \%$ of scenario 4 
areas) were also constructed from the same output. These four sets of replacement areas were then used to alter the plant functional type (PFT) inputs to represent the conversion of existing land to bioenergy cropland in each grid cell. In all, replaced crops in the six most likely bioenergy producing regions totaled 314 Mha in Africa, 152 Mha in China, 111 Mha in Europe, 151 Mha in India, 256 Mha in South America, and 123 Mha in the United States under the full replacement case (Table 2). While the full replacement scenario represents an upper extreme for potential bioenergy land-use, the low end 10\% replacement is fairly conservative in most regions. By way of comparison, Ashworth et al., 2012 examined the replacement of 70 Mha in Europe and 18 Mha in the United States.

Table 2. Total replacement area by region and case (Mha)

\begin{tabular}{ccccc}
\hline & $\mathbf{1 0 \%}$ & $\mathbf{2 5 \%}$ & $\mathbf{5 0 \%}$ & $\mathbf{1 0 0 \%}$ \\
\hline Africa & 31.4 & 78.5 & 157 & 314 \\
China & 15.2 & 38.0 & 76.0 & 152 \\
Europe & 11.1 & 27.8 & 55.5 & 111 \\
India & 15.1 & 37.8 & 75.5 & 151 \\
South America & 25.6 & 64.0 & 128 & 256 \\
United States & 12.3 & 30.8 & 61.5 & 123 \\
\hline
\end{tabular}

Starting from the stock land-use maps used by CESM to generate biogenic emissions via MEGAN, existing PFT percentages in each grid cell were modified to fit the selected estimates of underutilized land. Due to discrepancies between these estimates and the default land-use map used in CESM, cropland PFT was added to the base case that any effects of deforestation were not included in final 
comparisons. Monthly leaf area indices (LAIs) for replacement crops were generated following literature values for peak LAI for each crop, modified to match the existing annual cycle of PFTs most similar to the crop in question in that area: $\mathrm{C} 4$ grasses for switchgrass and broadleaf evergreens for eucalyptus and giant reed.

Three individual crop emission types were modeled, representing high emissions of both isoprene and monoterpenes (eucalyptus), high isoprene only (giant reed), and trace emissions (switchgrass). The measurements of Guenther et al. 1994 were used for eucalyptus (70 $\mu \mathrm{g} \mathrm{C} \mathrm{g} \mathrm{g}^{-1} \mathrm{hr}^{-1}$ for isoprene, $3 \mu \mathrm{g} \mathrm{C} \mathrm{g}{ }^{-1} \mathrm{hr}^{-1}$ for monoterpenes), though it should be noted that there has been a great deal of variability between literature estimates for this species. ${ }^{149}$ For example, Winters et al. 2009 found lower isoprene emissions and much higher monoterpene emissions, though they note several possible unique circumstances during their measurements that might explain these discrepancies. Further work will be necessary to explain these variations and improve estimates ${ }^{150}$ Emissions for switchgrass were taken from Eller et al., 2011 and Graus et al., 2011 (18 ng isoprene $\mathrm{g}^{-1} \mathrm{hr}^{-1}$ and $0.13 \mu \mathrm{g}$ monoterpenes $\left.\mathrm{g}^{-1} \mathrm{hr}^{-1}\right) .{ }^{84,151}$ To represent the emissions of giant reed, measurements gathered at a working test plot in Boardman, OR were normalized for temperature and incoming radiation (Rosenstiel, personal communication). The results of this analysis were much higher than previous greenhouse measurements, but in line with other literature 
values from measurements taken in field conditions (135 $\mu$ g isoprene $\mathrm{g}^{-1} \mathrm{hr}^{-1}$, no monoterpene emissions). ${ }^{152,153}$

\section{Model details}

CESM 1.1 was used for all output simulations in this work. Specified meteorology was first generated for both present day (2000-2002) and future (2030-2032) cases using fully active atmosphere, land, ocean, and ice components, and this output was then used to generate dynamics for each of the emissions cases listed below. For the future climate cases, simulations following two different projected emissions scenarios were used, RCP8.5 and RCP4.5, representing emissions scenarios in which radiative forcing is increased by $8.5 \mathrm{~W}$ $\mathrm{m}^{-2}$ and $4.5 \mathrm{~W} \mathrm{~m} \mathrm{~m}^{-2}$ by the year 2100 , respectively. These two scenarios cover a range of emissions projections spanning relatively high anthropogenic emissions in the absence of comprehensive greenhouse gas policies (RCP8.5) and stabilized emissions due to widespread regulations (RCP4.5), and therefore provide some indication of how uncertainties in future anthropogenic emissions could affect the results of this work. Percent changes for $\mathrm{NO}_{\mathrm{x}}$ and its oxidation products $\left(\mathrm{NO}_{\mathrm{y}}\right)$ for both emissions scenarios can be seen in Figure 8. Spatial resolution for all simulations was $1.9^{\circ} \times 2.5^{\circ}$ horizontally with 26 vertical levels.

After initial land conditions were generated for each replacement scale using a land-only spinup, the atmosphere and land components of CESM were run for 
three years for each of the 3 base cases and 48 replacement cases, with the first year discarded. The final two years of each run were then analyzed.

Table 3. Settings used for all 46 simulated cases

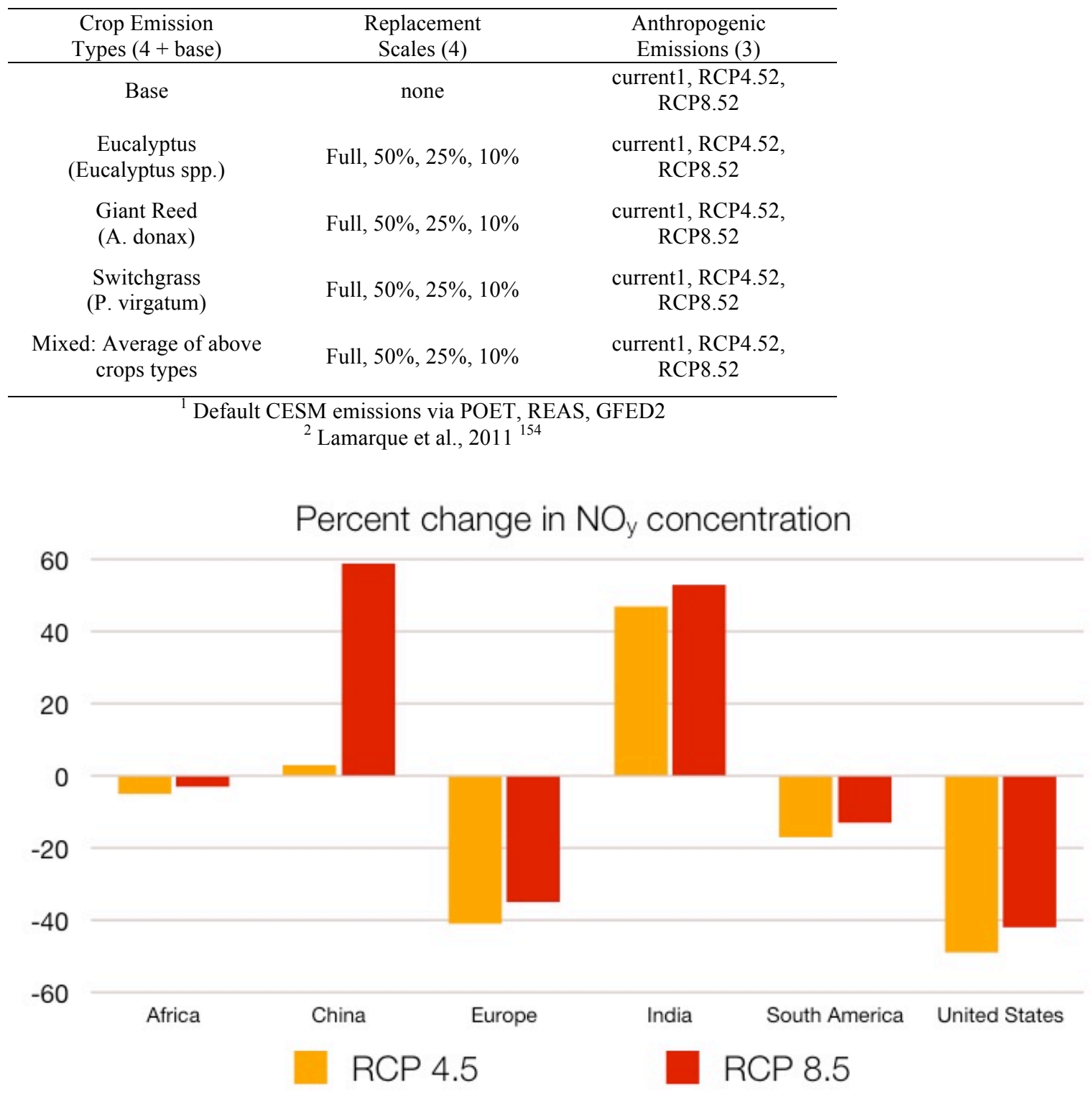

Figure 8. Changes in $\mathrm{NO}_{\mathrm{x}}+$ oxidation product $\left(\mathrm{NO}_{\mathrm{y}}\right)$ concentrations under $\mathrm{RCP}$ scenarios 


\section{Air Quality Results}

$\mathrm{O}_{3}$ and $\mathrm{PM}_{2.5}$

Changes to ozone occurred for all cases involving high-emitting crops, and were highly dependent on replacement area scale. In the $10 \%$ replacement area cases, increases in ozone resulted in all regions with the eucalyptus, giant reed, and mixed crop types. $\mathrm{O}_{3}$ continued to increase in the $25 \%$ and $50 \%$ scale cases for areas with low replacement area density, but the changes were reduced or even opposite in sign in areas with particularly heavy replacement densities (see concentration maps in Appendix B for more info). This inversion indicates extreme BVOC levels and high $\mathrm{NO}_{\mathrm{x}}$ sensitivity, with the additional hydrocarbon burden beginning to act as an $\mathrm{O}_{3}$ sink. Despite the lower $\mathrm{O}_{3}$ levels in these regions, the high $\mathrm{NO}_{\mathrm{x}}$ sensitivity would be of some concern for future air quality, as increases in local $\mathrm{NO}_{x}$ emissions could result in drastic and sudden $\mathrm{O}_{3}$ increases. ${ }^{155}$ The effects of modified crop emissions on annual $\mathrm{O}_{3}$ cycles in each region can be seen in Figure 9. 

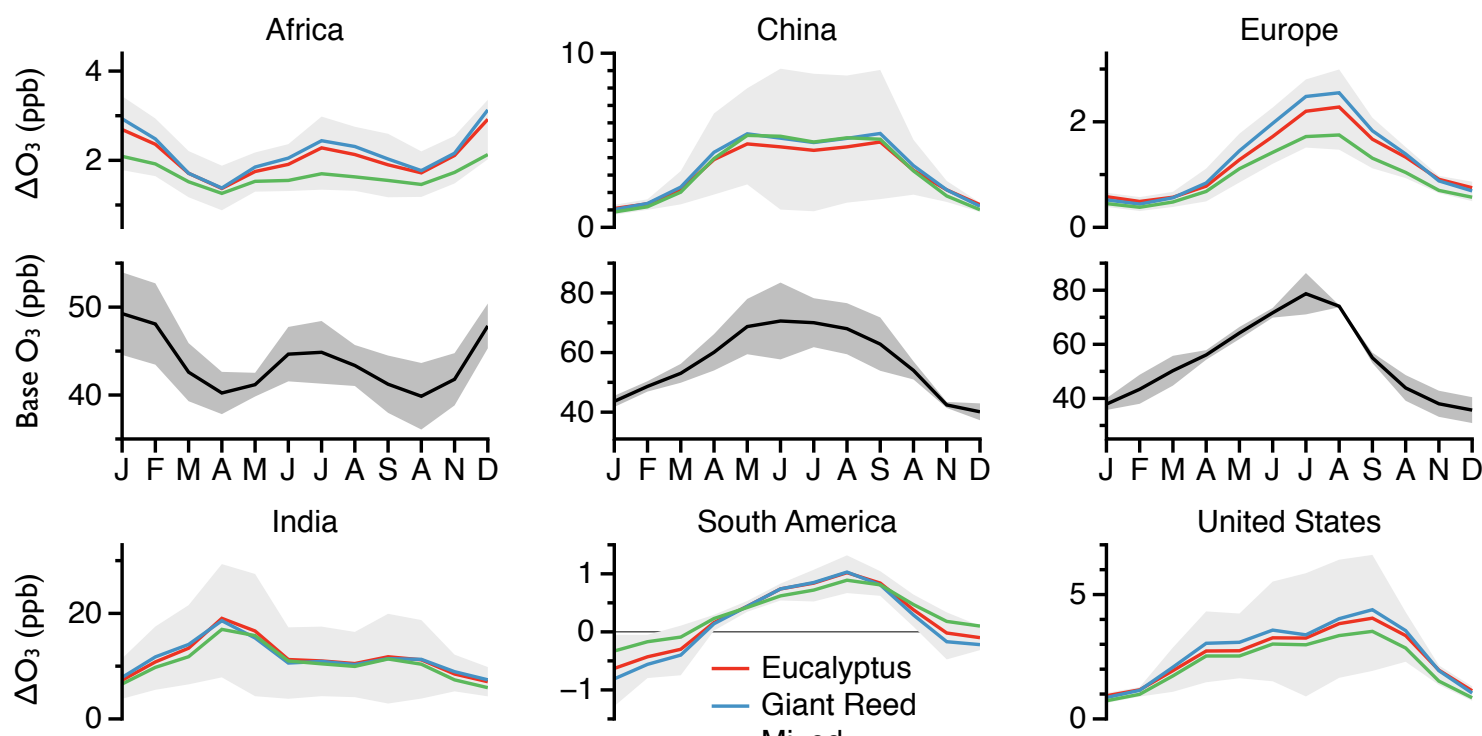

South America
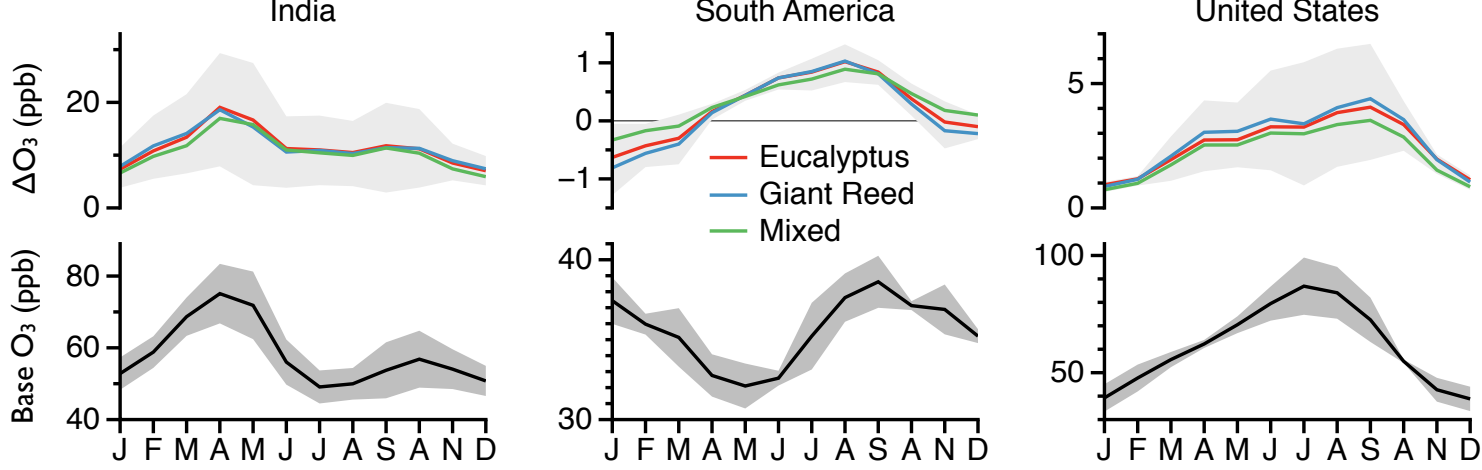

Figure 9. Annual cycles for population-weighted base $\mathrm{O}_{3}$ and changes with $25 \%$ replacement for each region. Shading indicates maxima and minima for all three anthropogenic emission scenarios, \pm annual standard deviations.

The sensitivity of tropospheric $\mathrm{O}_{3}$ levels to future climate and emission uncertainties is highlighted by differences in the cases following RCP 8.5 and RCP 4.5 emission scenarios. The additional anthropogenic emissions in the year 2030 predicted by the RCP 8.5 scenario lead to much higher global averages of surface $\mathrm{O}_{3}$, consistent with other modeling efforts. ${ }^{156,157}$ Due to the widespread increase in $\mathrm{NO}_{x}$ levels, increased sensitivity to the extra BVOCs produced in the high-emitting bioenergy crop cases was also apparent; scenarios using RCP 4.5 emissions were characterized by reduced $\mathrm{NO}_{x}$ emissions in many areas, and were much closer to the base atmosphere results. A reduced sensitivity to 
biogenic emissions was seen in many regions, as lower $\mathrm{NO}_{x}$ levels reduced BVOC sensitivity. All in all, population-weighted $\mathrm{O}_{3}$ increases for the highemitting cases were nearly 3 times greater under the high- $\mathrm{NO}_{x} \mathrm{RCP} 8.5$ emissions than those using modern emission datasets, while increases with the reduced RCP 4.5 emissions were approximately $25 \%$ less.

Organic aerosol formation in all regions occurred primarily in cases involving monoterpene emitters: the eucalyptus and mixed cases (Figure 10). Unlike $\mathrm{O}_{3}$, $\mathrm{PM}_{2.5}$ resulting from changing BVOC emissions continued to increase with greater replacement area density, especially for the eucalyptus and mixed emission cases. Giant reed replacement cases showed some $\mathrm{PM}_{2.5}$ response, but at much reduced levels, while switchgrass had a negligible impact on fine particulate matter concentrations. 

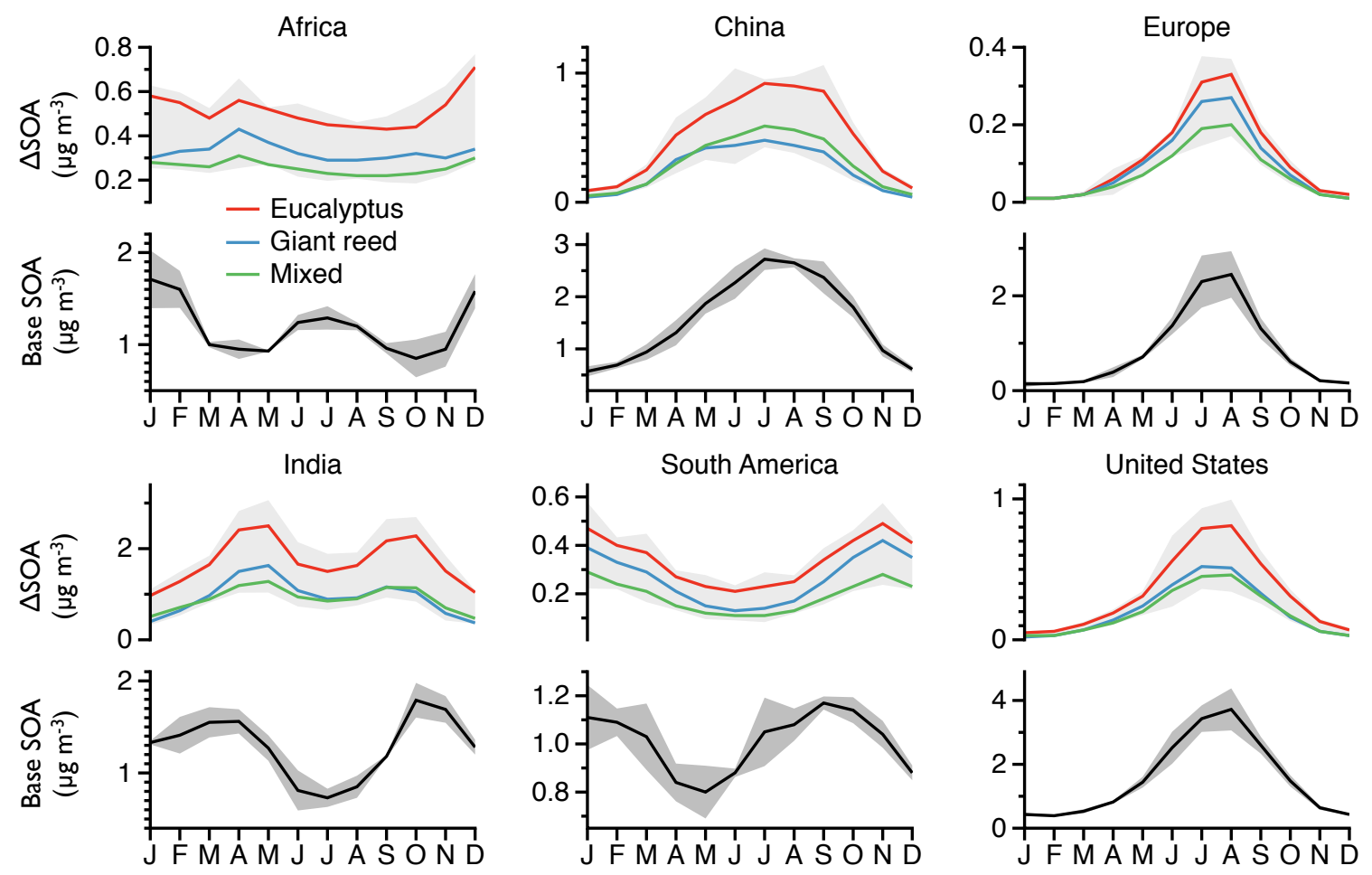

Figure 10. Annual cycles for population-weighted base fine SOA and changes with $25 \%$ replacement for each region. Shading indicates maxima and minima for all three anthropogenic emission scenarios, \pm annual standard deviations.

$\mathrm{PM}_{2.5}$ levels showed much less sensitivity to future changes in climate and emissions, though there were still differences. Under RCP 8.5 emissions, future scenarios showed a population-weighted $25 \%$ increase in $\mathrm{PM}_{2.5}$ levels, while RCP 4.5 emissions resulted in an increase in changes of around $8 \%$ compared to modern temperatures and emissions. For all future results, impacts of crops compared to base conditions for all three sets (current, future RCP 8.5, and future RCP 4.5) were averaged, with standard deviations included in associated uncertainties. 


\section{Total air quality impacts}

Overall air quality impacts were calculated using established WHO standards for $\mathrm{O}_{3}$ and fine particulate matter. ${ }^{92}$ Average changes to $\mathrm{O}_{3}$ and $\mathrm{PM}_{2.5}$ were normalized by their respective standard concentrations and summed using

$$
100 \times \frac{\Delta\left[\mathrm{O}_{3}\right]}{\left[\mathrm{O}_{3}\right]_{s t d}}+100 \times \frac{\Delta\left[\mathrm{PM}_{2.5}\right]}{\left[\mathrm{PM}_{2.5}\right]_{s t d}},
$$

producing a single metric for expected impacts of that particular replacement scenario (Figure 11). Full replacement with a heavy emitter such as eucalyptus would likely have serious impacts on regional air quality, increasing $\mathrm{O}_{3}$ and $\mathrm{PM}_{2.5}$ by levels comparable to those of the standards themselves. Areas with high replacement density, such as Africa, India, and China, show high total changes even in the reduced area sets, indicating that high emitters may not be suitable for heavy adoption in these regions. 

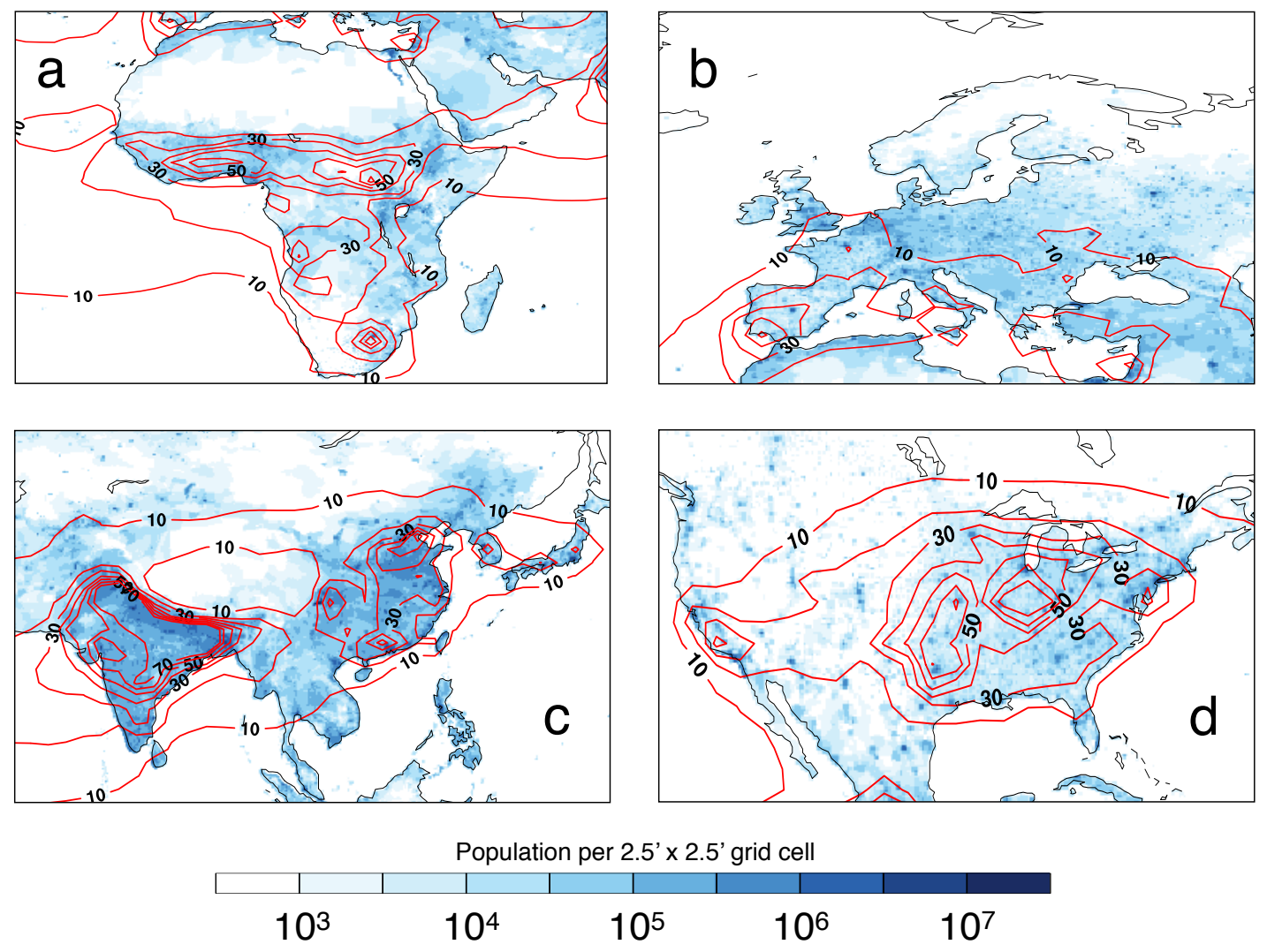

Figure 11. Normalized and summed air quality impacts (equation 9, results in red contours) for the $25 \%$ eucalyptus case, with population distribution (in blue) for Africa (a), Europe (b), India and China (c), and the United States (d).

\section{Mortality}

Impacts of changes in $\mathrm{O}_{3}$ and $\mathrm{PM}_{2.5}$ were calculated following epidemiological studies showing that excess deaths can be expected to follow a log-linear relationship between relative risk (RR), concentration-response factor $(\beta)$, and changes in concentration $(\Delta \mathrm{x})$ as given in the following equation: ${ }^{158}$

$$
\mathrm{RR}=\exp (\beta \Delta x) .
$$

The fraction of the disease burden attributable to this relative risk (AF) is then 


$$
\mathrm{AF}=\frac{\mathrm{RR}-1}{\mathrm{RR}}=1-e^{-\beta \Delta x} .
$$

Changes in mortalities can then be estimated using existing mortality rates $\left(y_{0}\right)$ and total population exposed to the increased concentrations using

$$
\Delta \text { Mort }=y_{0}\left(1-e^{-\beta \Delta x}\right) \text { Pop . }
$$

It remains unclear whether or not the influence of $\mathrm{O}_{3}$ changes on mortality rates have an upper or lower limit, but recent studies suggest that changes continue to affect mortality rates even well below typical concentration standards. For this study, a low-end concentration response factor of $0.30 \pm 0.15 \%$ per $10 \mathrm{ppb}_{3}$ was chosen, with no upper or lower threshold on effects. ${ }^{159} \mathrm{PM}_{2.5}$ was handled similarly, using a constant factor of $4 \pm 3 \%$ for each $10 \mu \mathrm{g} \mathrm{m}^{-3}$ increase in $\mathrm{PM}_{2.5}$ concentration. ${ }^{160}$ Both uncertainty ranges represent $95 \%$ confidence intervals in their respective studies. One notable source of potential uncertainty in these calculations lies in possible differences in mortality responses worldwide, as most epidemiological studies have been performed in the United States and Europe. 

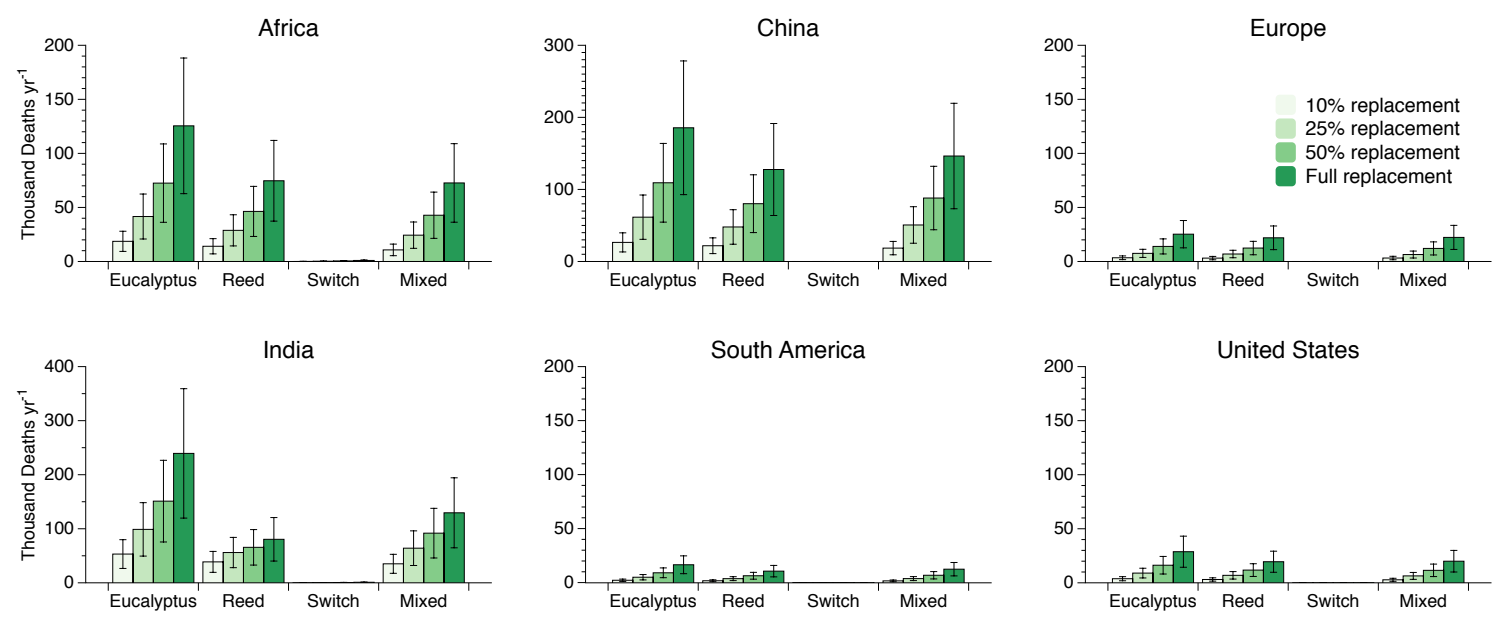

Figure 12. Total deaths predicted in each region, by crop type and replacement scale. Error bars represent uncertainty in mortality rate changes. Note increased y-axis bounds for China and India.

Using population distribution data and concentration response estimates, the number of lives affected by degraded air quality can be estimated and a health cost assessed to conversion on a regional basis. ${ }^{159,160}$ As the health risks associated with $\mathrm{PM}_{2.5}$ exceed those of tropospheric $\mathrm{O}_{3}$, the high monoterpene emissions of eucalyptus resulted in the greatest estimated health costs among the four crop types, with over 750,000 premature deaths worldwide associated with the highest replacement level (Figure 12). The high isoprene emissions of the giant reed crop type were also impactful, with over 380,000 premature deaths associated with the $\mathrm{PM}_{2.5}$ and $\mathrm{O}_{3}$ generated from the additional isoprene burden produced by the maximum cultivation case. While these numbers are remarkably high, it should be noted that they represent maximum replacement scenarios. For the $25 \%$ replacement scenario using giant reed, the 7,400 predicted premature deaths in Europe (56 Mha replaced) is comparable to the 1,400 deaths 
projected by Ashworth et al., 2013 (72 Mha replaced), especially considering that only $\mathrm{O}_{3}$ impacts of lower-emitting crops were considered in that work. Conversion of land to switchgrass showed negligible increases in $\mathrm{O}_{3}$ and $\mathrm{PM}_{2.5}$ due to the small magnitude of emissions, comparable to grass and agricultural crop PFTs. However, mixing the three crop types proved to be more detrimental than might be predicted, with mortality increases generally greater than the average of the three crops. Regionally, the scale of estimated land availability and dense population distributions in India, Africa, and China made those regions the most susceptible to high-emitting crops; approximately $70 \%$ of the increased mortality worldwide occurred in those areas.

\section{Region-specific Crop Suitability}

Changes in $\mathrm{O}_{3}$ and $\mathrm{PM}_{2.5}$ were weighted by population density and normalized by replacement scale to generate an aggregate energy crop air quality score for each crop and region. This score can be understood as the population-weighted average change in air quality (measured in terms of WHO standards for $\mathrm{O}_{3}$ and $\mathrm{PM}_{2.5}$ ) per 10 Mha of energy crop planted in that region. Total scores for Eucalyptus range from -0.76 in South America, where low $\mathrm{NO}_{\mathrm{x}}$ levels and fairly disperse population keep health impacts low, all the way to -8.8 in India, where the density of population and replacement areas make the air quality consequences of crop selection an especially important factor. Uncertainties listed in these numbers reflect their sensitivity to crop replacement scale - large 
values here show crops whose impact per 10 Mha vary greatly depending on the scale of replacement, while low values reveal low scale-sensitivity. In general, areas with a large sensitivity to replacement scale (India, in particular) show reduced negative impacts per Mha as the replacement area increases, reflecting a saturation of $\mathrm{O}_{3}$ and $\mathrm{PM}_{2.5}$ production.

Table 4. Average Energy Crop Air Quality Scores by region and pollutant for 25\% peak regional replacement. ECAQS represents change in population-weighted, standard-normalized air quality per 10 Mha of energy crop planted. (Scores in parentheses calculated using only single worst AQ month.)

\begin{tabular}{c|ccc|ccccccc}
\hline \multicolumn{3}{c}{} & \multicolumn{3}{c}{ Africa } & \multicolumn{3}{c}{ China } & \multicolumn{3}{c}{ Europe } \\
\multicolumn{1}{c}{$\mathrm{O}_{3}$} & $\mathrm{PM}_{2.5}$ & Total & $\mathrm{O}_{3}$ & $\mathrm{PM}_{2.5}$ & Total & $\mathrm{O}_{3}$ & $\mathrm{PM}_{2.5}$ & Total \\
\hline Euc & -0.51 & -0.90 & -1.41 & -1.63 & -3.33 & -4.96 & -0.84 & -0.75 & -1.59 \\
Reed & -0.54 & -0.55 & -1.09 & -1.77 & -2.40 & -4.16 & -0.91 & -0.64 & -1.55 \\
Switch & 0.00 & -0.01 & -0.01 & 0.00 & 0.00 & 0.00 & 0.00 & 0.01 & 0.01 \\
Mixed & -0.41 & -0.48 & -0.89 & -1.68 & -2.61 & -4.29 & -0.67 & -0.66 & -1.33 \\
\hline \multicolumn{2}{r}{ Euc } & -5.88 & -4.84 & -10.72 & -0.07 & -0.74 & -0.81 & -1.59 & -2.05 & -3.63 \\
Reed & -5.88 & -1.74 & -7.62 & -0.05 & -0.54 & -0.59 & -1.68 & -1.40 & -3.08 \\
Switch & -0.03 & -0.02 & -0.04 & 0.00 & 0.00 & 0.00 & 0.00 & -0.01 & -0.01 \\
Mixed & -5.40 & -2.51 & -7.91 & -0.10 & -0.53 & -0.63 & -1.39 & -1.35 & -2.74 \\
\hline
\end{tabular}

The extent to which air quality concerns should be taken into account in the selection of bioenergy crops on a regional basis can be evaluated by comparing differences in ECAQS for each crop within the region. The potential increase in productivity of higher-emitting crops when compared to low-emitting crops such as miscanthus or switchgrass may be justifiable when the populationweighted impacts of the higher emissions are relatively low, as in Africa and 
South America. On the other hand, the larger impacts shown in the other four regions suggest that finding low-emitting solutions may be crucial for any region-wide implementation of a bioenergy cultivation strategy. Furthermore, comparing the eucalyptus and giant reed cases can highlight the relative importance of monoterpene and isoprene emissions in each region. While $\mathrm{PM}_{2.5}$ impacts are larger for the eucalyptus case in all regions, in some areas (such as Europe) the health effects of increased $\mathrm{O}_{3}$ may outweigh those of $\mathrm{PM}_{2.5}$, reducing the difference between isoprene-only emitters such as giant reed and monoterpene emitters such as eucalyptus.

\section{Climate Results}

$\mathrm{CO}_{2}$

As a primary driver for the land-use conversion scenarios described here, reductions in $\mathrm{CO}_{2}$ emissions could potentially be quite large, assuming sufficient energy efficiencies could be realized through appropriate crop processing. If all energy produced in these simulations were to replace coal (with coal emissions assumed to be approximately 1 ton $\mathrm{CO}_{2} \mathrm{MWh}^{-1}$ ) with net zero $\mathrm{CO}_{2}$ emissions, maximum replacement scenarios would imply the prevention of $130 \mathrm{Gt}$ of emitted $\mathrm{CO}_{2}$ - several times larger than current total $\mathrm{CO}_{2}$ emissions. However, for all cases, other climate-related impacts would be projected to affect these savings, including increases in $\mathrm{CH}_{4}$ and aerosols. 
$\mathrm{CH}_{4}$

$\mathrm{CH}_{4}$ levels have increased by a factor of approximately 2.5 since 1750 , leading to a radiative forcing of approximately $0.5 \mathrm{~W} \mathrm{~m}^{-2} .{ }^{94}$

While $\mathrm{CH}_{4}$ sources are varied, and include significant contributions from anthropogenic activities such as fossil fuel combustion, as well as natural sources such as methanogen activity in wetland areas, its sinks are dominated almost entirely by oxidation via the hydroxyl radical $\mathrm{OH}$. In the most extreme crop emission case simulated - full eucalyptus replacement - annual OH levels were reduced by approximately $20 \%$ compared to the base simulation. OH reductions of this magnitude would increase average $\mathrm{CH}_{4}$ lifetimes by up to 2 years, leading to higher concentrations and a corresponding increase in $\mathrm{CH}_{4}$ radiative forcing. While reduced replacement areas and lower-emitting crops would have a lesser impact on $\mathrm{CH}_{4}$, the inclusion of even small impacts on $\mathrm{CH}_{4}$ radiative forcing may be important to the overall cost-benefit calculations. Based on $\mathrm{OH}$ reductions in the simulations of current atmospheric conditions, changes to $\mathrm{CH}_{4}$ radiative forcing could be as high as $0.19 \mathrm{~W} \mathrm{~m}^{-2}$ in the full eucalyptus case, over $1 / 3$ of the total modern $\mathrm{CH}_{4}$ radiative forcing compared to the preindustrial atmosphere. Peak changes for the giant reed and switchgrass cases are predicted to be less than that, at 0.13 and $0.12 \mathrm{~W} \mathrm{~m}^{-2}$ respectively, with reduced replacement schemes scaling down nearly linearly. 
Recent studies into possible $\mathrm{HO}_{x}$ recycling mechanisms under high-isoprene, low- $\mathrm{NO}_{x}$ conditions indicate that the reductions in $\mathrm{OH}$ modeled here may overestimate the impacts of elevated isoprene, especially in pristine, tropical regions. ${ }^{161,162}$ While specific mechanisms capable of reconciling known $\mathrm{OH}$ discrepancies in low- $\mathrm{NO}_{x}$ environments without reducing the accuracy of other species are still under development, it seems clear that isoprene's capacity to eliminate the hydroxyl radical in pristine environments may need correction. To represent this uncertainty, $\Delta \mathrm{OH}$ in grid cells with low $\mathrm{NO}_{\mathrm{x}}$ (less than $1 \mathrm{ppb}$ ) and over areas with high isoprene (greater than $1 \mathrm{ppb}$ ) was reduced by $80 \%$ - a highend estimate for $\mathrm{OH}$ recycled under pristine isoprene chemistry. ${ }^{163}$ The final result was used along with the original output to produce a likely range for total $\mathrm{OH}$ changes.

$P M_{2.5}$

The increase in total organic aerosol burden would have complex impacts on the net energy budget of the atmosphere, impacting not only incoming radiation directly, but also a variety of cloud properties such as albedo and lifetime. With greater levels of SOA predicted for most replacement scenarios, the direct impact of these aerosols would have a cooling effect on the earth due to a greater aerosol optical depth over replacement areas.

Taken together, the increased $\mathrm{CH}_{4}$ lifetime and aerosol burden resulting from enhanced BVOC emissions would be expected to have competing impacts on 
radiative forcing, with the $\mathrm{CH}_{4}$ effect greater by a factor of approximately five. Since the reduction of radiative forcing from greenhouse emissions is one of the main goals driving the present move towards bioenergy options, taking feedbacks such as these into account will be important from a global perspective.

\section{Total estimated costs}

Total Atmospheric Cost of Conversion

Economic assessments of climatic impacts were performed using $\mathrm{CO}_{2}-$

equivalents of $\mathrm{CH}_{4}$ and aerosol radiative forcing changes, along with estimates of the social cost of carbon. Figures for this cost vary greatly and depend heavily upon future economic and atmospheric assumptions; for this work the US Department of Energy value of $\$ 21$ per ton $\mathrm{CO}_{2}$ was used. Costs associated with increased $\mathrm{CH}_{4}$ (minus the cooling effects of increased SOA) are approximately $10 \%$ of the expected value of reduced $\mathrm{CO}_{2}$ emissions for eucalyptus, giant reed, and mixed emission cases, and negligible for switchgrass. Globally summed health costs are larger in general, totaling $18-27 \%$ of the dollar value of reduced $\mathrm{CO}_{2}$ emissions for the high-emitting crops. 


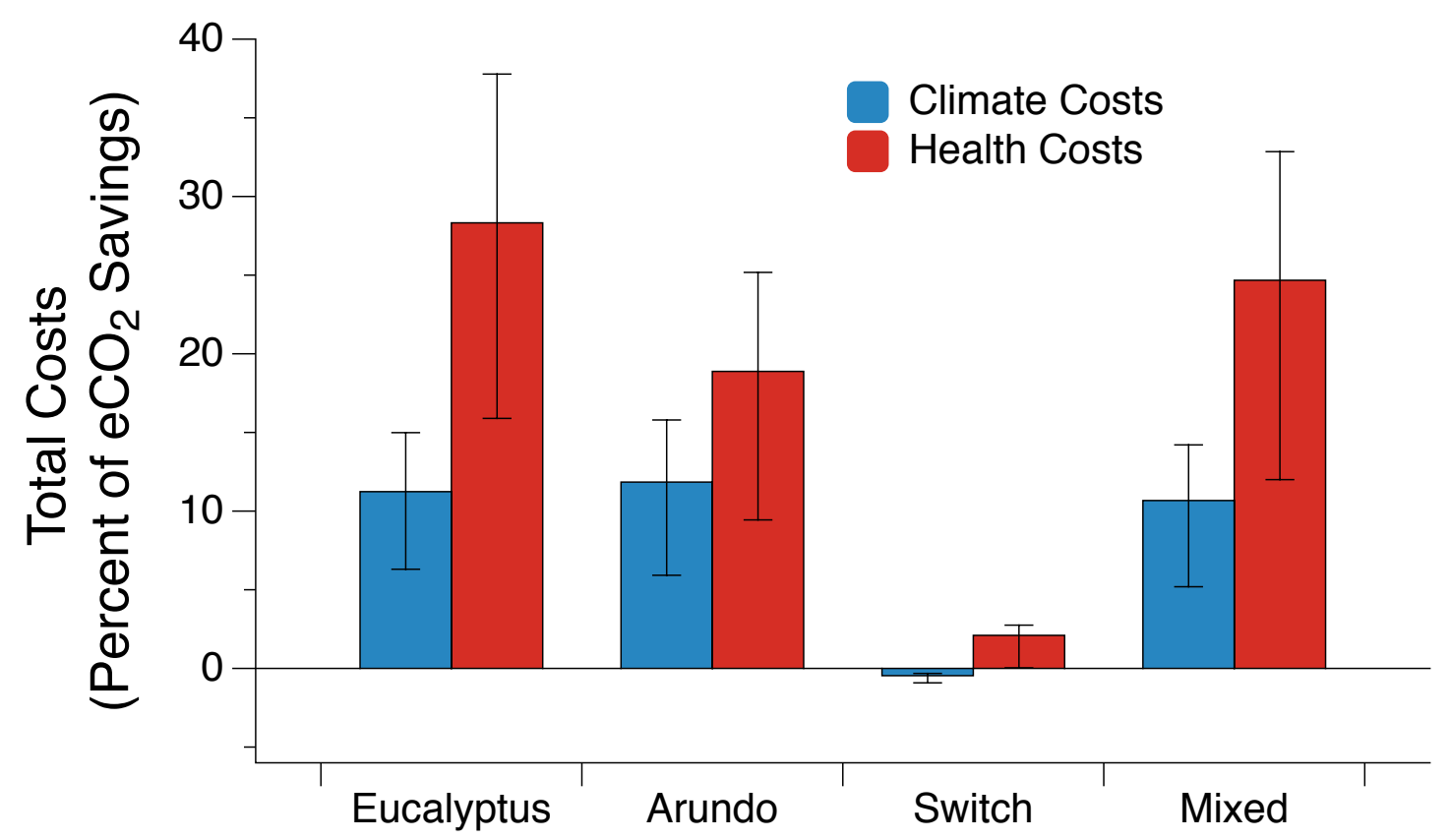

Figure 13. Averaged climate and health costs over all replacement scales for each crop type, given as a percentage of estimated value of $\mathrm{CO}_{2}$ emission savings.

Clearly, while bioenergy crops have demonstrated great potential to form a significant contributor to the future global energy budget, care must be taken in crop selection and placement. The uniform adoption of high emitters would be likely to introduce unintended consequences to both regional air quality and global climate, and therefore both BVOC emission profiles and local air quality sensitivities should be considered along with other limiting factors when selecting appropriate bioenergy feedstocks. 


\section{Conclusions}

The results of regional and global modeling show that location and crop choice will both be significant factors in determining air-quality impacts of bioenergy crop cultivation. Conversion of grassland or agricultural cropland to low or nonemitting energy crops such as switchgrass or miscanthus will likely have little to no impact on air quality, no matter where they are planted. On the other hand, the large-scale conversion to high-emitting cane or plantation trees would likely bring about negative air-quality consequences in regions with high ambient $\mathrm{NO}_{\mathrm{x}}$ concentrations. The increase in VOC emissions that would likely follow from the cultivation of these crop types could be dangerous even in areas with low $\mathrm{NO}_{x}$ levels, as air quality sensitivity to future changes in emissions would be greatly enhanced. Climate impacts of a global shift towards high VOC-emitting crops would also be important to recognize. Increases in $\mathrm{CH}_{4}$ lifetimes due to $\mathrm{OH}$ competition would be expected to overpower the cooling impact of larger aerosol burdens, offsetting the $\mathrm{CO}_{2}$ reductions which largely drive the move towards biomass as a fossil-fuel alternative. 


\section{Bibliography}

1. Service, R. F. Biofuel researchers prepare to reap a new harvest. Science 315, 1488-1491 (2007).

2. Dominguez-Faus, R., Powers, S. E., Burken, J. G. \& Alvarez, P. J. The Water Footprint of Biofuels: A Drink or Drive Issue? Environ. Sci. Technol. 43, 30053010 (2009).

3. Ditomaso, J. M. et al. Biofuel vs Bioinvasion: Seeding Policy Priorities. Environ. Sci. Technol. 44, 6906-6910 (2010).

4. Hewitt, C., Monson, R. \& Fall, R. Isoprene emissions from the grass Arundo donax L. are not linked to photorespiration. Plant Science 66, 139-144 (1990).

5. Hewitt, C. et al. Nitrogen management is essential to prevent tropical oil palm plantations from causing ground-level ozone pollution. Proceedings of the National Academy of Sciences of the United States of America 106, 18447-51 (2009).

6. Rosenstiel, T. N., Potosnak, M. J., Griffin, K. L., Fall, R. \& Monson, R. K. Increased $\mathrm{CO} 2$ uncouples growth from isoprene emission in an agriforest ecosystem. Nature 421, 256-259 (2003).

7. Kiendler-Scharr, A. et al. Isoprene in poplar emissions: effects on new particle formation and $\mathrm{OH}$ concentrations. Atmospheric Chemistry and Physics 12, 1021-1030 (2012).

8. Eller, A. et al. Volatile organic compound emissions from switchgrass cultivars used as biofuel crops. Atmospheric Environment (2011).

9. Chameides, W. L., Lindsay, R. W., Richardson, J. \& Kiang, C. S. The role of biogenic hydrocarbons in urban photochemical smog: Atlanta as a case study. Science 241, 1473-1475 (1988).

10. Derwent, R. G., Jenkin, M. E. \& Saunders, S. M. Photochemical ozone creation potentials for a large number of reactive hydrocarbons under European conditions. Atmospheric Environment 30, 181-199 (1996).

11. Fiore, A. M., Levy, H. \& Jaffe, D. A. North American isoprene influence on intercontinental ozone pollution. Atmospheric Chemistry \& Physics 11, 16971710 (2011).

12. Edney, E. O. et al. Formation of 2-methyl tetrols and 2-methylglyceric acid in secondary organic aerosol from laboratory irradiated isoprene/NOX/SO2/air mixtures and their detection in ambient PM2.5 samples collected in the eastern United States. Atmospheric Environment 39, 5281-5289 (2005).

13. Kroll, J. H., Ng, N. L., Murphy, S. M., Flagan, R. C. \& Seinfeld, J. H. Secondary Organic Aerosol Formation from Isoprene Photooxidation. Environ. Sci. Technol. 40, 1869-1877 (2006). 
14. Henze, D. K. \& Seinfeld, J. H. Global secondary organic aerosol from isoprene oxidation. Geophysical Research Letters 33, 6-9 (2006).

15. Guenther, A. et al. A global model of natural volatile organic compound emissions. J. Geophys. Res. 100, 8873-8892 (1995).

16. Lamarque, J.-F. et al. Historical (1850-2000) gridded anthropogenic and biomass burning emissions of reactive gases and aerosols: methodology and application. Atmospheric Chemistry and Physics 10, 7017-7039 (2010).

17. Guenther, A. et al. Estimates of global terrestrial isoprene emissions using MEGAN (Model of Emissions of Gases and Aerosols from Nature). Atmospheric Chemistry and Physics 6, 3181-3210 (2006).

18. Owen, S. M., Boissard, C. \& Hewitt, C. N. Volatile organic compounds (VOCs) emitted from 40 Mediterranean plant species:: VOC speciation and extrapolation to habitat scale. Atmospheric Environment 35, 5393-5409 (2001).

19. Helmig, D. et al. Biogenic volatile organic compound emissions (BVOCs) I. Identifications from three continental sites in the U.S. Chemosphere 38, 21632187 (1999).

20. Chameides, W. L. et al. Ozone Precursor Relationships in the Ambient Atmosphere. J. Geophys. Res. 97, 6037-6055 (1992).

21. Geron, C. D., Pierce, T. E. \& Guenther, A. B. Reassessment of biogenic volatile organic compound emissions in the Atlanta area. Atmospheric Environment 29, 1569-1578 (1995).

22. Hoffmann, T. et al. Formation of organic aerosols from the oxidation of biogenic hydrocarbons. Journal of Atmospheric Chemistry 26, 189-222 (1997).

23. Sakulyanontvittaya, T., Guenther, A., Helmig, D., Milford, J. \& Wiedinmyer, C. Secondary organic aerosol from sesquiterpene and monoterpene emissions in the United States. Environmental science \& technology 42, 8784-90 (2008).

24. Ganzeveld, L. \& Lelieveld, J. Impact of Amazonian deforestation on atmospheric chemistry. Geophys. Res. Lett. 31, L06105 (2004).

25. Fiore, A. M. et al. Evaluating the contribution of changes in isoprene emissions to surface ozone trends over the eastern United States. J. Geophys. Res. 110, D12303 (2005).

26. Lathière, J. et al. Impact of climate variability and land use changes on global biogenic volatile organic compound emissions. Atmos. Chem. Phys. 6, 21292146 (2006).

27. Wiedinmyer, C., Tie, X., Guenther, A., Neilson, R. \& Granier, C. Future Changes in Biogenic Isoprene Emissions: How Might They Affect Regional and Global Atmospheric Chemistry? Earth Interactions 10, 1-19 (2006).

28. Chen, J. et al. The effects of global changes upon regional ozone pollution in the United States. Atmospheric Chemistry and Physics 9, 1125-1141 (2009). 
29. Chen, J. et al. Future land use and land cover influences on regional biogenic emissions and air quality in the United States. Atmospheric Environment 43, 5771-5780 (2009).

30. Ashworth, K., Folberth, G., Hewitt, C. N. \& Wild, O. Impacts of near-future cultivation of biofuel feedstocks on atmospheric composition and local air quality. Atmospheric Chemistry and Physics 12, 919-939 (2012).

31. Wu, S., Mickley, L. J., Kaplan, J. O. \& Jacob, D. J. Impacts of changes in land use and land cover on atmospheric chemistry and air quality over the 21st century. Atmospheric Chemistry and Physics 12, 1597-1609 (2012).

32. Jiang, X., Wiedinmyer, C., Chen, F., Yang, Z. \& Lo, J. C. Predicted Impacts of Future Climate Change and Land-Use Change on Surface Ozone in the Houston Area. Environmental Protection 83145201-83145201 (2007).

33. Arneth, A., Schurgers, G., Hickler, T. \& Miller, P. A. Effects of species composition, land surface cover, $\mathrm{CO} 2$ concentration and climate on isoprene emissions from European forests. Plant Biology 10, 150-162 (2008).

34. Heald, C. L. et al. Predicted change in global secondary organic aerosol concentrations in response to future climate, emissions, and land use change. J. Geophys. Res. 113, D05211 (2008).

35. Ganzeveld, L. et al. Impact of future land use and land cover changes on atmospheric chemistry-climate interactions. Journal of Geophysical Research 115, (2010).

36. IPCC. The IPCC Special Report on Renewable Energy Sources and Climate Change Mitigation. (Cambridge Univ. Press, 2011).

37. U.S. Energy Information Administration. Annual Energy Outlook 2011, with Projections to 2035. (2011). at <www.eia.gov/forecasts/aeo/>

38. Guenther, A. et al. Natural emissions of non-methane volatile organic compounds, carbon monoxide, and oxides of nitrogen from North America. Atmospheric Environment 34, 2205-2230 (2000).

39. Hakola, H., Rinne, J. \& Laurila, T. The hydrocarbon emission rates of tealeafed willow (Salix phylicifolia), silver birch (Betula pendula) and European aspen (Populus tremula). Atmospheric Environment 32, 1825-1833 (1998).

40. Cronn, D. R. \& Nutmagul, W. Analysis of atmospheric hydrocarbons during winter MONEX. Tellus 34, 159-165 (1982).

41. Haagen-Smit, A. Chemistry and physiology of Los Angeles smog. Industrial E Engineering Chemistry 44, 1342-1346 (1952).

42. Sillman, $\mathrm{S}$. The relation between ozone, NOx and hydrocarbons in urban and polluted rural environments. Atmospheric Environment 33, 1821-1846 (1999).

43. Ryerson, T. B. et al. Observations of ozone formation in power plant plumes and implications for ozone control strategies. Science (New York, N.Y.) 292, 719-23 (2001). 
44. Barket, D. J., Jr. et al. A study of the NOx dependence of isoprene oxidation. J. Geophys. Res. 109, D11310 (2004).

45. Hickman, J. E., Wu, S., Mickley, L. J. \& Lerdau, M. T. Kudzu (Pueraria montana) invasion doubles emissions of nitric oxide and increases ozone pollution. Proceedings of the National Academy of Sciences of the United States of America 107, 10115-9 (2010).

46. Energy Information Administration. Annual Energy Outlook 2013: Early Release Overview. (Department of Energy, 2013).

47. Energy Information Administration. Monthly Energy Review: January 2013. (Department of Energy, 2013).

48. Offermann, R. et al. Assessment of global bioenergy potentials. Mitig Adapt Strateg Glob Change 16, 103-115 (2011).

49. Hamelinck, C. N. \& Faaij, A. P. C. Outlook for advanced biofuels. Energy Policy 34, 3268-3283 (2006).

50. Hill, J., Nelson, E., Tilman, D., Polasky, S. \& Tiffany, D. Environmental, economic, and energetic costs and benefits of biodiesel and ethanol biofuels. PNAS 103, (2006).

51. McKendry, P. Energy production from biomass (part 3): gasification technologies. Bioresource Technology 83, 55-63 (2002).

52. Six, J., Conant, R. T., Paul, E. A. \& Paustian, K. Stabilization mechanisms of soil organic matter: Implications for C-saturation of soils. Plant and Soil 241, 155-176 (2002).

53. Johnson, E. Goodbye to carbon neutral: Getting biomass footprints right. Environmental Impact Assessment Review 29, 165-168 (2009).

54. Bracmort, K. Is Biopower Carbon Neutral? (Congressional Research Service, Library of Congress, 2011).

55. Cherubini, F., Peters, G. P., Berntsen, T., Strømman, A. H. \& Hertwich, E. $\mathrm{CO} 2$ emissions from biomass combustion for bioenergy: atmospheric decay and contribution to global warming. GCB Bioenergy 3, 413-426 (2011).

56. Mohr, S. H. \& Evans, G. M. Forecasting coal production until 2100. Fuel 88, 2059-2067 (2009).

57. Olejarnik, P. World Energy Outlook. International Energy Agency, Paris, France (2010).

58. Reijnders, L. Conditions for the sustainability of biomass based fuel use. Energy Policy 34, 863-876 (2006).

59. Fallot, A. et al. Biomass sustainability, availability and productivity. Revue de Metallurgie, Cahiers d'Informations Techniques 106, 410-418 (2009).

60. Serra, T., Zilberman, D., Gil, J. M. \& Goodwin, B. K. Nonlinearities in the U.S. corn-ethanol-oil-gasoline price system. Agricultural Economics 42, 35-45 (2011).

61. Hanjra, M. A. \& Qureshi, M. E. Global water crisis and future food security in an era of climate change. Food Policy 35, 365-377 (2010). 
62. Amigun, B., Sigamoney, R. \& von Blottnitz, H. Commercialisation of biofuel industry in Africa: A review. Renewable and Sustainable Energy Reviews 12, 690-711 (2008).

63. U.S. Department of Energy. US Billion-Ton Update: Biomass Supply for a Bioenergy and Bioproducts Industry. 227 (Oak Ridge National Laboratory (ORNL), 2011).

64. Rockwood, D. L., Rudie, A. W., Ralph, S. A., Zhu, J. Y. \& Winandy, J. E. Energy product options for eucalyptus species grown as short rotation woody crops. International journal of molecular sciences 9, 1361-78 (2008).

65. Carle, J. \& Holmgren, P. Wood from planted forests: a global outlook 20052030. Forest Products Journal 58, 6-18 (2008).

66. Del Lungo, A., Ball, J. \& Carle, J. Global planted forests thematic study. Results and analysis. Planted Forests and Trees Working Papers (2006). at $<$ http://agris.fao.org/agrissearch/search/display.do?f=2008/XF/XF0709.xml;XF2007431885>

67. Tilman, D., Hill, J. \& Lehman, C. Carbon-Negative Biofuels from Low-Input High-Diversity Grassland Biomass. Science 314, 1598-1600 (2006).

68. Copeland, N., Cape, J. N. \& Heal, M. R. Volatile organic compound emissions from Miscanthus and short rotation coppice willow bioenergy crops. Atmospheric Environment 60, 327-335 (2012).

69. Bourne Jr, J. K. Green Dreams. National Geographic (2007). at <https://ssl.cbsd.org/sites/teachers/hs/jucollins/Documents/Unit $\% 205 \%$ 20-\%20Botany/Article\%20I\%20-\%20Green\%20Dreams.pdf>

70. Tew, T. L. \& Cobill, R. M. in Genetic Improvement of Bioenergy Crops (Vermerris, W.) 273-294 (Springer New York, 2008). at <http://link.springer.com/chapter/10.1007/978-0-387-70805-8_9>

71. Rasmussen, R. A. Isoprene Plant Species List, Special Report of Air Pollution Research Section. (Washington State University, 1978).

72. Food and Agriculture Organization of the United Nations. FAOSTAT. Statistical Database (2013). at <http:// faostat.fao.org/>

73. Misztal, P. K. et al. Direct ecosystem fluxes of volatile organic compounds from oil palms in South-East Asia. Atmos. Chem. Phys 11, 8995-9017 (2011).

74. Misztal, P. K. et al. Large estragole fluxes from oil palms in Borneo. Atmos. Chem. Phys 10, 4343-4358 (2010).

75. Geron, C., Harley, P. \& Guenther, A. Isoprene emission capacity for US tree species. Atmospheric Environment 35, 3341-3352 (2001).

76. Behnke, K. et al. Isoprene emission-free poplars - a chance to reduce the impact from poplar plantations on the atmosphere. New Phytologist 194, 7082 (2012).

77. Behnke, K. et al. Transgenic, non-isoprene emitting poplars don't like it hot. The Plant Journal 51, 485-499 (2007). 
78. Volk, T. A., Verwijst, T., Tharakan, P. J., Abrahamson, L. P. \& White, E. H. Growing Fuel: A Sustainability Assessment of Willow Biomass Crops. Frontiers in Ecology and the Environment 2, 411-418 (2004).

79. Volk, T. A. et al. Yields of willow biomass crops across a range of sites in North America. Asp Appl Biol 112, 67-74 (2011).

80. Scott, D. A. \& Tiarks, A. Dual-Cropping Loblolly Pine for Biomass Energy and Conventional Wood Products. Southern Journal of Applied Forestry 32, 3337 (2008).

81. Helmig, D., Ortega, J., Guenther, A., Herrick, J. D. \& Geron, C. Sesquiterpene emissions from loblolly pine and their potential contribution to biogenic aerosol formation in the Southeastern US. Atmospheric Environment 40, 4150-4157 (2006).

82. Helmig, D. et al. Sesquiterpene Emissions from Pine Trees - Identifications, Emission Rates and Flux Estimates for the Contiguous United States. Environ. Sci. Technol. 41, 1545-1553 (2007).

83. Geron, C. D. \& Arnts, R. R. Seasonal monoterpene and sesquiterpene emissions from Pinus taeda and Pinus virginiana. Atmospheric Environment 44, 4240-4251 (2010).

84. Graus, M. et al. Biosphere-atmosphere exchange of volatile organic compounds over C4 biofuel crops. Atmospheric Environment 1-8 (2011). doi:10.1016/j.atmosenv.2011.12.042

85. Winer, A. M. et al. Emission rates of organics from vegetation in California's Central Valley. Atmospheric Environment. Part A. General Topics 26, 2647-2659 (1992).

86. Kesselmeier, J. \& Staudt, M. Biogenic Volatile Organic Compounds (VOC): An Overview on Emission, Physiology and Ecology. Journal of Atmospheric Chemistry 23-88 (1999).

87. Sharkey, T. D. \& Yeh, S. Isoprene emission from plants. Annual Review of Plant Biology 52, 407-436 (2001).

88. Sharkey, T. D., Chen, X. \& Yeh, S. Isoprene Increases Thermotolerance of Fosmidomycin-Fed Leaves. Plant Physiol. 125, 2001-2006 (2001).

89. Loreto, F. et al. Ozone Quenching Properties of Isoprene and Its Antioxidant Role in Leaves. Plant Physiol. 126, 993-1000 (2001).

90. Loreto, F. \& Velikova, V. Isoprene Produced by Leaves Protects the Photosynthetic Apparatus against Ozone Damage, Quenches Ozone Products, and Reduces Lipid Peroxidation of Cellular Membranes. Plant Physiol. 127, 1781-1787 (2001).

91. Sharkey, T. D., Wiberley, A. E. \& Donohue, A. R. Isoprene Emission from Plants: Why and How. Ann Bot 101, 5-18 (2008).

92. World Health Organization. WHO Air Quality Guidelines for Particulate Matter, Ozone, Nitrogen Dioxide and Sulfur Dioxide. Global Update 2005, Summary of Risk Assessment. (2006). 
93. Ashworth, K., Wild, O. \& Hewitt, C. N. Impacts of biofuel cultivation on mortality and crop yields. Nature Climate Change (2013). doi:10.1038/nclimate1788

94. IPCC. Climate change 2007: The physical science basis. (Cambridge Univ Press, 2007).

95. Pandis, S. N., Harley, R. A., Cass, G. R. \& Seinfeld, J. H. Secondary organic aerosol formation and transport. Atmospheric Environment. Part A. General Topics 26, 2269-2282 (1992).

96. Pankow, J. F. An absorption model of gas/particle partitioning of organic compounds in the atmosphere. Atmospheric Environment 28, 185-188 (1994).

97. Pankow, J. F. An absorption model of the gas/aerosol partitioning involved in the formation of secondary organic aerosol. Atmospheric Environment 28, 189-193 (1994).

98. Odum, J. R. et al. Gas/particle partitioning and secondary organic aerosol yields. Environmental Science \& Technology 30, 2580-2585 (1996).

99. Donahue, N. M., Robinson, a L., Stanier, C. O. \& Pandis, S. N. Coupled partitioning, dilution, and chemical aging of semivolatile organics. Environmental Science \& Technology 40, 2635-43 (2006).

100. Pankow, J. F. \& Barsanti, K. C. The carbon number-polarity grid: A means to manage the complexity of the mix of organic compounds when modeling atmospheric organic particulate matter. Atmospheric Environment 43, 28292835 (2009).

101. Kroll, J. H. et al. Carbon oxidation state as a metric for describing the chemistry of atmospheric organic aerosol. 3, 133-140 (2011).

102. Ott, W. R. \& Hunt,, W. F. A Quantitative Evaluation of the Pollutant Standards Index. Journal of the Air Pollution Control Association 26, 1050-1054 (1976).

103. Swamee, P. K. \& Tyagi, A. Formation of an Air Pollution Index. Journal of the Air E Waste Management Association 49, 88-91 (1999).

104. Sowlat, M. H., Gharibi, H., Yunesian, M., Tayefeh Mahmoudi, M. \& Lotfi, S. A novel, fuzzy-based air quality index (FAQI) for air quality assessment. Atmospheric Environment 45, 2050-2059 (2011).

105. Kyrkilis, G., Chaloulakou, A. \& Kassomenos, P. A. Development of an aggregate Air Quality Index for an urban Mediterranean agglomeration: Relation to potential health effects. Environment International 33, 670-676 (2007).

106. Donovan, R. G., Stewart, H. E., Owen, S. M., MacKenzie, A. R. \& Hewitt, C. N. Development and Application of an Urban Tree Air Quality Score for Photochemical Pollution Episodes Using the Birmingham, United Kingdom, Area as a Case Study. Environ. Sci. Technol. 39, 6730-6738 (2005).

107. Cosentino, S. L., Patanè, C., Sanzone, E., Copani, V. \& Foti, S. Effects of soil water content and nitrogen supply on the productivity of 
Miscanthus $\times$ giganteus Greef et Deu. in a Mediterranean environment. Industrial Crops and Products 25, 75-88 (2007).

108. Van der Voo, L. PGE tests biomass process for Boardman. Sustainable Business Oregon (2011). at <http://www.sustainablebusinessoregon.com/articles/2010/09/pge_tests_ biomass_process_for_boardman.html>

109. $\mathrm{Ng}, \mathrm{N}$. L. et al. Effect of $\mathrm{NO}_{x}$ level on secondary organic aerosol (SOA) formation from the photooxidation of terpenes. Atmospheric Chemistry and Physics Discussions 7, 10131-10177 (2007).

110. $\mathrm{Ng}$, N. L. et al. Secondary organic aerosol formation from m-xylene, toluene, and benzene. Atmospheric Chemistry and Physics Discussions 7, 4085-4126 (2007).

111. Carlton, A. G., Wiedinmyer, C. \& Kroll, J. A review of Secondary Organic Aerosol ( SOA ) formation from isoprene. Atmospheric Chemistry and Physics (2009). at <http://dspace.mit.edu/handle/1721.1/60228>

112. Barsanti, K. C., Carlton, A. G. \& Chung, S. H. Analyzing Experimental Data and Model Parameters: Implications for Predictions of SOA using Chemical Transport Models. In preparation for submission to Atmospheric Chemistry and Physics Discussions

113. Grell, G. a. et al. Fully coupled 'online' chemistry within the WRF model. Atmospheric Environment 39, 6957-6975 (2005).

114. Lin, Y. L., Farley, R. D. \& Orville, H. D. Bulk parameterization of the snow field in a cloud model. Journal of Climate and Applied Meteorology 22, 10651092 (1983).

115. Chou, M. D. \& Suarez, M. J. An efficient thermal infrared radiation parameterization for use in general circulation models. NASA Tech. Memo 104606, 85 (1994).

116. Mlawer, E. J., Taubman, S. J., Brown, P. D., Iacono, M. J. \& Clough, S. A. Radiative transfer for inhomogeneous atmospheres: RRTM, a validated correlated-k model for the longwave. Journal of Geophysical Research 102, 16663-16 (1997).

117. Chen, F. \& Dudhia, J. Coupling an advanced land surface-hydrology model with the Penn State-NCAR MM5 modeling system. Part I: Model implementation and sensitivity. Monthly Weather Review 129, 569-585 (2001).

118. Wesely, M. L. Parameterization of surface resistances to gaseous dry deposition in regional-scale numerical models. Atmospheric Environment (1967) 23, 1293-1304 (1989).

119. Frost, G. J. et al. Effects of changing power plant NOx emissions on ozone in the eastern United States: Proof of concept. J. Geophys. Res. 111, D12306 (2006). 
120. Tie, X. et al. Characterizations of chemical oxidants in Mexico City: A regional chemical dynamical model (WRF-Chem) study. Atmospheric Environment 41, 1989-2008 (2007).

121. Tie, X., Geng, F., Peng, L., Gao, W. \& Zhao, C. Measurement and modeling of O3 variability in Shanghai, China: Application of the WRF-Chem model. Atmospheric Environment 43, 4289-4302 (2009).

122. Kim, S. W. et al. NO2 columns in the western United States observed from space and simulated by a regional chemistry model and their implications for NOx emissions. J. Geophys. Res 114, 11301 (2009).

123. Kim, S.-W. et al. Evaluations of NOx and highly reactive VOC emission inventories in Texas and their implications for ozone plume simulations during the Texas Air Quality Study 2006. Atmospheric Chemistry and Physics 11, 11361-11386 (2011).

124. Stockwell, W. R., Kirchner, F., Kuhn, M. \& Seefeld, S. A new mechanism for regional atmospheric chemistry modeling. Journal of Geophysical Research 102, 25847-25 (1997).

125. Geiger, $\mathrm{H}$. The tropospheric degradation of isoprene: an updated module for the regional atmospheric chemistry mechanism. Atmospheric Environment 37, 1503-1519 (2003).

126. Tyndall, G. S. et al. Atmospheric chemistry of small organic peroxy radicals. J. Geophys. Res. 106, PP. 12,157-12,182 (2001).

127. Orlando, J. J., Tyndall, G. S., Bertman, S. B., Chen, W. \& Burkholder, J. B. Rate coefficient for the reaction of $\mathrm{OH}$ with $\mathrm{CH} 2=\mathrm{C}(\mathrm{CH} 3) \mathrm{C}(\mathrm{O}) \mathrm{OONO} 2$ (MPAN). Atmospheric Environment 36, 1895-1900 (2002).

128. Madronich, S. Photodissociation in the atmosphere 1 . Actinic flux and the effects of ground reflections and clouds. Journal of Geophysical Research 92, 9740-9752 (1987).

129. Carter, W. P. L. Implementation of the SAPRC-99 chemical mechanism into the Models-3 framework. Report to the United States Environmental Protection Agency, January 29, (2000).

130. Zaveri, R. A., Easter, R. C., Fast, J. D. \& Peters, L. K. Model for simulating aerosol interactions and chemistry (MOSAIC). J. Geophys. Res 113, D13204 (2008).

131. Shrivastava, M. et al. Modeling organic aerosols in a megacity: comparison of simple and complex representations of the volatility basis set approach. Atmospheric Chemistry and Physics 11, 6639-6662 (2011).

132. Arneth, A. et al. Global terrestrial isoprene emission models: sensitivity to variability in climate and vegetation. Atmos. Chem. Phys. Discuss. 11, 1061510652 (2011).

133. Possell, M., Nicholas Hewitt, C. \& Beerling, D. J. The effects of glacial atmospheric $\mathrm{CO} 2$ concentrations and climate on isoprene emissions by vascular plants. Global Change Biology 11, 60-69 (2005). 
134. Heald, C. L. et al. Response of isoprene emission to ambient CO2 changes and implications for global budgets. Global Change Biology 15, 1127-1140 (2009).

135. Arneth, A. et al. CO2 inhibition of global terrestrial isoprene emissions: Potential implications for atmospheric chemistry. Geophys. Res. Lett. 34, L18813 (2007).

136. Sillman, S. \& He, D. Some theoretical results concerning O3-NOx-VOC chemistry and NOx-VOC indicators. J. Geophys. Res. 107, 4659 (2002).

137. EPA, U. Air quality criteria for ozone and related photochemical oxidants (Final). US Environmental Protection Agency, Washington, DC 1, 705-735 (2006).

138. EPA. National Ambient Air Quality Standards for Ozone. Federal Register 75, 2938 (2010).

139. US Environmental Protection Agency. National Ambient Air Quality Standards for Ozone. 2938-3052 (US EPA, 2010).

140. Guenther, A. B., Monson, R. K. \& Fall, R. Isoprene and Monoterpene Emission Rate Variability: Observations With Eucalyptus and Emission Rate Algorithm Development. J. Geophys. Res. 96, 10799-10,808 (1991).

141. Guenther, A. B., Zimmerman, P. R., Harley, P. C., Monson, R. K. \& Fall, R. Isoprene and Monoterpene Emission Rate Variability: Model Evaluations and Sensitivity Analyses. J. Geophys. Res. 98, 12609-12,617 (1993).

142. Arneth, A. et al. Process-based estimates of terrestrial ecosystem isoprene emissions: incorporating the effects of a direct $\mathrm{CO}_{2}$-isoprene interaction. Atmospheric Chemistry and Physics 7, (2007).

143. Wilkinson, M. J. et al. Leaf isoprene emission rate as a function of atmospheric CO2 concentration. Global Change Biology 15, 1189-1200 (2009).

144. Goldstein, A. H. \& Galbally, I. E. Known and Unexplored Organic Constituents in the Earth's Atmosphere. Environ. Sci. Technol. 41, 1514-1521 (2007).

145. Surratt, J. D. et al. Reactive Intermediates Revealed in Secondary Organic Aerosol Formation from Isoprene. PNAS 107, 6640-6645 (2010).

146. Chan, A. W. H. et al. Role of aldehyde chemistry and NOx concentrations in secondary organic aerosol formation. Atmospheric Chemistry and Physics 10, 7169-7188 (2010).

147. Paulot, F. et al. Isoprene photooxidation: new insights into the production of acids and organic nitrates. Atmospheric Chemistry and Physics 9, 1479-1501 (2009).

148. Cai, X., Zhang, X. \& Wang, D. Land availability for biofuel production. Environmental science \& technology 45, 334-9 (2011).

149. Guenther, A., Zimmerman, P. \& Wildermuth, M. Natural volatile organic compound emission rate estimates for U.S. woodland landscapes. Atmospheric Environment 28, 1197-1210 (1994). 
150. Winters, A. J. et al. Emissions of isoprene, monoterpene and short-chained carbonyl compounds from Eucalyptus spp. in southern Australia. Atmospheric Environment 43, 3035-3043 (2009).

151. Eller, A. S. D. et al. Volatile organic compound emissions from switchgrass cultivars used as biofuel crops. Atmospheric Environment 45, 3333-3337 (2011).

152. Hewitt, C. N., Monson, R. \& Fall, R. Isoprene emissions from the grass Arundo donax L. are not linked to photorespiration. Plant Science 66, 139144 (1990).

153. Owen, S. Volatile organic compounds (VOCs) emitted from 40 Mediterranean plant species: VOC speciation and extrapolation to habitat scale. Atmospheric Environment 35, 5393-5409 (2001).

154. Lamarque, J.-F. et al. Global and regional evolution of short-lived radiatively-active gases and aerosols in the Representative Concentration Pathways. Climatic Change 109, 191-212 (2011).

155. Hewitt, C. N. et al. Nitrogen management is essential to prevent tropical oil palm plantations from causing ground-level ozone pollution. Proceedings of the National Academy of Sciences of the United States of America 106, 18447-51 (2009).

156. Butler, T. M., Stock, Z. S., Russo, M. R., van der Gon, H. D. \& Lawrence, M. G. Megacity ozone air quality under four alternative future scenarios. Atmos. Chem. Phys 12, 4413-4428 (2012).

157. Wild, O. et al. Modelling future changes in surface ozone: a parameterized approach. Atmospheric Chemistry and Physics 12, 2037-2054 (2012).

158. Anenberg, S. C., Horowitz, L. W., Tong, D. Q. \& West, J. J. An Estimate of the Global Burden of Anthropogenic Ozone and Fine Particulate Matter on Premature Human Mortality Using Atmospheric Modeling. Environmental Health Perspectives 118, 1189-1195 (2010).

159. Bell, M. L., Peng, R. D. \& Dominici, F. The Exposure-Response Curve for Ozone and Risk of Mortality and the Adequacy of Current Ozone Regulations. Environmental Health Perspectives 114, 532-536 (2006).

160. Pope III, C. A. et al. Lung cancer, cardiopulmonary mortality, and long-term exposure to fine particulate air pollution. JAMA: the journal of the American Medical Association 287, 1132-1141 (2002).

161. Peeters, J., Nguyen, T. L. \& Vereecken, L. HOx radical regeneration in the oxidation of isoprene. Physical chemistry chemical physics: PCCP 11, 5935-9 (2009).

162. Da Silva, G., Graham, C. \& Wang, Z.-F. Unimolecular $\beta$-Hydroxyperoxy Radical Decomposition with OH Recycling in the Photochemical Oxidation of Isoprene. Environ. Sci. Technol. 44, 250-256 (2010).

163. Lelieveld, J. et al. Atmospheric oxidation capacity sustained by a tropical forest. Nature 452, 737-40 (2008). 


\section{Appendix A: Supplementary Information for Chapter 2}

\section{Settings and Scripts}

Anthropogenic Emissions

Hourly anthropogenic emissions were produced from the NEI2005 emissions inventory (http://www.epa.gov/ttnchie1/net/2005inventory.html) via emiss_v03_wps.F, open source code originally written by Stu McKeen and modified by Steven Peckham. Variables in the code were modified to fit the Oregon domain as follows (with similar changes for Texas and Illinois):

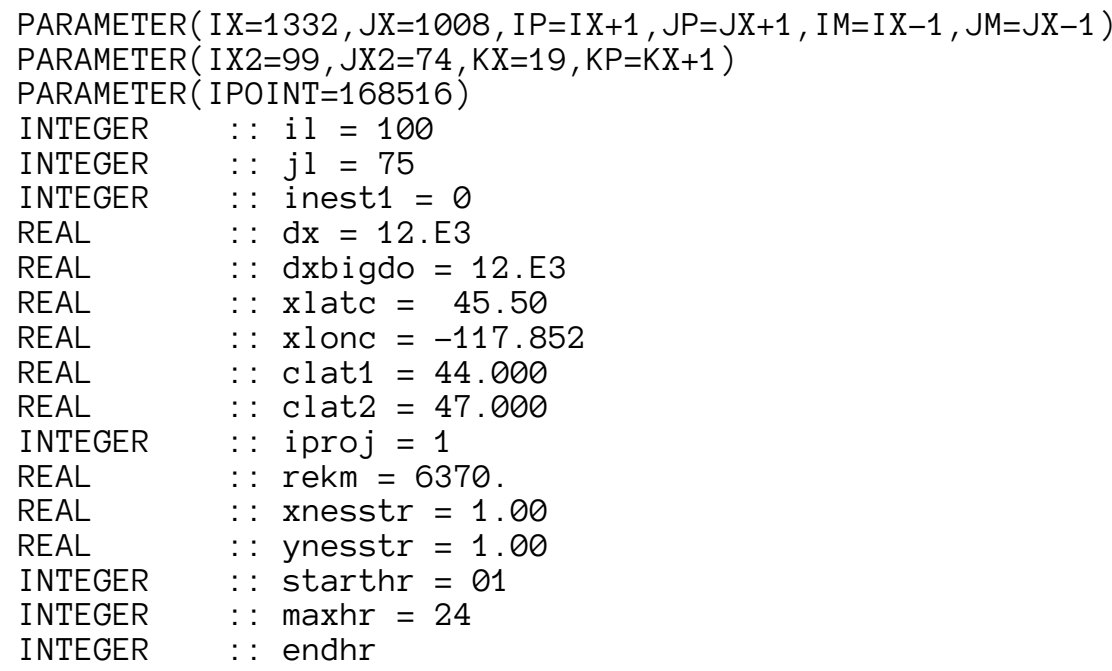




\section{Biogenic Emissions}

Biogenic emissions were generated via MEGAN using modified land-use maps.

The following outline illustrates the steps used to make these changes:

1. Set starting values

a. Set starting latitude and longitude

b. Set total area required

c. Set lower threshold for herbaceous PFT to trigger replacement

d. Set monthly LAI values for A. donax

2. Read in original NetCDF inputs for PFT, Isoprene EF, and monthly LAI

3. Set up loops generating concentric squares starting at the replacement site, over which to scan for cells meeting minimum herbaceous threshold

a. In each cell, test for herbaceous PFT

b. If herbaceous PFT found in sufficient magnitude, add to running total and mark for replacement

c. After sufficient area found, end loops

4. Take marked cells and modify isoprene EF and LAI values based on previously set inputs

5. Write to output files 


\section{WPS Namelist settings}

The WRF Preprocessing System was run using namelist inputs such as the following, used for the base Oregon summer case:

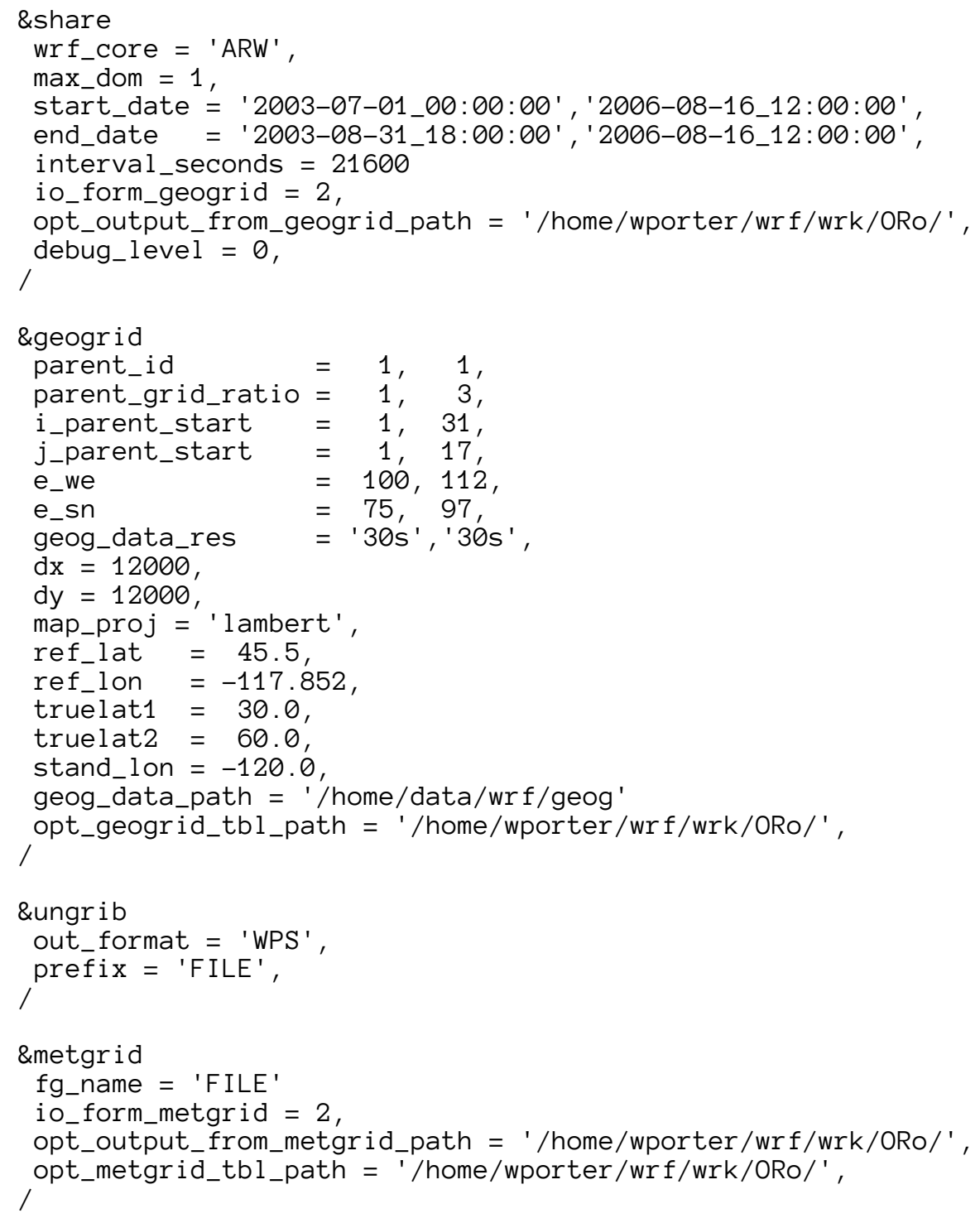

WRF namelist settings

WRF was run using namelist setting similar to the following, used for base Oregon summer runs (note that only the first column was used in this nonnested run): 


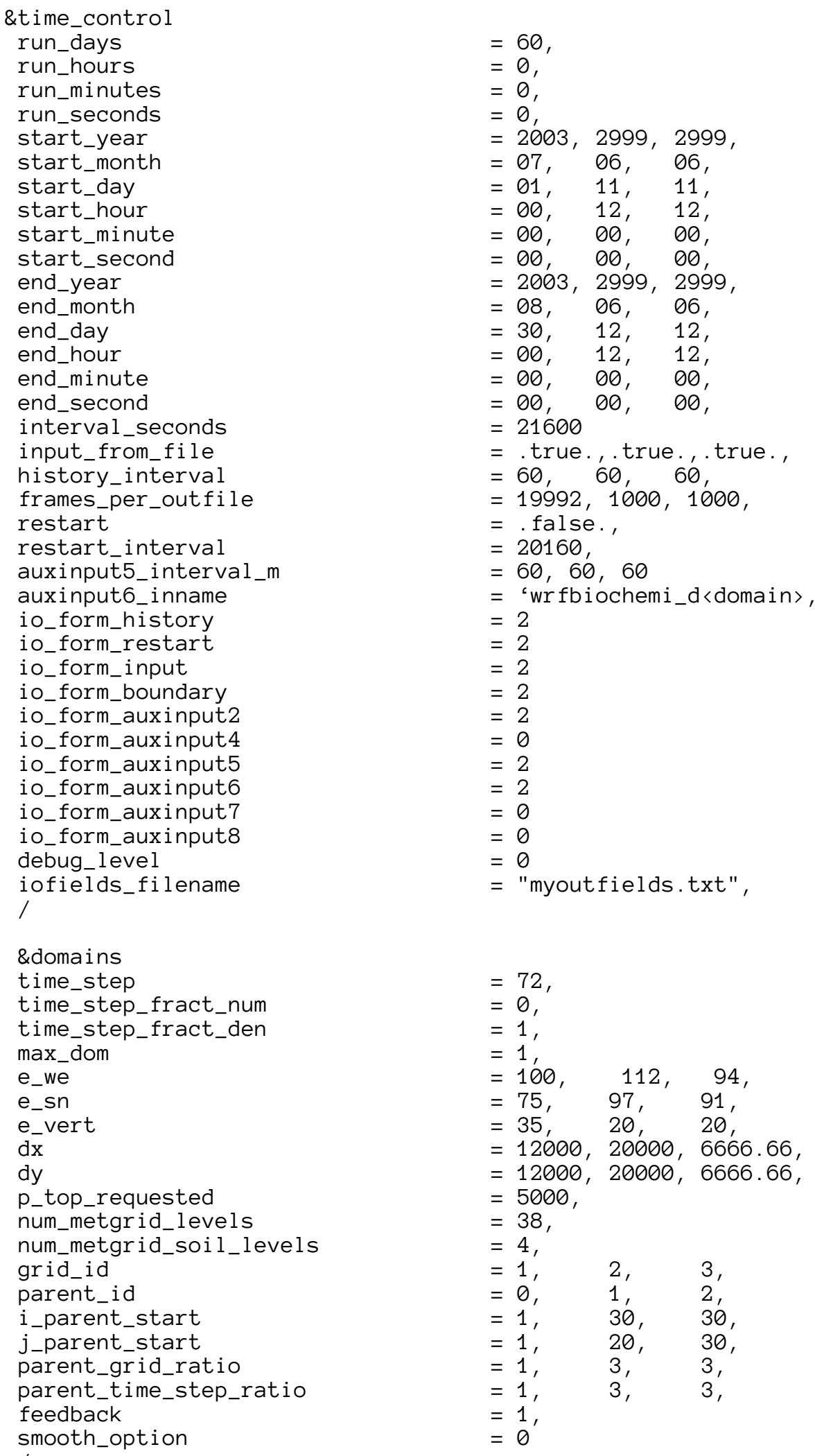




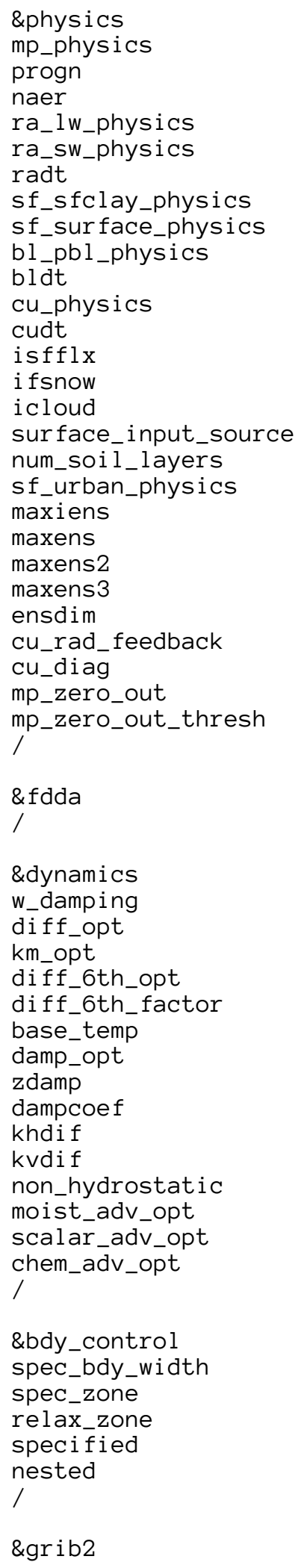

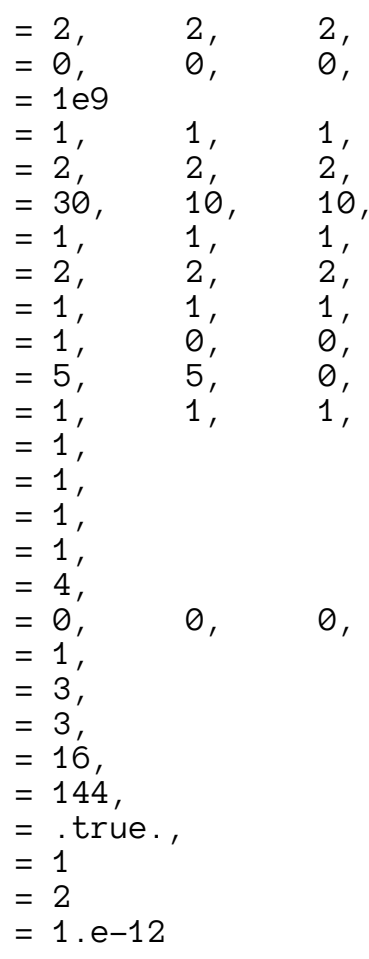

$$
\begin{aligned}
& =1, \\
& =1, \\
& =4, \\
& =0, \\
& =0.12, \quad 0.12, \quad 0.12, \\
& =290 .
\end{aligned}
$$$$
=0 \text {, }
$$$$
=5000 ., 5000 ., 5000 .,
$$$$
\begin{array}{lll}
0.2, & 0.2, \quad 0.2
\end{array}
$$$$
=0, \quad 0, \quad 0,
$$$$
=0, \quad 0, \quad 0,
$$$$
=\text {.true., true., true., }
$$$$
=2, \quad 1, \quad 1 \text {, }
$$$$
\text { = } 2, \quad 1, \quad 1 \text {, }
$$$$
\text { = }, 1,1,
$$$$
=5 \text {, }
$$$$
=1 \text {, }
$$$$
=4 \text {, }
$$$$
=\text { true., false. .false., }
$$$$
=\text {.false., true., true., }
$$ 
\&chem

kemit

chem_opt

bi oemdt

photdt

chemdt

io_style_emissions

emiss_inpt_opt

emiss_opt

chem_in_opt

phot_opt

gas_drydep_opt

aer_drydep_opt

bio_emiss_opt

dust_opt

dmsemis_opt

seas_opt

gas_bc_opt

gas_ic_opt

aer_bc_opt

aer_ic_opt

gaschem_onoff

aerchem_onoff

wetscav_onoff

cldchem_onoff

vertmix_onoff

chem_conv_tr

biomass_burn_opt

plumerisefire_frq

aer_ra_feedback

have_bcs_chem

ne_area

$=19$,

$=107$,

$=1.2$,

$20^{\prime}$

$=30$,

$=1.2$,

30 ,

$=1$,

$=1$,

$=3$,

$=0$,

$=1$,

$=1$,

$=1$,

$=3$,

$=0$,

$=0$,

$=0$,

$=1$,

$=1$,

$=1$,

$=1$,

$=1$,

$=1$,

$=0$,

$=0$,

$=1$,

$=1$,

$=0$,

$=30$,

2. ,

$=0$,

1,
3,

0

1,

1 ,

1 ,

1 ,

0 ,

/

=.false., false.,

$=42$

\&namelist_quilt

nio_tasks_per_group $=0$, nio_groups $=1$, / 


\section{Additional Figures}

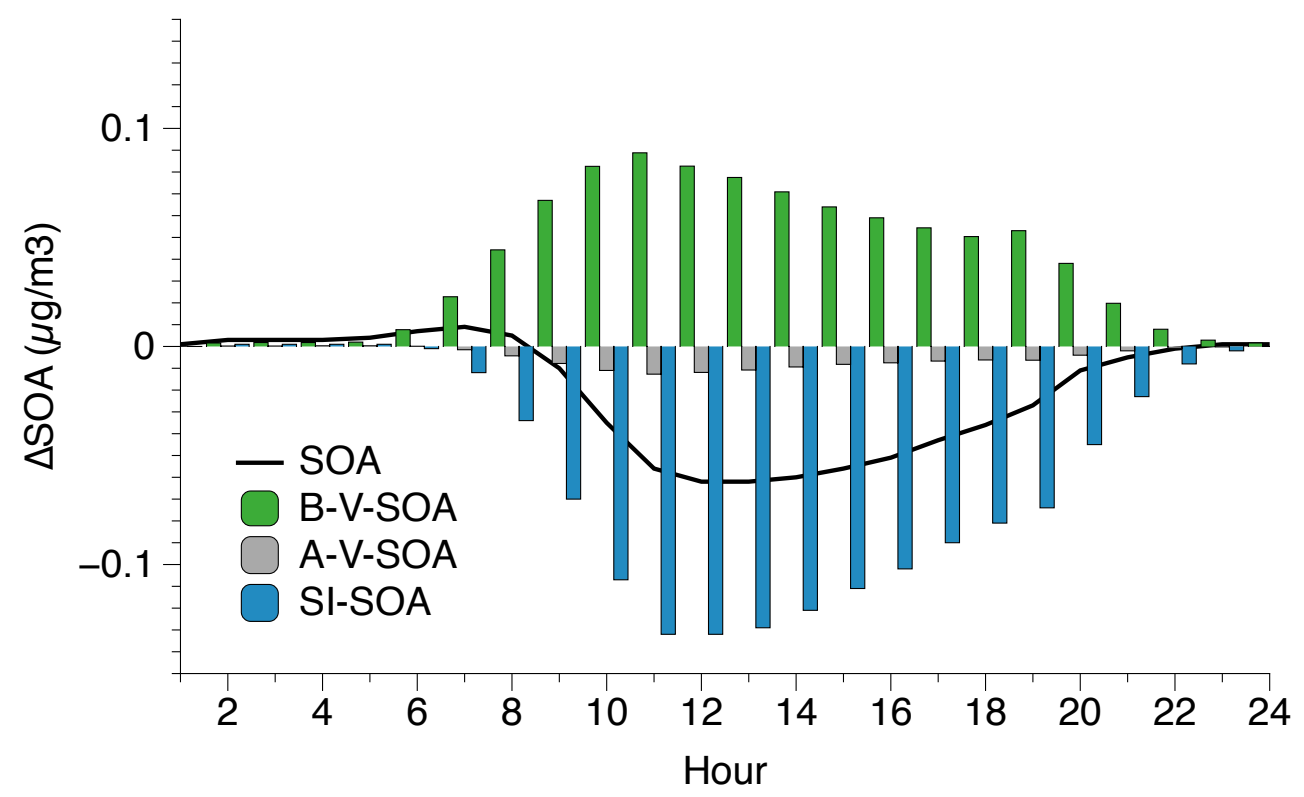

Figure 14. Changes in Oregon SOA by source. Biogenic volatile emissions (green) produced more SOA throughout the day due to enhanced isoprene from the additional A. donax. However, anthropogenic and semi- intermediate-volatility precursors show a decrease that begins soon after the increase in isoprene SOA, which results in a net reduction of SOA directly over the replacement site. 


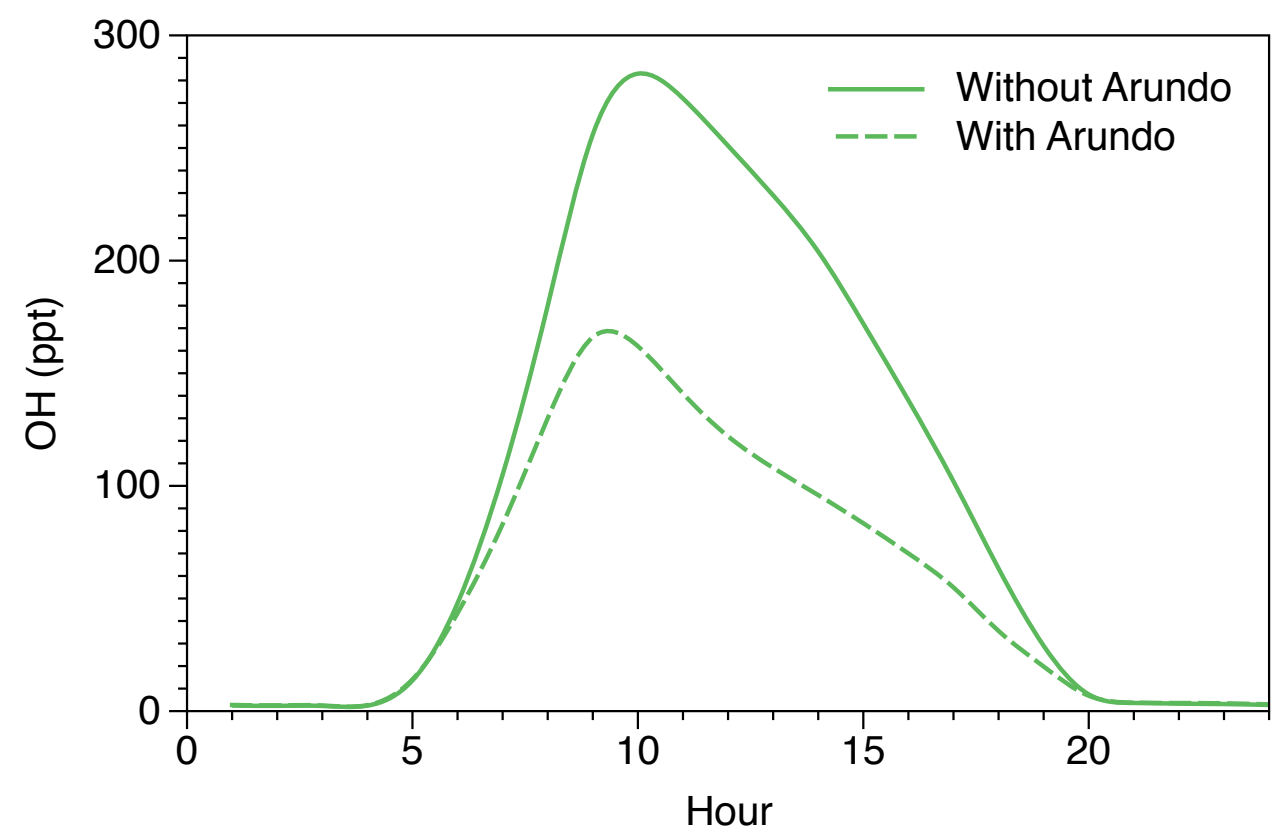

Figure 15. OH levels at Oregon site with and without $A$. donax. The previously described reduction in peak SOA at this site is likely due to increased competition for the $\mathrm{OH}$ radical, and was highly localized. 

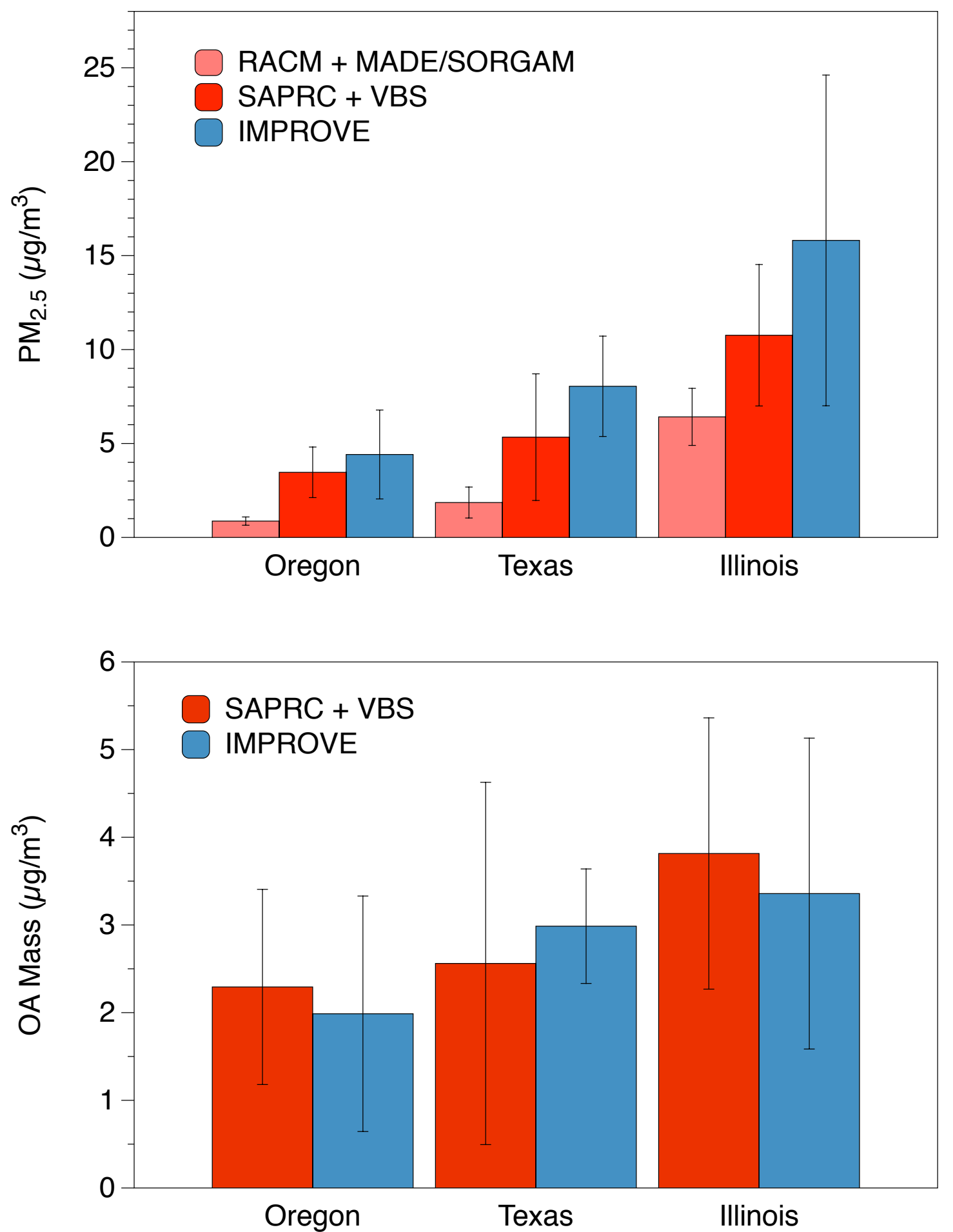

Figure 16. $\mathrm{PM}_{2.5}$ and OA mass concentrations measured at nearby OBSERVE sites vs. model output. Locations used for comparison were Starkey, OR; Sikes, LA; and Bondville, IL. 


\section{Appendix B: Supplementary Information for Chapter 3}

\section{Settings and Scripts}

\section{Land replacement}

Modification of CESM input maps was performed using literature estimates for replacement crop LAI and emissions, and regridded output from Cai et al., 2011:148

1. Set starting values for all 4 replacement crop types
a. Set crop emission factors
b. Set crop peak LAIs
c. Set crop height minima and maxima

2. Load original CESM input datasets and regridded Cai et al., 2011 output 3. Modify LAI maps

a. For existing broadleaf and crop/grass LAIs, normalize global values to percent of maxima to produce regional and monthly scaling factors based on ambient growing conditions

b. In areas identified for replacement, adjust LAIs for new crop type, scaled by existing broadleaf or crop/grass scaling factors

4. Modify PFT maps

a. Set new crop PFT percentage to value based on estimated land availability divided by total grid cell land area

b. Reduce existing bare/crop PFT types according to area determined by regridded available land map 


\section{Additional figures}
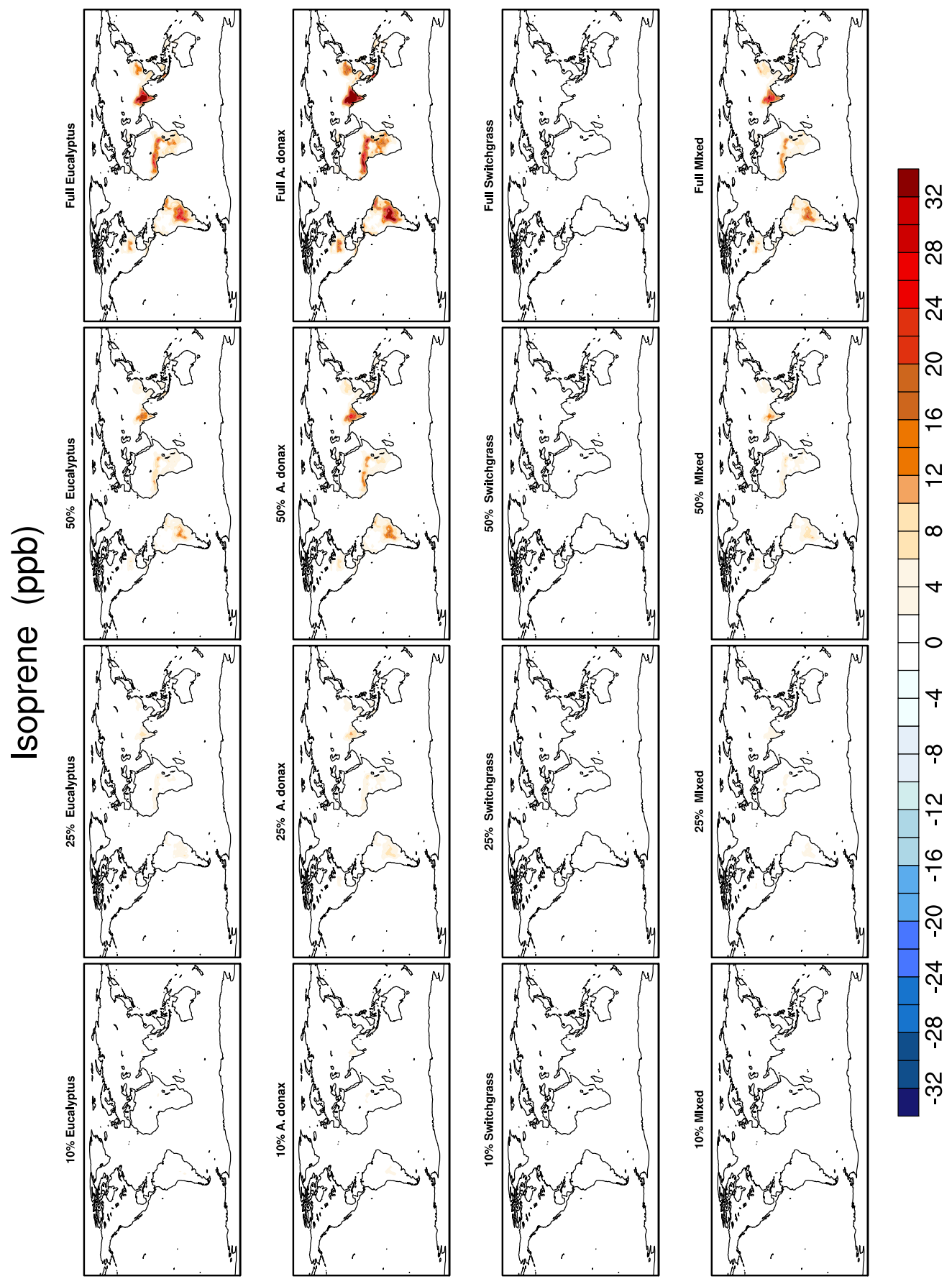

Figure 17. Change in average annual isoprene levels for all current climate replacement scenarios. 

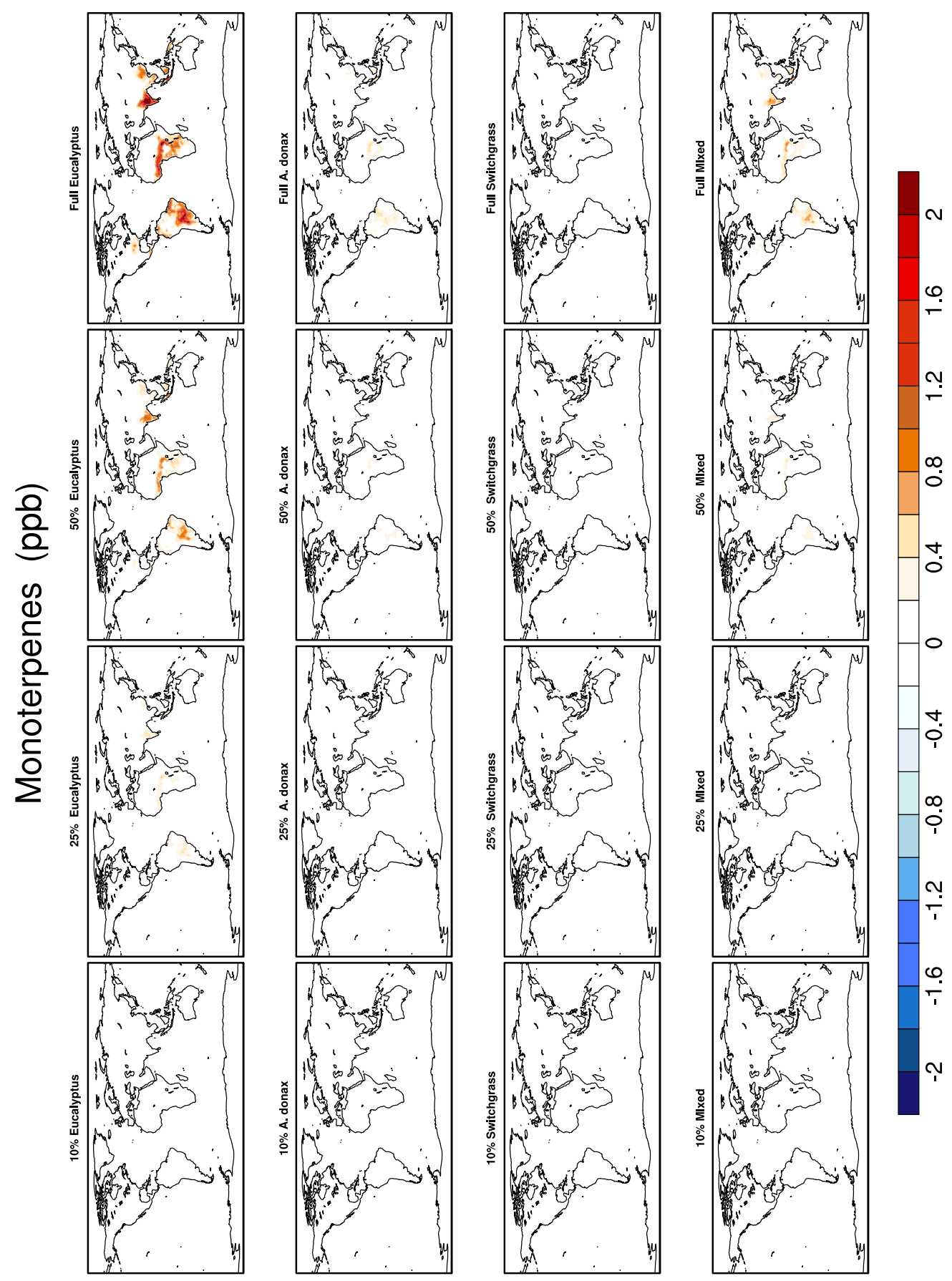

Figure 18. Change in average annual monoterpene concentration for all current climate replacement scenarios. 

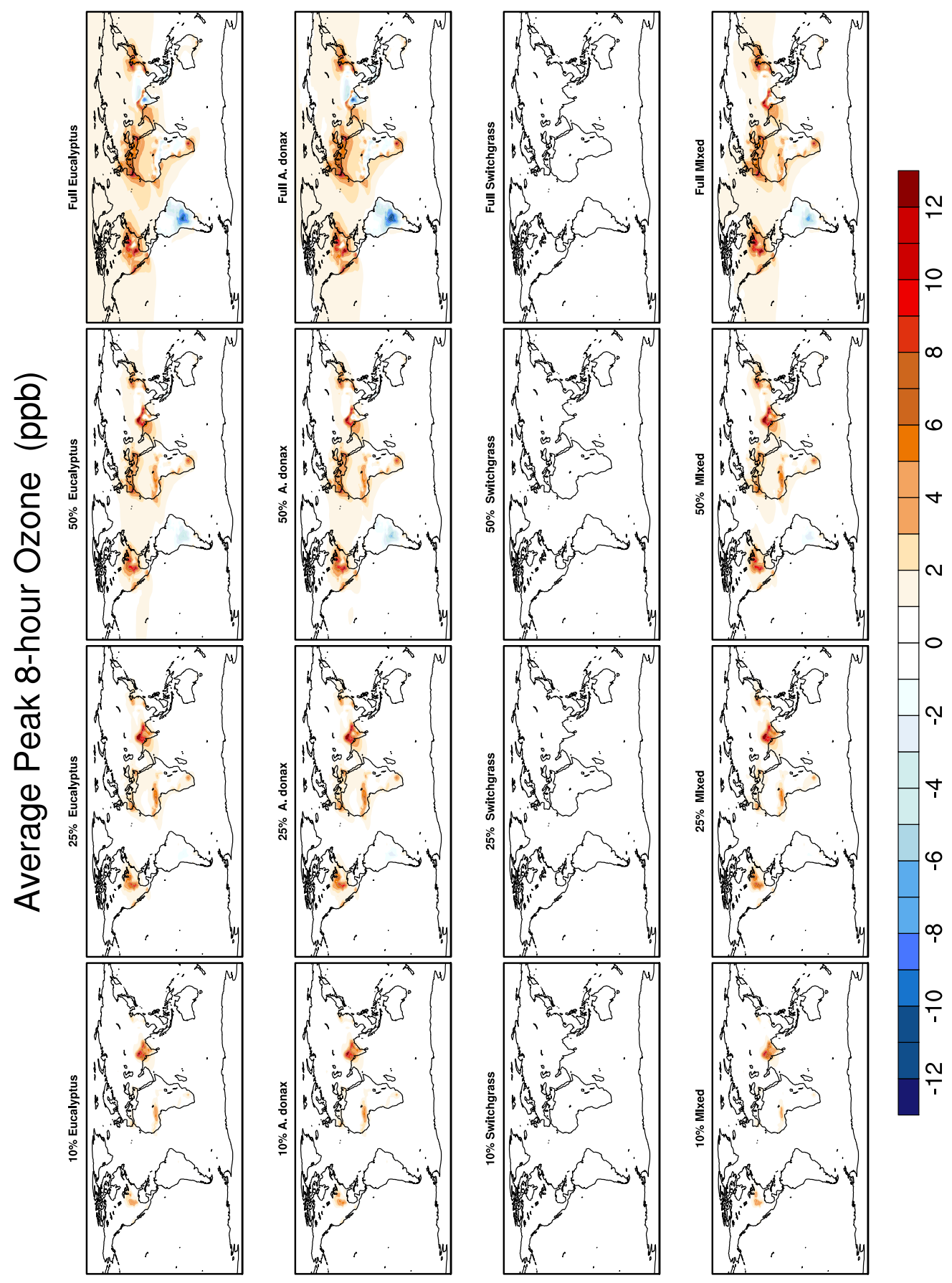

Figure 19. Change in average peak 8-hour $\mathrm{O}_{3}$ levels for all current climate replacement scenarios. 

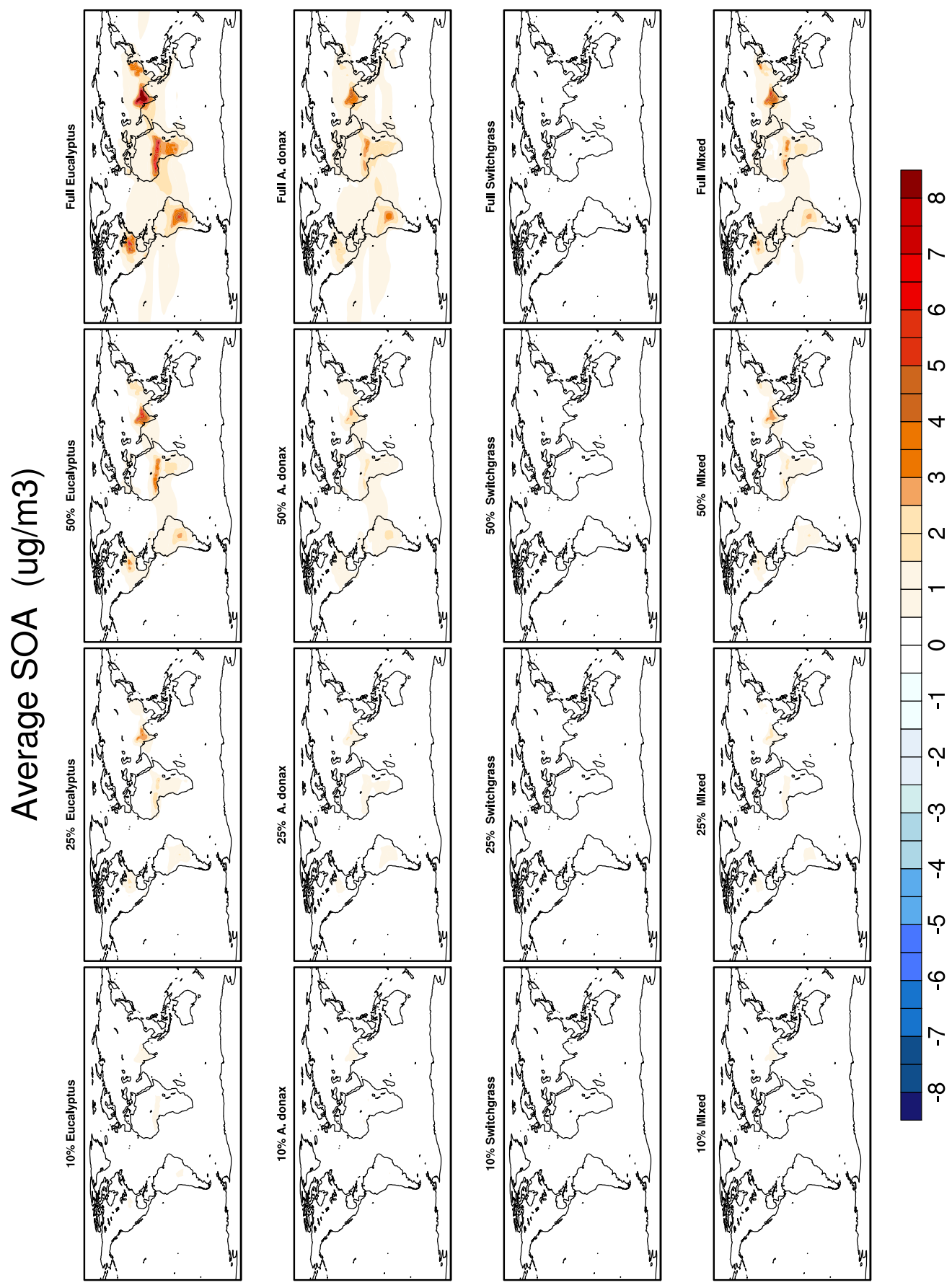

Figure 20. Change in average annual SOA concentration for all current climate replacement scenarios. 


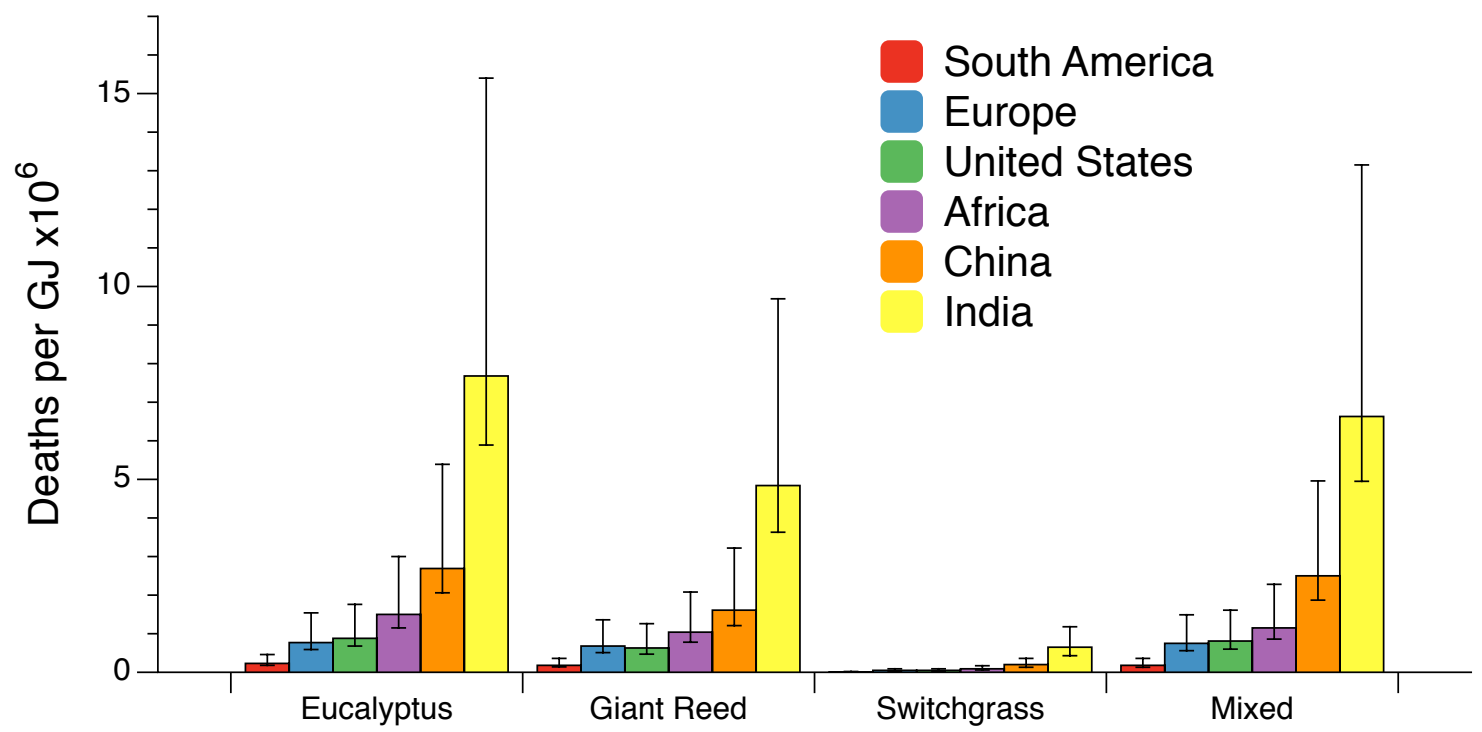

Figure 21. Estimated increase in deaths related to $\mathrm{O}_{3}$ and $\mathrm{PM}_{2.5}$ per $10^{6} \mathrm{GJ}$ produced, by crop and region. Error bars indicate uncertainty in productivities and percent increases in mortality. 